\title{
Match-related risk factors for injury in male professional football
}

\author{
Håkan Bengtsson
}

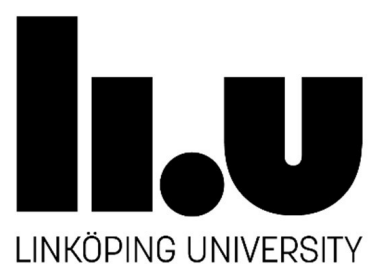

Division of Physiotherapy

Department of Medical and Health Sciences

Linköping University, Sweden

Linköping 2017 
Match-related risk factors for injury in male professional football

(CHåkan Bengtsson, 2017

Cover photo by Carl Recine, Bildbyrån and cover art by Shutterstock. Cover design by Per Lagman.

Published articles and figures have been reprinted with the permission of the copyright holders.

Printed in Sweden by LiU-Tryck, Linköping, Sweden, 2017

ISBN 978-91-7685-400-6

ISSN 0345-0082 
To my family.

My body could stand the crutches but my mind couldn't stand the sideline.

Michael Jordan 



\section{PREFACE}

Sport, football in particular, has always been an important part of my life. After following my brother and sister to their football practices for several years, I was finally allowed to join a team at the age of four. Ever since that day I have considered myself a football player, and still do to this day even though it is now more than two years since I last was able to play a game. It is hard for me to explain the one thing about sports that made me fall in love with it. After all, sport is so many different things. It is the anticipation as you tie your laces in the locker room before a match, it is the anxiety before you have been able to figure out whether your team is better than the opposition and it is the euphoria of scoring a decisive goal just minutes before the final whistle.

Unfortunately, sport is also the disappointment and sorrow of missing out. In my case this became abundantly clear as I tore my left anterior cruciate ligament just a couple of weeks before what would have been the biggest game of my life in sport. Even though I never came anywhere close to elite level sports or big arenas I still, fifteen years later, from time to time find myself thinking back, wishing that I was just able to play that ONE game.

I believe that it was in this process, missing the game that I for several years had been looking forward to and the rehabilitation that followed, that my interest in sports medicine started to evolve. I still love to compete, but during the years I have come to know that I find almost the same satisfaction in trying to understand. Unfortunately, in sports medicine as well as in life, it is very rare to fully understand anything. However, realising that I will be able to add just a small piece of knowledge to the very complex puzzle of understanding injuries in football gives me the same excitement that the most intense games I have played ever did.

In this thesis, I will present the pieces that I have found during my six years working full time in football medicine. I will show how different match related factors may contribute to the injury rate in professional football and I will also discuss the clinical implications these findings may have for professional football teams. I have spent most of my time during the past seven years trying to learn why football injuries occur and am still just scratching the surface. This fact could of course lead to some frustration. However, I chose to look at it from another point of view; there are still plenty of things for me to learn and understand, and I cannot wait to take the next step!

Falkenberg 2017/10/28

Håkan Bengtsson 



\section{CONTENTS}

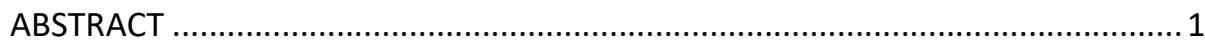

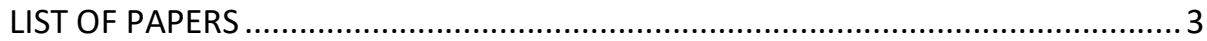

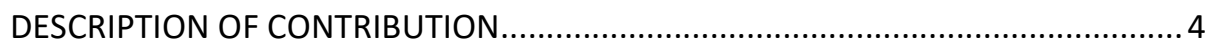

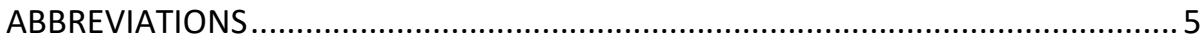

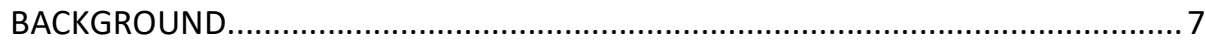

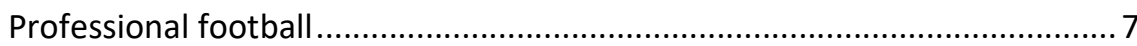

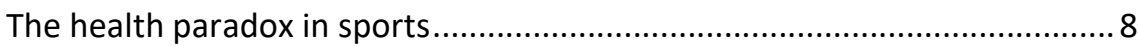

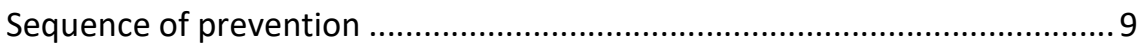

The injury problem in professional football ...............................................

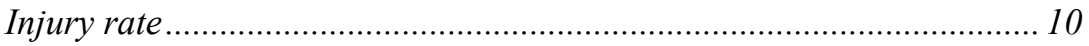

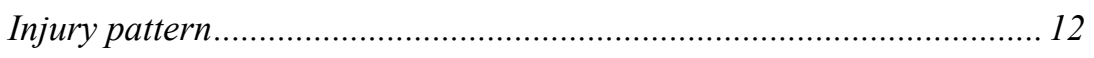

Aetiology of football injuries ................................................................13

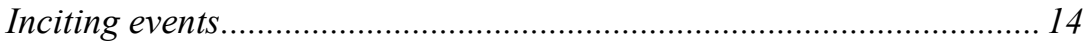

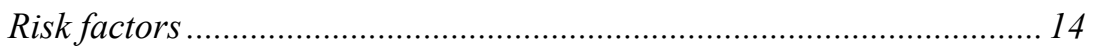

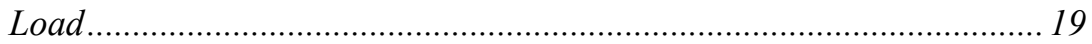

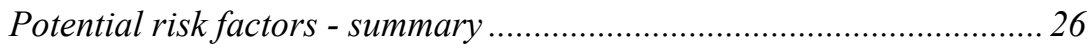

AIM

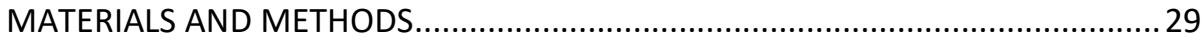

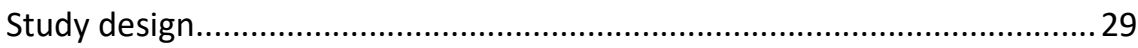

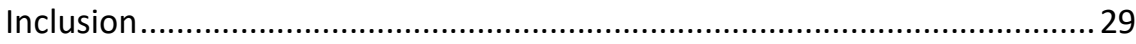

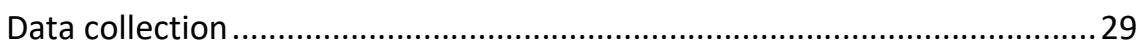

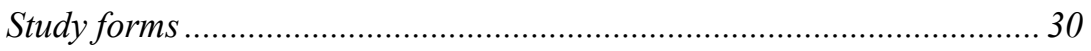

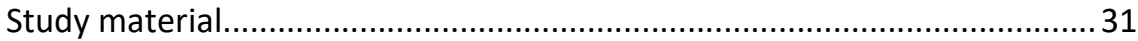

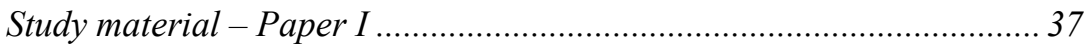

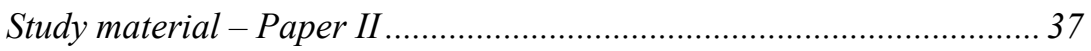

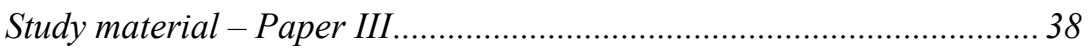

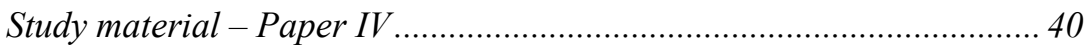

Variables and statistical methods ................................................................ 41

Match characteristics ............................................................................ 43 


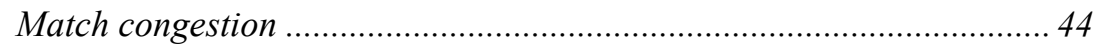

Training sessions between RTS and the first match exposure ................47

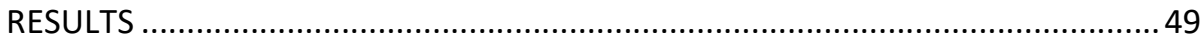

Injury rates in different competitions .......................................................... 49

Injury rates on different match venues.......................................................51

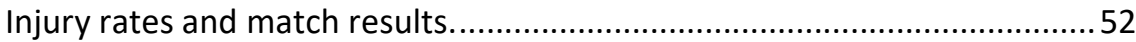

Short-term match congestion .................................................................... 53

Long-term match congestion ................................................................... 57

Interactions between short- and long-term match congestion.....................57

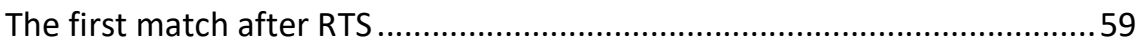

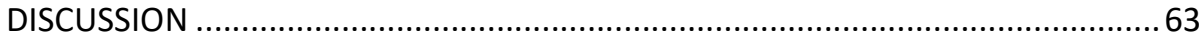

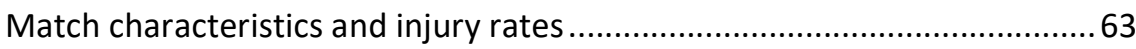

Association between injury rates and the importance of competitions... 63

More injuries at the home stadium...................................................... 64

Worse results in matches with injury occurrences .................................. 64

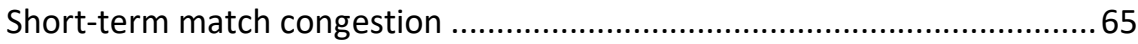

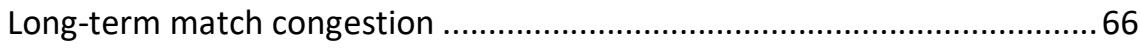

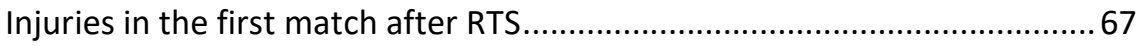

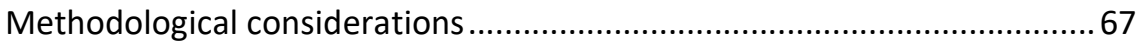

Clinical application and future perspectives .............................................. 71

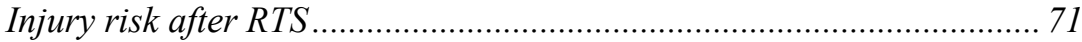

Risk for injury in relation to match congestion....................................... 72

Risk tolerance in professional football.................................................... 73

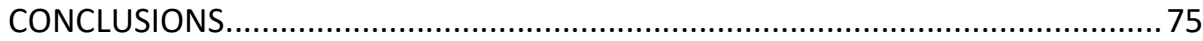

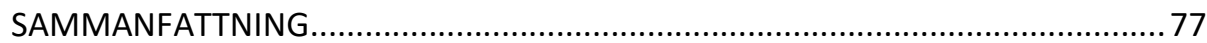

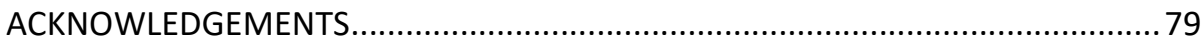

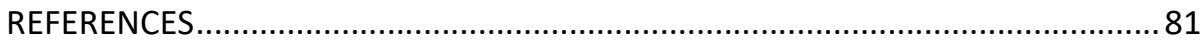




\section{ABSTRACT}

Background: Injuries are common in professional football, especially during matches, and they cause suffering for players, in both the short and the long term. It is therefore important to try to prevent these injuries. One of the most important steps in injury prevention is to fully understand the different risk factors that contribute to these injuries.

Aim: The aim of this thesis was therefore to investigate several match-related factors that have been suggested to be important for the risk of sustaining injuries during professional football matches.

Methods: The thesis consists of four papers, and all analyses are based on data gathered during a large-scale prospective cohort study that has been running since 2001: the UEFA Elite Club Injury Study. Medical teams from 61 clubs have been involved in this study, and they have prospectively gathered data about football exposure and injuries for their first team players.

Associations between the following factors and injuries have been analysed:

- Match characteristics in terms of match venue, match result, and competition

- Match congestion, both short and long term, and at team and individual player level

- Number of completed training sessions between return to sport after an injury and the first match exposure

Results: All match characteristics studied were shown to be associated with injury rates, with higher injury rates during home matches compared with away matches, in matches that were lost or drawn compared with matches won, and in domestic league and Champions League matches compared with Europa League and other cup matches (Paper I).

It was also shown that injury rates, muscle injury rates in particular, were higher if the recovery time between matches was short. This association between match congestion and injury rates was shown when match congestion was considered at both team (Paper II) and individual player level (Paper III).

Finally, the odds of injury during the first match exposure after a period of absence due to injury was found to be higher if players had completed few training sessions between return to sport and their first match (Paper IV). 
Conclusion: There are several match-related risk factors that contribute to the injury rate during professional football matches. A better understanding of these risk factors will help teams to make better estimations of the injury risks to which players are exposed in different situations (e.g. during periods of match congestion and when players return to sport after an injury). Knowledge about risk factors will also offer the possibility of reducing the number of injuries for football teams by addressing them with appropriate measures. 


\section{LIST OF PAPERS}

Paper I. Håkan Bengtsson, Jan Ekstrand, Markus Waldén, Martin Hägglund. Match injury rates in professional soccer vary with match result, match venue, and type of competition. Am J Sports Med. 2013;41(7):1505-1510.

Paper II. Håkan Bengtsson, Jan Ekstrand, Martin Hägglund. Muscle injury rates in professional football increase with fixture congestion: an 11-year followup of the UEFA Champions League injury study. Br J Sports Med. 2013;47(12):743-747.

Paper III. Håkan Bengtsson, Jan Ekstrand, Markus Waldén, Martin Hägglund. Muscle injury rate in professional football is higher in matches played within 5 days since the previous match: a 14-year prospective study with more than 130000 match observations. Accepted by Br J Sports Med, October 2017. Br J Sports Med Published Online First. doi:10.1136/ bjsports-2016-097399

Paper IV. Håkan Bengtsson, Jan Ekstrand, Markus Waldén, Martin Hägglund. Few training sessions between return to sport and first match appearance are associated with an increased propensity for injury: a prospective study of male professional football players during 15 consecutive seasons. In manuscript, planned submission to Knee Surg Sports Traumatol Arthrosc. 


\section{DESCRIPTION OF CONTRIBUTION}

\section{Paper I}

Study design

Data Collection

Data Analysis

Manuscript Writing

Manuscript Revision

Journal Correspondence

\section{Paper II}

Study design

Data Collection

Data Analysis

Manuscript Writing

Manuscript Revision

Journal Correspondence

\section{Paper III}

Study design

Data Collection

Data Analysis

Manuscript Writing

Manuscript Revision

Journal Correspondence

\section{Paper IV}

Study design

Data Collection

Data Analysis

Manuscript Writing

Manuscript Revision

Journal Correspondence
Håkan Bengtsson, Martin Hägglund, Jan Ekstrand, Markus Waldén Håkan Bengtsson study specific variables, Football Research Group* Håkan Bengtsson, Martin Hägglund

Håkan Bengtsson

Håkan Bengtsson, Martin Hägglund, Jan Ekstrand, Markus Waldén

Håkan Bengtsson, Martin Hägglund

Håkan Bengtsson, Martin Hägglund

Håkan Bengtsson during one season, Football Research Group*

Håkan Bengtsson

Håkan Bengtsson

Håkan Bengtsson, Martin Hägglund, Jan Ekstrand

Håkan Bengtsson

Håkan Bengtsson, Martin Hägglund

Håkan Bengtsson during four seasons, Football Research Group*

Håkan Bengtsson

Håkan Bengtsson

Håkan Bengtsson, Martin Hägglund, Jan Ekstrand, Markus Waldén

Håkan Bengtsson

\section{Håkan Bengtsson}

Håkan Bengtsson during five seasons, Football Research Group* Håkan Bengtsson

Håkan Bengtsson

Håkan Bengtsson, Martin Hägglund, Jan Ekstrand, Markus Waldén

Håkan Bengtsson

*several members of the Football Research Grup have been involved in data collection during different seasons. 


\section{ABBREVIATIONS}

$\mathrm{ACL} \quad$ Anterior cruciate ligament

$\mathrm{Cl} \quad$ Confidence interval

$\mathrm{CL} \quad$ Champions League

ECIS Elite Club Injury Study

EL Europa League

FIFA International Federation of Association Football

FRG Football Research Group

GEE Generalised estimating equations

GPS Global positioning system

IQR Interquartile range

IR Injury rate

OR Odds ratio

RPE Rating of perceived exertion

RR Rate ratio

RTS Return to sport

SD Standard deviation

StARRT Strategic Assessment of Risk and Risk Tolerance

UEFA Union of European Football Associations 


\section{BACKGROUND}

Football refers to several different sports, such as association football, rugby football and Australian Rules football, depending on your geographic location. Association football, commonly referred to as "football" in Europe and for the remainder of this thesis, is the world's largest sport with 265 million active players according to the latest worldwide survey performed by the international governing body of football, Fédération Internationale de Football Association (FIFA), in 2006 [1]. This means that about $4 \%$ of the world's population are active football players. The popularity of the sport seems to be growing, at least at the beginning of the 21st century, showing an almost $10 \%$ increase in the number of active players between the 2006 survey and the previous one performed in 2000. The amount of professional players also increased by about $10 \%$ between these two surveys, and most of the 113,000 professional players in 2006 were located in Europe [1].

\section{Professional football}

All four papers included in this thesis have investigated different aspects of male professional football, only including players who have made playing football their profession, and most of the cited studies have also been conducted on male professional football players. A season for a professional football team is typically divided into two phases: the pre-season and the competitive season. During a season, teams are exposed to five to six times more training exposure than match exposure [2, 3]. The difference in the amount of training exposure and match exposure is especially large during pre-season, whereas it is smaller during the competitive phase of the season [3]. The competitive season in Europe typically starts at the middle or the end of August and lasts until the middle or the end of May. During the competitive season, teams play on average about 60 matches. This average number of matches per season has been shown to be essentially constant between the 2001/2002 and 2013/2014 seasons [2].

Most of the matches during a season are part of the domestic league, but there are also several matches in various domestic cups. In addition, some teams will compete internationally in either the Union of European Football Associations (UEFA) Champions League ( $\mathrm{CL}$ ) or the UEFA Europa League (EL). Each season, last season's champions from high ranked European domestic leagues and the European cups qualify for the CL. In addition, last season's champions from lower ranked domestic leagues as well as teams that finished in top positions of high ranked leagues (2nd-4th) are invited to qualify for the CL. In all, 32 teams enter the group stage of the tournament each season [4]. Teams that have finished in top positions of their domestic leagues or cups in the previous season, but failed to qualify for the $\mathrm{CL}$, may instead enter the EL. In addition, teams that are relegated from the CL at an early stage 
may also enter the EL [5]. These different competitions often have rules about how many players that teams are allowed to use in the competition during a season. In the European international competitions, for example, before the start of the competition, teams must submit a list of 25 players who can play for the team during the season. In addition to this list, teams are also allowed to use other players who are under 22 years of age $[4,5]$.

\section{The health paradox in sports}

Regular physical activity is associated with a decreased risk of several common widespread diseases such as osteoporosis and cardiovascular diseases [6,7]. Regular physical activity may also decrease the risk of premature death by more than $30 \%$ [8]. Recreational football has been suggested as one way to introduce regular physical activity, and regular recreational football training can have several positive effects associated with better health and survival [9]. Although there are important positive effects on an individual's health when playing football, there is also a substantial risk of sustaining injuries, especially among professional football players [10]. It has been shown that professional football is associated with a more than 1000 -fold higher injury rate than other professions often considered to be high risk, such as manufacturing and construction [11]. It has also been shown that $60 \%$ of retired football players have ended their careers due to injury [12].

In addition to injuries, professional football players have also been found to be more likely to experience symptoms associated with mental disorders compared with the general public [13]. Symptoms of mental disorder are more common during the 12 month period after an injury [14] and are also more common among players who have sustained severe injuries during their career [15]. Professional football may also have long-lasting negative physiological consequences for the players, with residual pain affecting their quality of life $[16,17]$. These physiological consequences have also been found to occur more frequently among players who have sustained significant injuries during their careers, [12] which can potentially be explained by an increased risk of osteoarthritis after injuries [18]. It is therefore important to try to reduce the risk of injury in professional football. 


\section{Sequence of prevention}

A widely acknowledged approach to injury prevention in sport medicine is the sequence of prevention, as introduced by van Mechelen et al. in 1992 [19]. According to this sequence, injury prevention in sports should ideally follow a four-step model. The first step is to describe and understand the magnitude of the injury problem of interest. In the second step, the objective is to get a better understanding of the cause of injuries in terms of the mechanisms causing the injuries and the factors that increase the risk of athletes sustaining injuries. Based on the knowledge that is gained in step two, a preventive measure that is believed to be able to reduce the injury problem is introduced. The fourth and final step is to evaluate the effectiveness of this preventive measure by repeating step one and again study the magnitude of the injury problem [19]. This thesis contributes to step two in this model by analysing the relationships between different match-related risk factors and injury rates in professional football.

\section{The injury problem in professional football}

A sports injury may intuitively be referred to as any damage that an athlete suffers when participating in sports [19]. However, in a consensus statement about epidemiological research in football, several different possible definitions on what constitutes a sports injury were suggested (table 1). Some studies include all injuries whereas others use a stricter definition such as "medical attention injury" or "time loss injury". Although all of these approaches have different positive as well as negative features, it seems that a "time loss" definition is used most frequently in studies of professional football [20]. Injuries are common in professional football, not only in comparison with other professions but also in comparison with other sports. During the summer Olympics in Beijing 2008, London 2012 and Rio de Janeiro 2016, football was among the sports with the highest injury rate [21-23].

Table 1. Definitions of injury commonly used in epidemiological studies of football.

\begin{tabular}{|c|c|}
\hline & Definition* \\
\hline Injury & $\begin{array}{l}\text { Any physical complaint sustained by a player that results from a } \\
\text { football match or football training, irrespective of the need for } \\
\text { medical attention or time loss from football activities }\end{array}$ \\
\hline Medical attention injury & An injury that results in a player receiving medical attention \\
\hline Time loss injury & $\begin{array}{l}\text { An injury that results in a player being unable to take a full part } \\
\text { in future football training or match play }\end{array}$ \\
\hline
\end{tabular}


Injury rate

The injury rate is often defined as the number of injury occurrences/1000 hours of exposure and is one of the most commonly reported outcomes in epidemiological studies. However, the terminology to describe this variable varies between studies; "injury rate" and "injury incidence" are used most frequently. For the remainder of this thesis, the term "injury rate" is used to describe the relationship between injury occurrences and exposure hours.

The injury rate in male professional football in Europe has been reported in several large (including several teams) cohort studies in the $21^{\text {st }}$ century [3, 25-32]. In these studies, injury rates have been found to be much higher during match play compared with training. On average, the match injury rate has been 27.8 injuries/1000 hours of match exposure (range, 15.9-43.5), whereas the training injury rate has been 3.4 injuries/1000 hours of training exposure (range, 1.9-5.2). This means that the injury rate in matches has been reported to be almost ten times higher than in training (table 2 ). This difference in injury rate indicates that more than $50 \%$ of all injuries in professional football occur during match play even though, in terms of exposure, training is five times more common.

Two studies have analysed whether the injury rate in professional football has changed over time. One study, covering European professional football from 2001 to 2012, showed that injury rates, general as well as training and match injury rates specifically, remained stable over 11 seasons [26]. However, the other study, covering the first division in Norwegian football from 2002 to 2007, showed a 49\% increase in the acute match injury rate over the six-season period [32]. 
Table 2. Cohort studies from the 21st century including large cohorts that have reported training and match injury rates in male professional football in Europe.

\begin{tabular}{|c|c|c|c|c|c|}
\hline Reference & Participants & $\begin{array}{l}\text { Study } \\
\text { period }\end{array}$ & $\begin{array}{l}\text { Training } \\
\text { IR }\end{array}$ & $\begin{array}{l}\text { Match } \\
\text { IR }\end{array}$ & $\begin{array}{l}\text { Match/training } \\
\text { RR }\end{array}$ \\
\hline $\begin{array}{l}\text { Waldén et al. } \\
2005 \text { [3] }\end{array}$ & $\begin{array}{l}14 \text { clubs from the } \\
\text { first division in } \\
\text { Sweden }\end{array}$ & $\begin{array}{l}1 \text { season, } \\
2001\end{array}$ & 5.2 & 25.9 & 5.0 \\
\hline $\begin{array}{l}\text { Ekstrand et al. } \\
2013 \text { [26] }\end{array}$ & $\begin{array}{l}27 \text { clubs from } \\
\text { European first } \\
\text { divisions }\end{array}$ & $\begin{array}{l}11 \text { seasons, } \\
2001-2012\end{array}$ & 4.0 & 26.7 & 6.7 \\
\hline $\begin{array}{l}\text { Kristenson et al. } \\
2013 \text { [28] }\end{array}$ & $\begin{array}{l}32 \text { clubs from the } \\
\text { first divisions in } \\
\text { Sweden and } \\
\text { Norway }\end{array}$ & $\begin{array}{l}2 \text { seasons, } \\
2010-2011\end{array}$ & 3.7 & 21.7 & 5.9 \\
\hline $\begin{array}{l}\text { aus der Funten et } \\
\text { al. } 2014 \text { [25] }\end{array}$ & $\begin{array}{l}9 \text { clubs from the } \\
\text { first division in } \\
\text { Germany }\end{array}$ & $\begin{array}{l}2 \text { seasons, } \\
2008-2010\end{array}$ & 3.3 & 29.0 & 8.8 \\
\hline $\begin{array}{l}\text { Bjørneboe et al. } \\
2014 \text { [32] }\end{array}$ & $\begin{array}{l}14 \text { clubs from the } \\
\text { first division in } \\
\text { Norway }\end{array}$ & $\begin{array}{l}6 \text { seasons, } \\
2002-2007\end{array}$ & $1.9 *$ & $15.9 *$ & 8.4 \\
\hline $\begin{array}{l}\text { Salces et al. } 2014 \\
\text { [29] }\end{array}$ & $\begin{array}{l}16 \text { clubs from the } \\
\text { first division in } \\
\text { Spain }\end{array}$ & $\begin{array}{l}1 \text { season, } \\
2008 / 2009\end{array}$ & 3.6 & 43.5 & 12.1 \\
\hline $\begin{array}{l}\text { Haxhiu et al. } 2015 \\
\text { [27] }\end{array}$ & $\begin{array}{l}12 \text { clubs from the } \\
\text { first division in } \\
\text { Kosovo }\end{array}$ & $\begin{array}{l}1 \text { season, } \\
2012 / 2013\end{array}$ & 3.2 & 20.7 & 6.5 \\
\hline $\begin{array}{l}\text { van Beijsterveldt } \\
\text { et al. } 2015 \text { [31] }\end{array}$ & $\begin{array}{l}8 \text { clubs from the } \\
\text { first division in } \\
\text { the Netherlands }\end{array}$ & $\begin{array}{l}1 \text { season, } \\
2009 / 2010\end{array}$ & 2.1 & 31.8 & 15.1 \\
\hline $\begin{array}{l}\text { Shalaj et al. } 2016 \\
\text { [30] }\end{array}$ & $\begin{array}{l}11 \text { clubs from the } \\
\text { first division in } \\
\text { Kosovo }\end{array}$ & $\begin{array}{l}1 \text { season, } \\
2013 / 2014\end{array}$ & 3.2 & 35.4 & 11.1 \\
\hline
\end{tabular}

$I R$, injury rates (number of injuries/1000 hours of exposure)

$\mathrm{RR}$, Rate ratio.

*study reports acute injury rates only excluding all overuse injuries 
Injury pattern

Most injuries in professional football affect the lower extremities; thigh, knee, hip/groin, ankle and lower leg are the five most common locations. On average, these five locations have been responsible for $78 \%$ of all injuries reported in professional football (ranging from $65 \%$ to $86 \%$ ) [3, 25-32]. The three most common types of injury in professional football have consistently been shown to be muscle/tendon injuries, joint/ligament injuries and contusions [25-32]. Together, these three injury types have constituted $79 \%$ of all reported injuries on average (ranging from $67 \%$ to $92 \%$ ) (table 3 ).

The injury rates for different injury types have developed differently in recent years. In a professional European cohort, the ligament injury rate was shown to decrease between 2001 and 2012, whereas the muscle injury rate was constant [26]. In further contrast with ligament injuries, the hamstring muscle injury rate has been shown to increase by $2.3 \%$ per season between 2001 and 2014 [2]. Specific ligament injury rates in this cohort have also developed differently. Whereas the ankle ligament injury rate [33] and medial collateral ligament injury rate to the knee have decreased, [34] an increase, although non-significant, in the anterior cruciate ligament (ACL) injury rate has been observed [35].

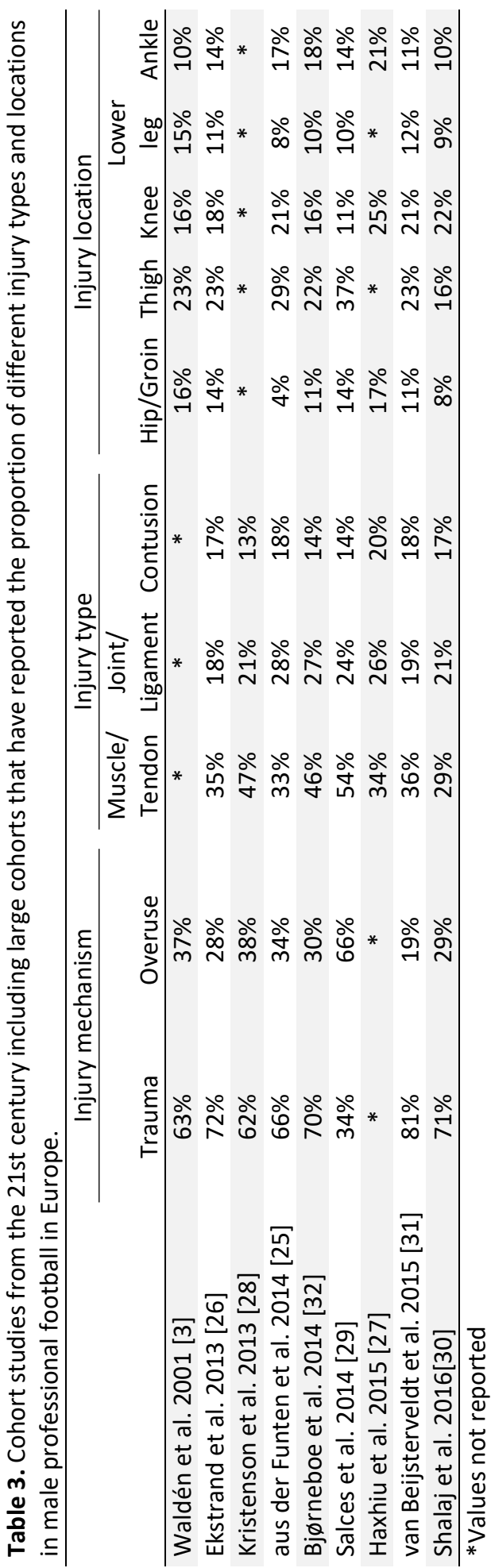




\section{Aetiology of football injuries}

In 1994, Willem Meeuwisse proposed an injury causation model that described the complex aetiology of sport injuries [36]. This model shows that, even though it may initially seem as if it is a single mechanism, such as a player being tackled, that is responsible, there could in fact be several different factors contributing to an athlete eventually suffering an injury. The model describes how different risk factors contribute to making athletes more susceptible to injuries and susceptible athletes may eventually suffer an injury in the case of an inciting event. The model also describes that a similar event would not necessarily cause an injury if potential risk factors were not present. It is therefore important to not only understand the mechanisms responsible for injuries within the sport but also the underlying risk factors that contribute to these injuries. Consequently, it is also possible in theory to prevent injuries simply by removing their risk factors [36].

The model has been developed further and several additions have been suggested over the years [37, 38]. One of these additions was suggested by Windt \& Gabbett in 2017, [39] who included workload as one of the most important aspects to consider in the model, influencing the risk of injury in three ways (figure 1).

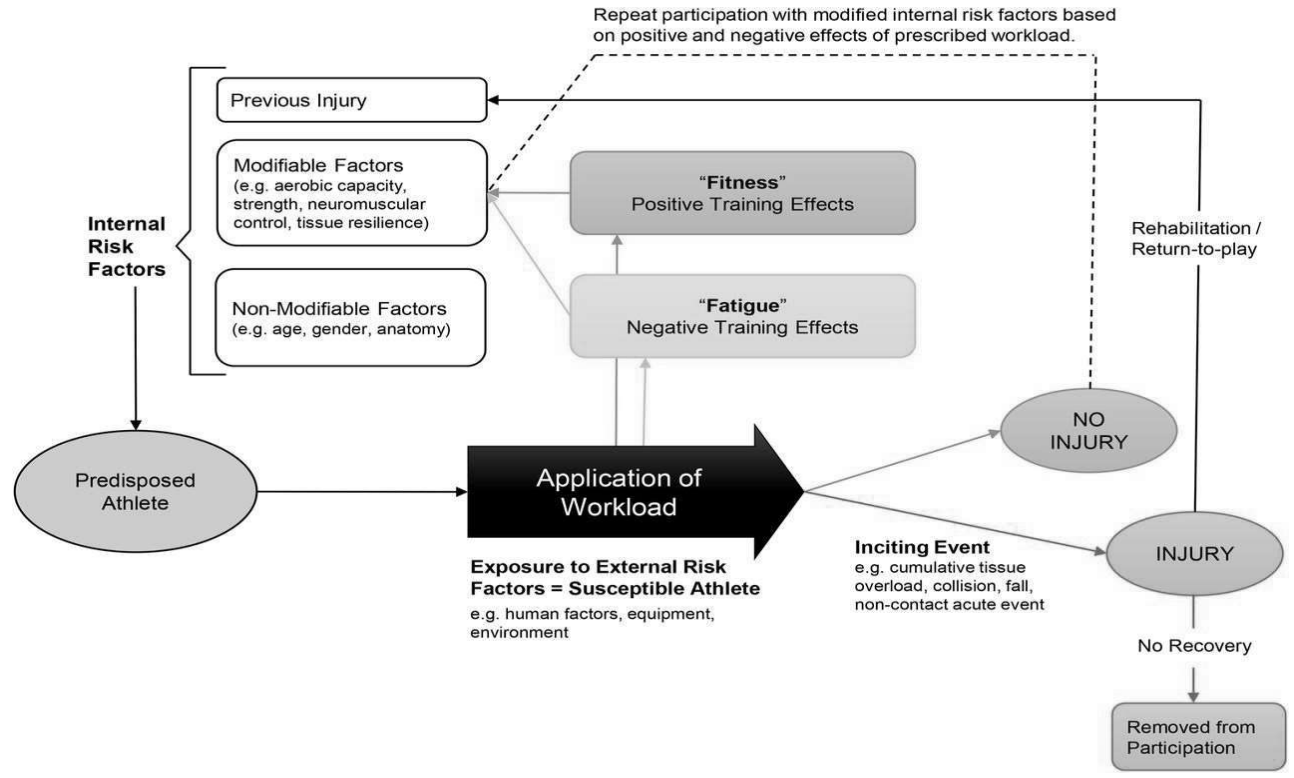

Figure 1. Injury aetiology model developed by Meeuwisse in 1994 and expanded by Windt and Gabbett in 2017[39]. Re-printed with permission from the British Journal of Sports Medicine. 
First, workload is used interchangeably with the term exposure, which means that it is during the workload that athletes are exposed to other risk factors and to the risk of inciting events. Second, workload may lead to athletes being fatigued, which in turn could make them more susceptible to injuries. Lastly, workload also leads to beneficial changes and improved fitness, which could reduce the risk of injuries [39].

All these models highlight the importance of understanding risk factors, which is the overall aim of this thesis, to be able to effectively reduce the injury rate in sports.

\section{Inciting events}

In football, most injuries are considered to be traumatic in nature, meaning that they result from a specific acute onset [24]. In epidemiological studies of football, on average $65 \%$ of all reported injuries have been considered to be traumatic (ranging from $34 \%$ to $81 \%$ ) (table 3). Overuse injuries, complaints with gradual onset that are caused by repeated (micro) trauma rather than one identifiable event, [24] have been found to be less frequent [3, 25, 26, 28-32]. However, it should be acknowledged that the amount of overuse injuries may be underreported in studies using a time loss definition of injury because these injuries will not always cause time loss even though they might have substantial impact on athletes' health and performance [40].

In English professional football, 39\% of all injuries have been shown to be caused by contact with another player or the ball; the remaining $61 \%$ were not. Running was shown to be the most common injury mechanism closely followed by being tackled (19\% and $15 \%$, respectively) [41]. However, the most common injury mechanism will vary for different injury diagnoses. Whereas muscle injuries are most frequent during high-speed movements, such as shooting or high-speed running, [42] ligament injuries, such as ACL injuries, may be more likely to occur when changing direction, for example during defensive pressing actions [43].

\section{Risk factors}

According to the model by Willem Meeuwisse [36] described previously, there are two different types of potential risk factors for sport injuries: internal and external. Internal risk factors are said to act on the athletes from within, and are internally related to the athlete. External risk factors, on the other hand, act on the athletes from the outside and are related to factors that are external to the athlete. The model describes how these different types of risk factors interact to make athletes vulnerable and at risk of sustaining an injury. If internal risk factors are present, then an athlete is said to be predisposed to sustain injuries. If these predisposed athletes are exposed to external risk factors, they become susceptible to injuries in the case of an inciting event [36]. 


\section{Internal risk factors}

Previous injury, muscle imbalance and fatigue are perceived as the three most important injury risk factors according to a survey among people involved in the medical or scientific department of 44 professional football clubs [44]. The scientific support for these risk factors is, however, limited [45].

\section{Previous injury}

Although the evidence for most of the proposed injury risk factors in football is inconsistent, previous injury has consistently been shown to be highly related to the risk of sustaining a new injury. Players who have been previously injured have been shown to be almost three times as likely to sustain an injury compared with their previously uninjured colleagues [46]. A previous injury increases the risk of sustaining an injury in different ways. First, a previous injury increases the risk of sustaining an injury of the same type again, a re-injury. It has been shown that $17 \%$ of all injuries in top level football are re-injuries and that the injury type that is most likely to suffer from re-injuries is muscle injuries. It has also been shown that most re-injuries occur quite soon after a player has returned to sport (RTS) from their previous injury, within two months of RTS [10]. Second, previous injuries may also increase the risk of sustaining another type of subsequent injury [47]. This has been shown by the fact that players who have suffered a concussion are significantly more likely to sustain any type of injury during the first year after the concussion [48]. Similarly, players who have sustained an ACL-injury are four times as likely to suffer a new knee injury of any type [49]. Even though it may be suspected that the risk of re-injuries is the most important risk after returning from an injury, a study on Australian rules football from 2017 showed that subsequent injuries of other types are more frequent than actual reinjuries [50]. 
One of the reasons why previous injuries could cause an increased risk of injury is that players RTS prematurely. The decision on when players RTS after an injury is made difficult by the fact that there are few evidence-based criteria for when an athlete should be considered ready for RTS, as pointed out in a review article from 2016 [51]. A period of absence from football due to an injury could also have caused deterioration in a player's physical fitness level, which could make him more vulnerable to the increased workload that he is subjected to on RTS and return to competition. Load management, defined as prescription, monitoring, and adjustment of external and internal loads may therefore be one of the most important aspects to consider when players RTS (definitions of the different types of load are presented in table 4) [52]. Based on previous studies showing that large variations in load may cause an increased risk of injury, it has also been hypothesised that the amount of training that athletes have completed before they return to competition after an injury absence is important for their risk of injury [53]. However, this hypothesis has not been tested in professional football.

Table 4. Definitions of load commonly used in studies of sports.

\begin{tabular}{ll}
\hline Load & $\begin{array}{l}\text { The sport and non-sport burden (single or multiple physiological, } \\
\text { psychological or mechanical stressors) as a stimulus that is applied to a } \\
\text { human biological system (including subcellular elements, a single cell, } \\
\text { tissues, one or multiple organ systems, or the individual) }\end{array}$ \\
External load & $\begin{array}{l}\text { Any external stimulus applied to the athlete that is measured } \\
\text { independently of their internal characteristics }\end{array}$ \\
Internal load & $\begin{array}{l}\text { Load measurable by assessing internal response factors within the } \\
\text { biological system, which may be physiological, psychological, or other }\end{array}$ \\
Absolute load & $\begin{array}{l}\text { Load applied to the biological system from training, competition and non- } \\
\text { sport activities, irrespective of the rate of load application, history of } \\
\text { Relative load } \\
\text { loading or fitness level } \\
\text { Load applied to the biological system from training, competition and non- } \\
\text { sport activities, taking into account the rate of load application, history of } \\
\text { loading or fitness level }\end{array}$ \\
\hline *Definitions according to consensus statement about load in sport [52]
\end{tabular}

*Definitions according to a consensus statement about load in sport [52].

\section{Muscle imbalances}

It has been suggested that muscle imbalance is a risk factor for injuries in football, specifically muscle injuries. The relationships between muscle imbalances and muscle injuries have been investigated in several previous studies [45]. In some of these studies, relationships between muscle imbalances and several different injury diagnoses, such as hamstring injuries, quadriceps injuries and ankle injuries, have been observed [54-56]. However, some recent studies have reported contradictory results showing no association between muscle imbalances and hamstring injury rates [57, 58]. 
Fatigue

Fatigue in this case could be defined as failure to maintain the required or expected capacity [59] and is demonstrated by a typical decrease in physical function. Fatigue after a physically demanding activity such as playing a professional football match is multifactorial and induced by muscle damage, dehydration, glycogen depletion and mental fatigue [60].

Several studies have examined the recovery process during the first days after a football match or similar physical activity. In these studies, it is common to evaluate residual fatigue by physical performance tests, subjective ratings of fatigue, muscle soreness or pain and measurements of biomarkers in the blood. The period of followup has varied to some extent but is usually 48 or 72 hours after the match.

Physical performance has often been measured by either a jump or sprint test. These tests have shown that players perform $7-10 \%$ worse in a counter movement jump after a football match or similar fatiguing activity. After 24 to 72 hours of recovery following the fatiguing activity, performance has returned to baseline values [61-63]. Similar results have been shown using sprint tests with an immediate $2-10 \%$ decline in performance after a match. Time needed for athletes to return to baseline values for sprint performance has varied somewhat ranging from 48 to 72 hours [62-66].

Studies investigating players subjective experiences have shown that players experience muscle soreness and fatigue directly after a football match [62-67]. Whereas post-match fatigue seems to return to baseline values within 48 hours after a match, $[63,65]$ the time to return to baseline values for muscle soreness have varied between 48 and 72 hours [62-67].

Post-match fatigue has also been evaluated through blood samples, measuring blood markers that indicate muscle damage and inflammation. Such studies have shown increased levels of creatine kinase for 24 to 72 hours after a football match or similar physical activity [62-68]. This inflammatory response seems to be higher after a football match compared with other team sports, possibly due to higher physical demands during football matches [69].

\section{External risk factors}

One example of an external risk factor in football is the geographic location of the team. Professional football teams in the northern parts of Europe have been shown to have a higher injury rate compared with their counterparts from the southern parts of Europe [70]. One possible explanation for this difference could be that teams in different parts of Europe have different playing styles, which could potentially influence their injury rates. Another possible explanation is the differences in climate 
between different regions. As in football, differences in injury rates between climate regions have also been found in Australian rules football. Although, in contrast with the results for football, the injury rate in Australian rules football was found to be higher in the warmer region [71]. However, it should be acknowledged that the climate in Australia is different than in Europe, which could explain the difference in results between these two studies.

It has also been argued that match play should be considered an external risk factor, keeping in mind that injury rates are significantly higher during matches compared with training. The context of matches will potentially also be important for the risk of sustaining injuries. In a study following a professional football team over four seasons, the ligament injury rate was shown to be higher in league matches than in cup matches and international matches even though the general injury rate was similar for the different competition formats [72]. In national team football, a study following the Swedish national team over six seasons found no difference in injury rate during friendly matches compared with competitive matches [73]. Other match-related external risk factors that have been suggested include different match characteristics that influence activities during matches, such as the match venue and the match result.

\section{Match venue}

The home field advantage in football is a well-known phenomenon and relates to the fact that teams are more likely to win matches when playing at home than when playing away. Several studies have shown that there are important differences between playing matches on the home field compared with playing away, confirming the home field advantage. These studies have consistently shown that home teams win about $50-100 \%$ more matches than away teams. A home field advantage has been shown in European cup matches (EL and CL) [74] as well as in several domestic leagues [75-78].

However, differences between home and away teams have not only been shown in the number of matches won but also in different match activities. Home teams have more possession of the ball than away teams, $[76,77,79,80]$ especially in the attacking zone of the playing field [81]. This also means that home teams take more offensive actions, such as offensive runs, offensive passes, shots etc [76-78]. Furthermore, It has been shown that teams playing away matches have more foul play decisions taken against them by the referee [77] and that they are more likely to be awarded yellow [74, 76, 77,82 ] and red cards than home teams [77]. It has been suggested that this difference in the likelihood of receiving yellow cards between home and away teams is influenced by the density of the crowd (defined as the percentage of occupied seats in the stadium) during the match [74]. 
The variances in activity profile between different match venues could potentially influence the risk of sustaining injuries, although similar injury rates have been found during home and away matches in a study following a national team over six seasons [73].

Match result

Similar differences in match activities to those shown between home and away teams have also been shown between teams when losing matches compared with when winning. Teams that are losing a match have been shown to have more ball possession than teams that are ahead or in matches that are drawn [79, 80, 83]. In the first division in Spain, an $11 \%$ reduction in ball possession has been shown for winning teams compared with teams that are losing [81]. It was also shown that teams had more possession in the offensive zone of the playing field and less possession in the defensive zone when losing than when winning, [81] indicating a more offensive style of play. This difference in style of play, between losing and winning teams, has also been shown by more offensive runs and more shots at goal by losing teams [83].

In national team football, one study has shown a higher injury rate during matches lost or drawn compared with matches won when following a national team over six seasons, [73] whereas another study covering nine European championships at senior and youth level found no associations between match results and injury rates [84].

Load

One of the potential risk factors that has received most attention in recent years is load of the athletes. Load in this case is a multifactorial concept including several different aspects: physiological, psychological and mechanical. There are two principal ways of describing the load of an athlete: internal and external. External load in this case refers to an external stimulus to which an athlete is exposed regardless of their reaction to this stimulus. Internal load, on the other hand, refers to how the athlete reacts to this external stimulus (table 4) [52].

\section{Measuring load}

The complexity of measuring load was shown in a survey including 41 professional football teams in which 56 different variables for load measurements were found to be used [85]. Accelerometers and global positioning system (GPS) units were used in almost all the teams to monitor the external training load of their players. GPS units have often been used to measure the total distance covered during a training session and the distance covered in different speed thresholds [86]. However, although GPS units perform well when measuring distances during a linear jog, reliability is poor when measuring distance in non-linear runs at higher intensities, [87-89] which is more similar to the activity profile when playing football. Accelerometers are often integrated in GPS units. They do not measure the distance travelled, as the GPS unit 
does, but rather measure accelerations and athlete contact with other objects, athletes or the ground [90]. However, these measurements have been shown to not be closely correlated with athletes' rating of perceived exertion (RPE) during football training [91].

RPE is a subjective measurement of an athletes' internal load. In sport, the concept of session RPE is often used. The session RPE is calculated by asking an athlete to rate the level of perceived exertion for the entire training session using a Borg scale. This rating is then multiplied by the duration of the training session [92]. In football, session RPE has been shown to be closely correlated with heart rate monitoring, and it is therefore considered to be a good way to measure internal training load [93].

In addition to the large number of different variables available for measuring load during a given training session or match, there are also different time aspects of these measurements that need to be considered; they are often defined as absolute or relative load (table 4) [52].

\section{Load and injuries in the football codes}

The most common approach in sport is to analyse athletes' absolute load [52]. Although there has been some inconsistency between the results of different studies on load and injuries in the different football codes, most studies seem to indicate that high loads are associated with an increased injury rate (table 5). In football, players who participate in more high intensity training, defined as time spent with a heart rate of $85-90 \%$ of their maximal heart rate, have been found to be more likely to sustain an injury [94].

However, in recent years, more attention has been given to athletes' relative load [52]. The relative load has been emphasised because recent studies have shown that it might not be the high absolute load per se that has been causing the higher injury rates shown in previous studies; it may instead be a rapid increase in load (a "spike") that is harmful [52]. It has also been suggested that high chronic loads give athletes the opportunity to develop physical qualities that could potentially have a preventive effect [95]. In football, associations between relative load and injuries have been observed in a study in which low and high relative load (depending on which method was used when measuring load) compared with players' season average was shown to be associated with an increased risk of injury [96]. One way of defining relative load is the acute to chronic workload ratio [95]. This concept relates to the difference between the acute load (often defined by the workload during the current week) and the mean workload during an extended period (often defined as the mean workload/week during the last 4 weeks). In professional football, a high $(\geq 1.5)$ acute to chronic workload ratio has been shown to increase the odds of injury three-fold. This 
study also showed that large variations in workload from one week to the other were associated with an increased odds of injury, especially for players with a low level of fitness in comparison with their team mates [97]. 


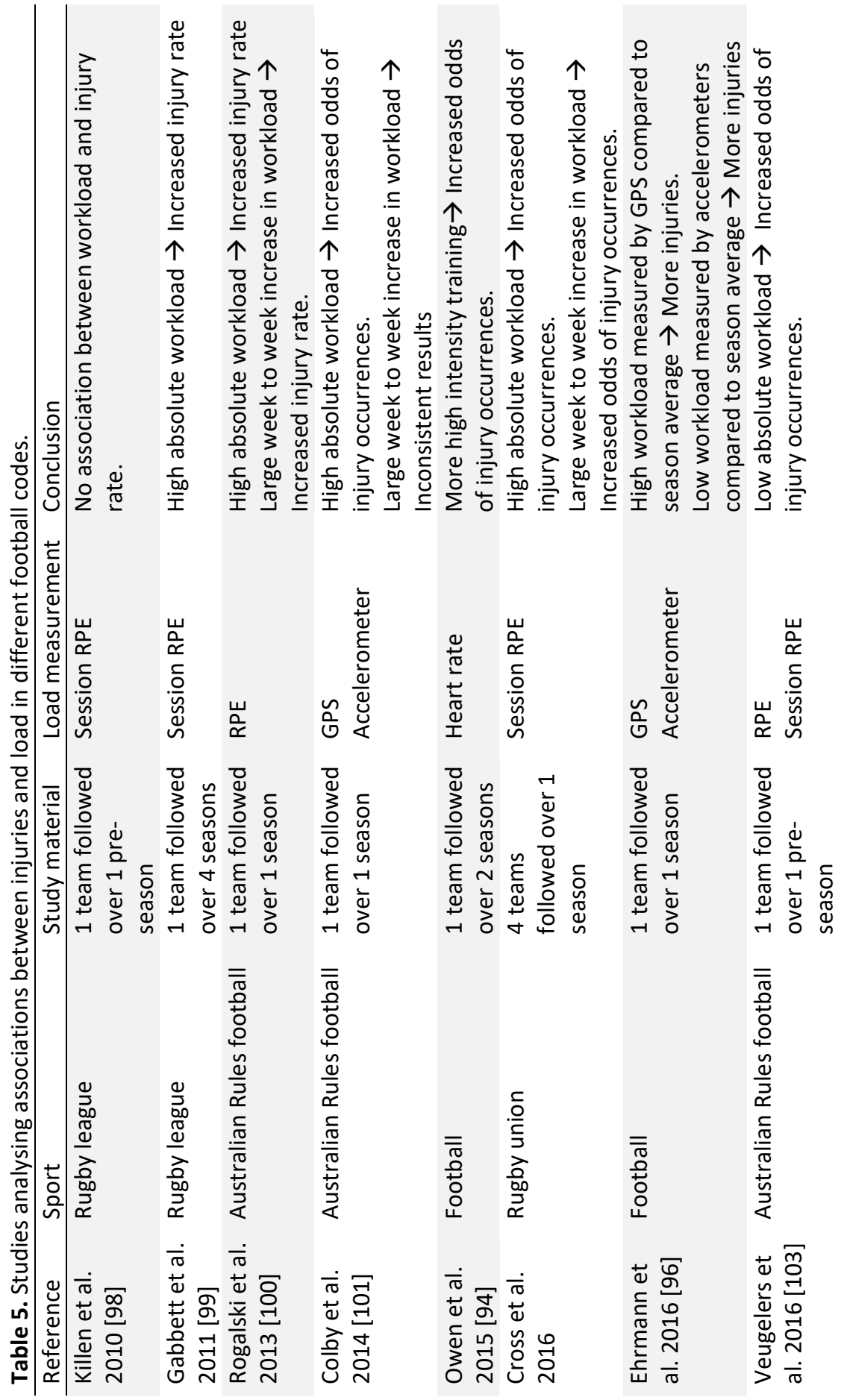




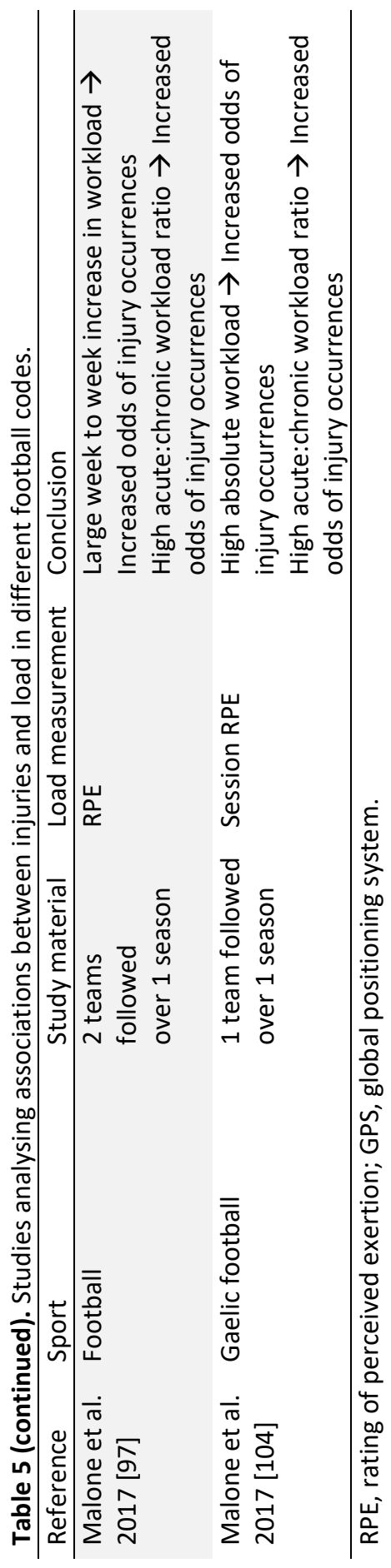




\section{Load during professional football matches}

The activity profiles of professional football players during matches show that on average they run more than 10,000 meters and that about $25 \%$ percent of this distance is covered at high intensity $[105,106]$. The mean distance covered during a match in the English Premier League has increased by $2 \%$ between $2006-07$ and 2012-13. There are also signs that the intensity of football matches has increased because it is mainly high intensity running and sprints that have increased during this period by $30 \%$ and $35 \%$, respectively. In addition, a $5 \%$ increase in the top speed of players was also observed between these two seasons [107].

Player activities during matches have been shown to be influenced by team formation [108] and by ball possession [109, 110]. Ball possession has in turn been shown to be influenced by match venue, quality of opposition and match status in terms of winning/losing [76, 79-81, 83]. This shows that several different match characteristics can influence the activity patterns of players during professional football matches. The activity profile has also been shown to change during a match with a decrease in the amount of high-speed running in the last 15 minutes of each half. This reduction in high-speed running has been interpreted as a sign that players are fatigued towards the end of each half $[105,106]$. The distance covered in the second half has also been shown to be shorter than in the first half, which has also been interpreted as a sign of player fatigue during matches [106].

\section{Match congestion}

Most of the matches played by professional football players during a season are for the club team in national and international competitions. In addition, some players also participate in matches with their national team, giving them the potential to play more than 60 matches during a season. Due to this large number of matches, professional football teams at times face periods of match congestion, referring to an accumulation of matches over a shorter period of time than usual [52]. During these periods, players in these teams are at risk of playing matches without sufficient time to recover from a previous match exposure; the recovery window between two matches may not be long enough. Players in a French professional team who were followed over four seasons were on average exposed to 16 occasions per season when two matches for the club team or the national team were separated by 3 days or less. This means that approximately $25 \%$ of all matches were played within 3 days of the previous match [111].

It has been suggested that playing matches with insufficient time for recovery in between could mean that players experience an accumulation of fatigue causing poor performance and increased risk of injury. However, when the physical performance of players playing two matches per week was compared with that of players who played one match per week, no differences were found [112-114]. In addition, no differences 
in the physical performance of players during longer periods of match congestion, six to seven matches over 18 to 24 days, compared with less congested periods have been found $[115,116]$. Previous studies on the relationship between match congestion and injury rates in professional football have used different definitions of match congestion, and they have also shown varying results (table 6).

Table 6. Studies analysing associations between injuries and match congestion in male professional football.

\begin{tabular}{|c|c|c|c|}
\hline Reference & Study material & Match congestion variable & Results \\
\hline $\begin{array}{l}\text { Dupont et al. } \\
2010 \text { [112] }\end{array}$ & $\begin{array}{l}1 \text { team followed } \\
\text { over } 2 \text { seasons }\end{array}$ & $\begin{array}{l}\text { Matches played within } 4 \\
\text { days following a previous } \\
\text { match compared with } \\
\text { matches played after } 6 \text { days } \\
\text { or more following a } \\
\text { previous match }\end{array}$ & $\begin{array}{l}\text { Injury rate was six times } \\
\text { higher in matches played } \\
\text { within } 4 \text { days following a } \\
\text { previous match }\end{array}$ \\
\hline $\begin{array}{l}\text { Carling et al. } \\
2010 \text { [72] }\end{array}$ & $\begin{array}{l}1 \text { team followed } \\
\text { over } 4 \text { seasons }\end{array}$ & $\begin{array}{l}\text { Matches played within } 3 \\
\text { days following a previous } \\
\text { match compared with } \\
\text { matches played after } 4 \text { days } \\
\text { or more following a } \\
\text { previous match }\end{array}$ & No significant differences \\
\hline $\begin{array}{l}\text { Carling et al. } \\
2012 \text { [117] }\end{array}$ & $\begin{array}{l}1 \text { team followed } \\
\text { over } 1 \text { season }\end{array}$ & $\begin{array}{l}\text { Matches during a congested } \\
\text { period ( } 8 \text { matches over } 26 \\
\text { days) compared with } \\
\text { matches outside this period }\end{array}$ & No significant differences \\
\hline $\begin{array}{l}\text { Dellal et al. } \\
2015 \text { [115] }\end{array}$ & $\begin{array}{l}1 \text { team followed } \\
\text { over } 1 \text { season }\end{array}$ & $\begin{array}{l}\text { Matches during three } \\
\text { congested periods ( } 6 \\
\text { matches over } 18 \text { days) } \\
\text { compared with matches } \\
\text { outside such periods }\end{array}$ & $\begin{array}{l}\text { Match injury rate was } \\
\text { more than twice as high } \\
\text { and the training injury } \\
\text { rate was three times } \\
\text { lower in the congested } \\
\text { periods }\end{array}$ \\
\hline \multirow[t]{2}{*}{$\begin{array}{l}\text { Carling et al. } \\
2016 \text { [118] }\end{array}$} & $\begin{array}{l}1 \text { team followed } \\
\text { over } 6 \text { seasons }\end{array}$ & $\begin{array}{l}\text { The last match in two } \\
\text { different congested match } \\
\text { cycles compared with } \\
\text { matches outside these } \\
\text { cycles: } \\
1 \text {. Two matches separated } \\
\text { by } \leq 3 \text { days }\end{array}$ & $\begin{array}{l}\text { 1.) No significant } \\
\text { differences in the last } \\
\text { match of the two-match } \\
\text { cycles } \\
\text { 2.) Injury rate was twice } \\
\text { as high in the last match } \\
\text { of the three-match } \\
\text { cycles }\end{array}$ \\
\hline & & $\begin{array}{l}\text { 2. Three matches all } \\
\text { separated by } \leq 4 \text { days }\end{array}$ & \\
\hline
\end{tabular}


Potential risk factors - summary

There are several potential match-related risk factors that have been shown to influence players in different ways. Some of these, such as match venue and match result, will influence players' activity pattern during matches, changing the distance that they cover and the actions that they perform during the match. Others, such as match congestion or a previous injury, could potentially influence players' preparation before matches. However, more studies are needed to establish if these factors are important for injury risk during professional football matches. More knowledge about risk factors in football could help clinicians in two ways. First, such knowledge will offer a better understanding of the risks to which football players are exposed in different situations, for example, when they face periods of match congestion and when they RTS after an injury. That means that decisions in these situations, such as player rotation in periods of match congestion or allowing players to return to playing matches after an injury, could be based on more accurate estimations about the injury risk for the players. Second, identification of injury risk factors will offer the possibility of reducing injury rates by addressing these factors with appropriate measures when possible. 


\section{AIM}

The overall aim of this thesis was to analyse if various potential match-related risk factors were associated with injury rates in professional football. The specific aims of the four papers were:

- To analyse associations between type of competition, match venue and match result and injury rates (Paper I).

- To analyse associations between match congestion and injury rates at team level (Paper II).

- To analyse associations between match congestion and injury rates at individual player level (Paper III).

- To analyse if the amount of training performed between RTS after an injury and a player's first match exposure is associated with the odds that they sustain an injury during their first match exposure (Paper IV). 


\section{MATERIALS AND METHODS}

\section{Study design}

In 2001, UEFA launched a research project now known as the UEFA Elite Club Injury Study (ECIS). ECIS is a prospective cohort study including male professional football players from teams in several European countries $[2,119,120]$. The study is being conducted by the Football Research Group (FRG) in Linköping, Sweden. The overall aim of the project is to increase the safety of all players who participate in any of the competitions that are arranged by UEFA and to contribute to a better understanding of the consequences and causes of injuries in football [121]. Towards this aim, ECIS primarily addresses the first two steps in the sequence of prevention: establishing the extent of the injury problem in professional football and increasing knowledge on the mechanisms and risk factors contributing to these injuries [19].

\section{Inclusion}

Before the start of each season, UEFA and FRG invited the 32 teams that qualified for the $\mathrm{CL}$ to join $\mathrm{ECIS}$. Invitations were also sent to teams that participated in ECIS in the previous season. Furthermore, teams who were among the 50 best teams in Europe, according to the UEFA club coefficient ranking, were also considered eligible for inclusion in ECIS. The UEFA club coefficient ranking is based on the results of the clubs, and other clubs from the same association, in European competitions over the last five seasons [122]. All players from the first team squads of the teams included were invited to participate and their written informed consent was obtained before inclusion in the study.

\section{Data collection}

The study period of each season typically lasted from July to May, beginning with the start of the pre-season and including the full competitive season. At the beginning of each season, the clubs appointed a member of the medical staff (the team physician or physiotherapist) as the contact person for the study. The contact person was responsible for all communication with the study group over the season. The contact person received a study manual at the beginning of the season with detailed instructions about the methodology of data registration and definitions of the variables that were of interest for the study. Data were sent to the study group in monthly reports using standard forms. After receiving these reports, a member of the study group reviewed the data in detail to make sure that it corresponded with the study methodology. If there were any questions or missing data after this review, prompt feedback was sent to the club to complete the report. 
Study forms

At the beginning of the season, data about each player included in the study were registered on a player data form including variables describing player anthropometrics and playing position. In addition, monthly reports consisting of an attendance record and injury cards were also completed and sent to the study group.

The attendance record contained information about all football exposures, in the club team as well as in national teams, for all players at an individual level. These exposures were described in terms of their duration and whether they were training or match exposures. The attendance record also described if players were absent for any reason.

If a player was marked as absent due to injury, a corresponding injury card was included in the team's monthly report to the study group describing the injury causing the absence. The injury card contained information about the nature of the injury (injury location, injury type, injury severity, diagnosis, etc.) as well as about the circumstances of the injury (injury occasion, injury mechanism, re-injury, etc.). The definitions of training exposure, match exposure, injury and injury severity are given in table 7.

Table 7. Exposure and injury definitions used in the study

\begin{tabular}{|c|c|}
\hline & Definition \\
\hline Training exposure & $\begin{array}{l}\text { Any team-based or individual physical activities under the control } \\
\text { or guidance of the team's coaching or fitness staff that are aimed } \\
\text { at maintaining or improving players' football skills or physical } \\
\text { condition }\end{array}$ \\
\hline Match exposure & Competitive or friendly match against another team \\
\hline Injury & $\begin{array}{l}\text { Any physical damage that occurs during a training session or match } \\
\text { that results in the player being unable to participate fully in } \\
\text { training or a match }\end{array}$ \\
\hline Injury severity & $\begin{array}{l}\text { The number of days that have elapsed from the date of injury to } \\
\text { the date of the player's return to full participation in team training } \\
\text { and availability for match selection. Injury severity was classified in } \\
\text { the following categories: slight ( } 0 \text { days), minimal ( } 1-3 \text { days), minor } \\
\text { (4-7 days), moderate ( } 8-28 \text { days), major ( }>28 \text { days) }\end{array}$ \\
\hline
\end{tabular}




\section{Study material}

During the 15 seasons that ECIS has been running, a total of 61 teams from 18 countries have been included, constituting an average of 20 teams per season. From these teams, a total of 3677 players have been included, with an average of 609 players/season. Players have on average been included for 2.5 seasons, adding up to a total of 9128 player-seasons. Player characteristics are presented in table 8.

After inclusion, teams have remained in the study for five seasons on average, with 13 teams included for more than ten seasons, adding up to a total of 304 team-seasons (table 9). Even though all four papers in the thesis are based on the same cohort, the inclusion period has varied among the papers as shown in table 9.

In Paper I and Paper II, all exposure and injury data were aggregated to a team level and the analysis was therefore performed on team data. In Paper III and Paper IV, exposure and injury data were considered at an individual player level, and the analyses were therefore performed on player data. In addition to the four papers, some additional analyses are presented. These analyses were all performed on player data and included exposure and injuries collected over 15 seasons.

Table 8. Player characteristics at inclusion.

\begin{tabular}{ll}
\hline Height, $\mathrm{cm}(\mathrm{SD})$ & $182(6.6)$ \\
Weight, $\mathrm{kg}(\mathrm{SD})$ & $78(7.4)$ \\
Age, years (SD) & $24(4.4)$ \\
Playing position & \\
Goalkeeper, $\mathrm{n}(\%)$ & $383(11)$ \\
Defender, $\mathrm{n}(\%)$ & $1119(31)$ \\
Midfielder, $\mathrm{n}(\%)$ & $1290(36)$ \\
Forward, $\mathrm{n}(\%)$ & $832(23)$ \\
\hline
\end{tabular}

$\mathrm{SD}$, standard deviation. 


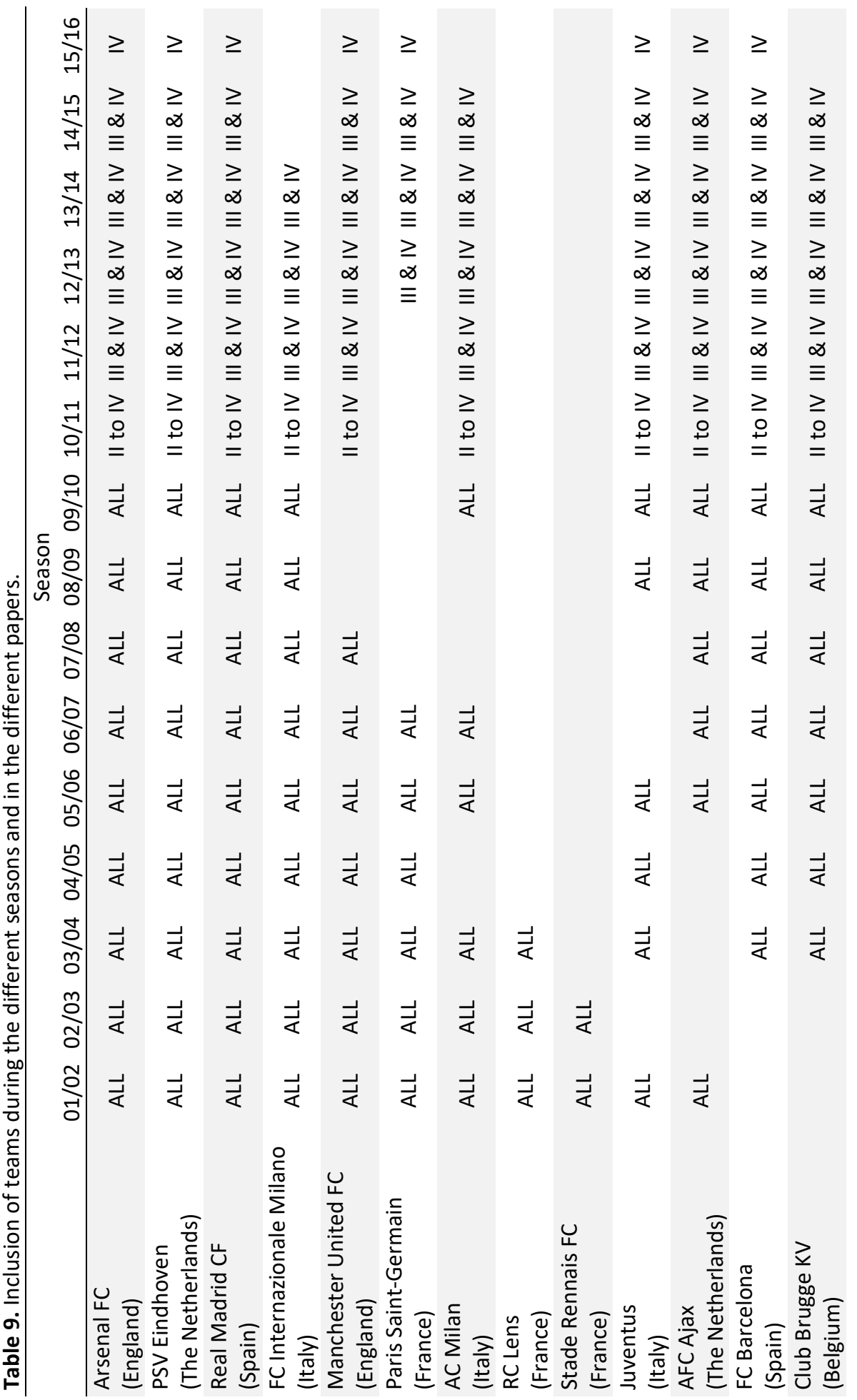




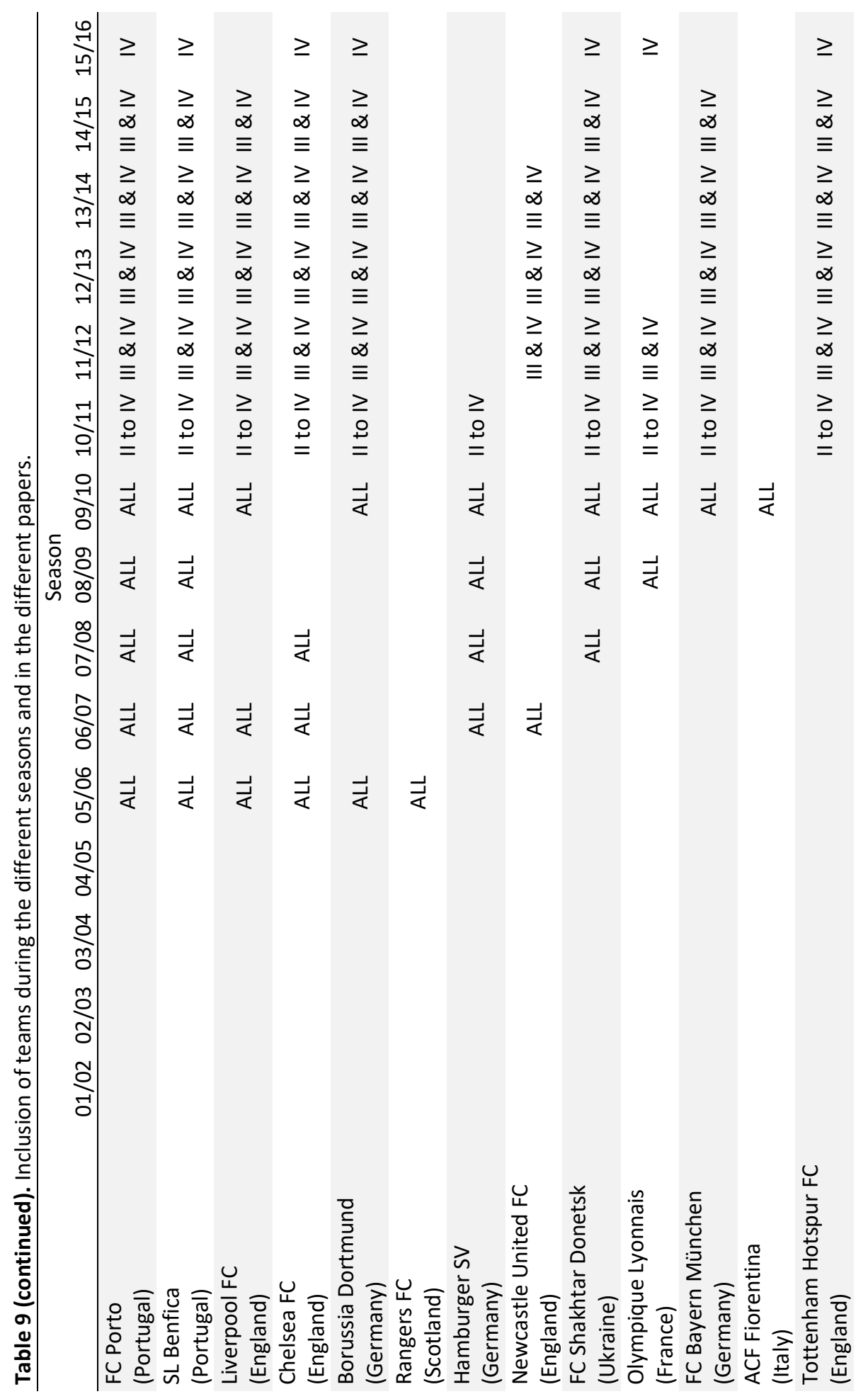




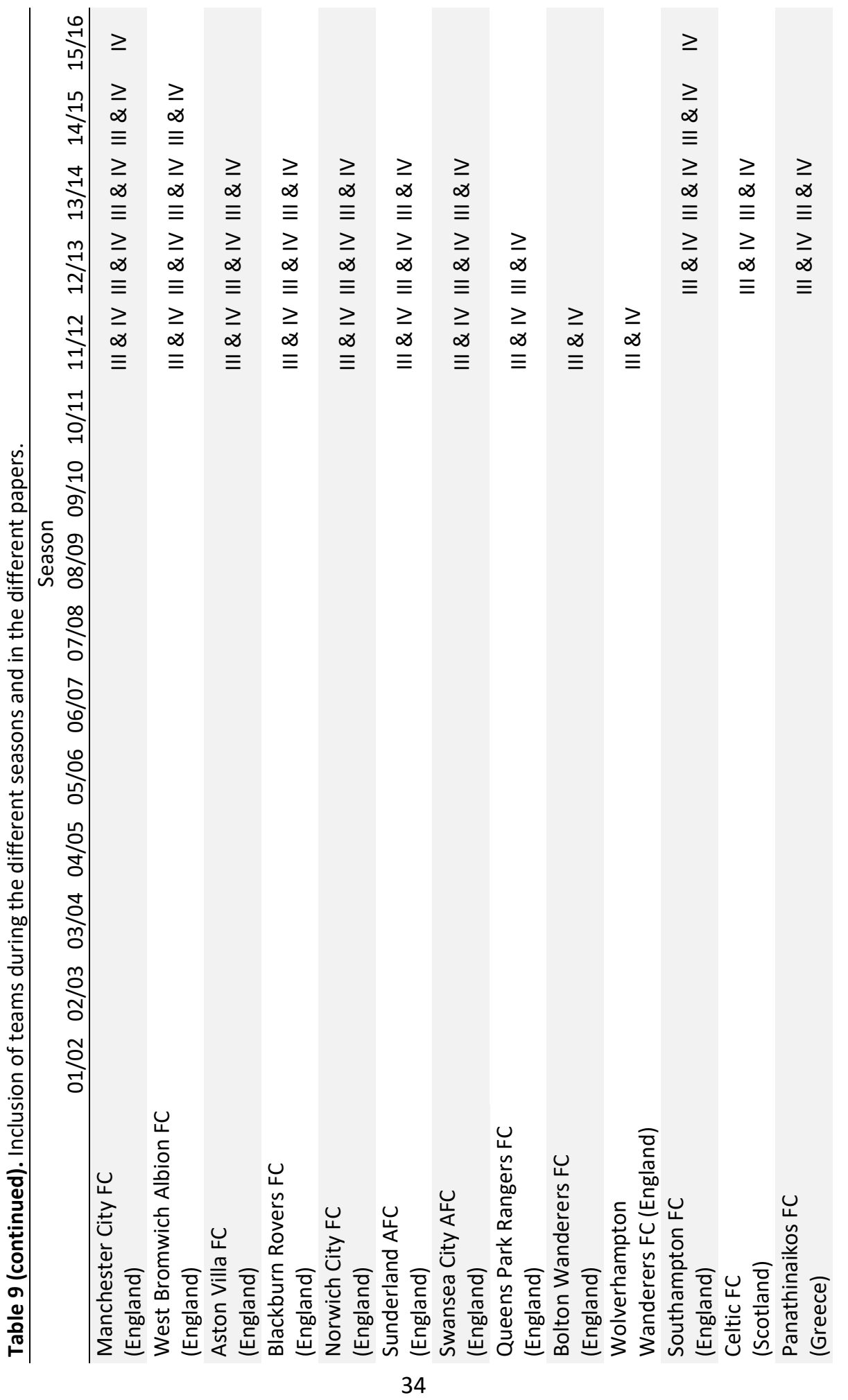




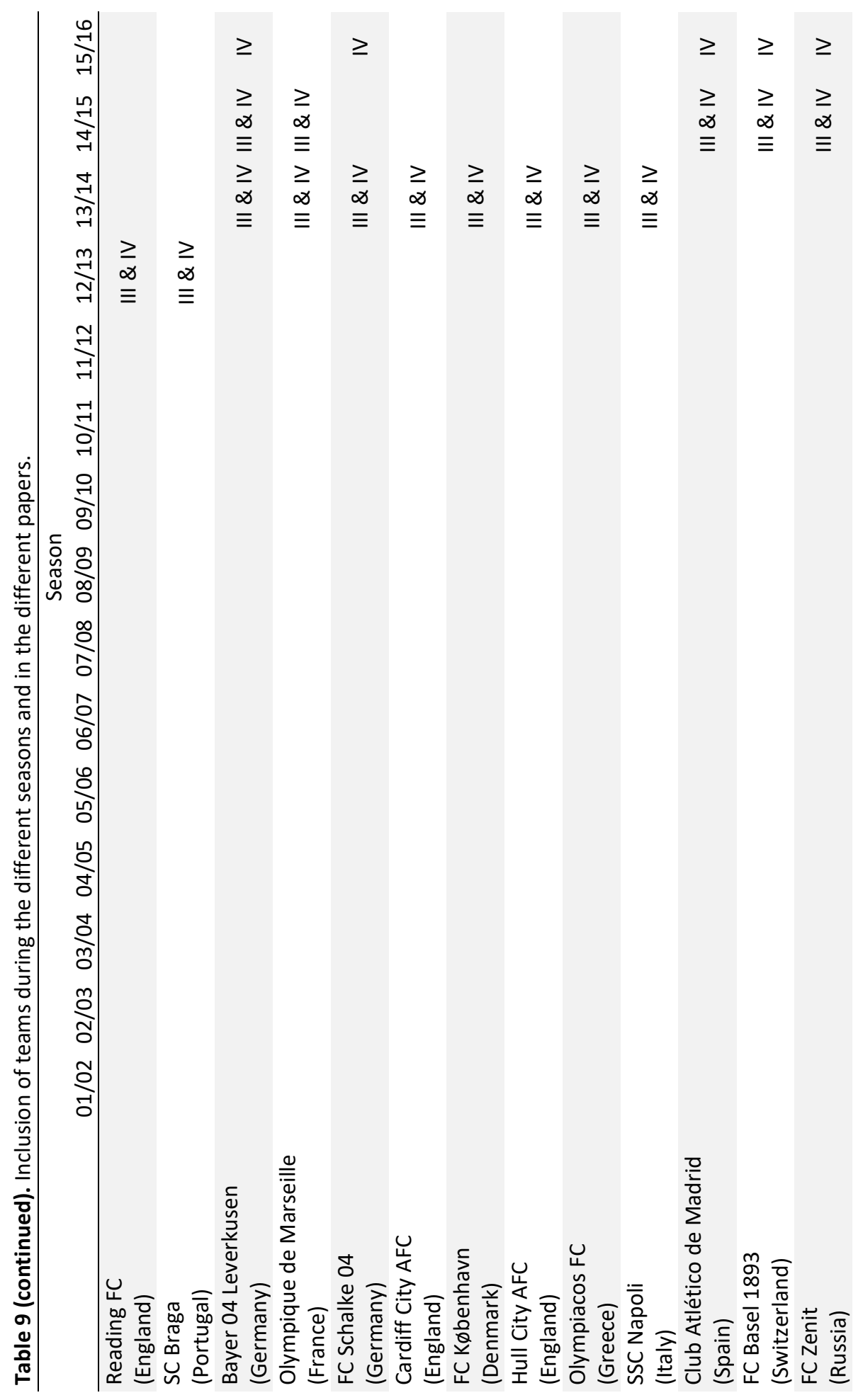




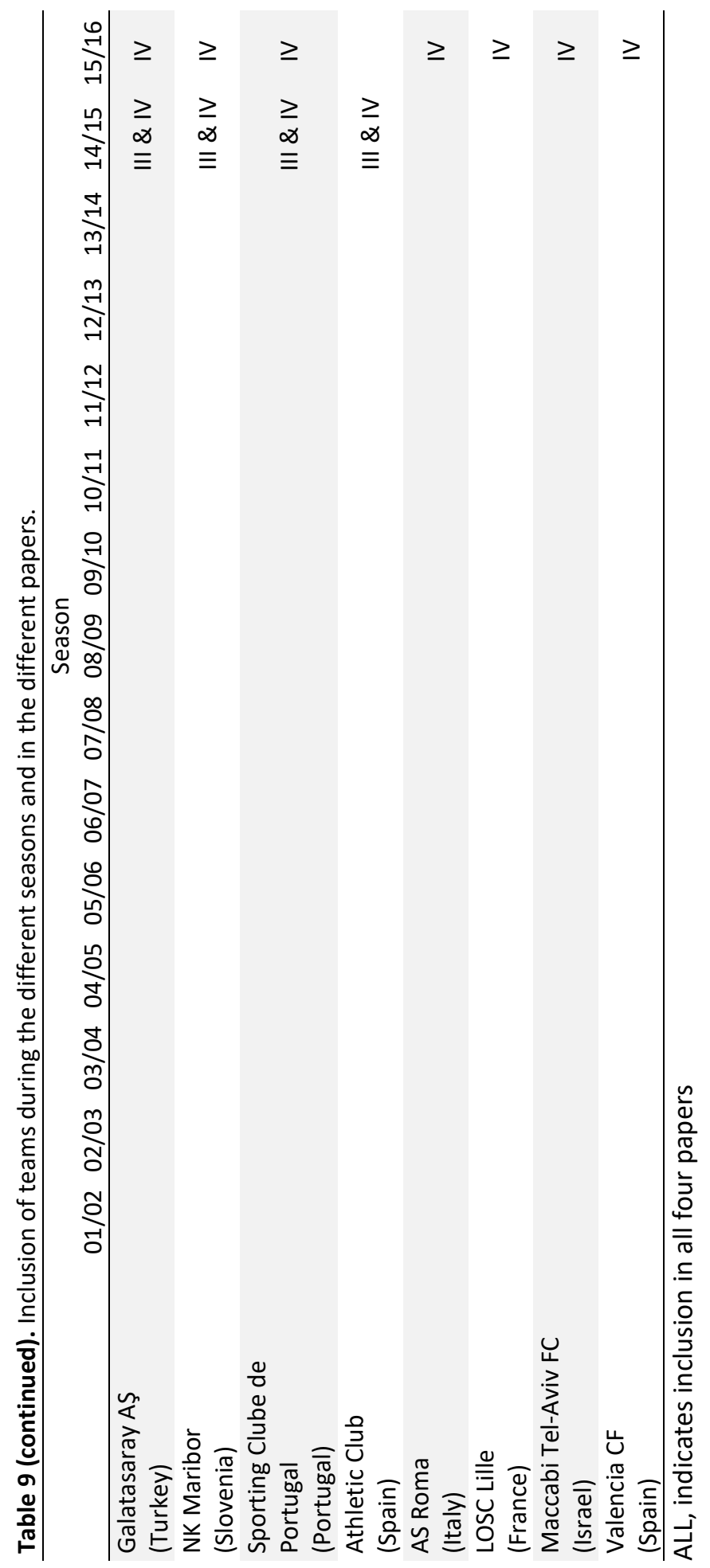


Study material - Paper I

In Paper I, data from nine consecutive seasons were analysed (2001/02 to 2009/10). In this paper, only first team competitive club matches at team level were included; friendly matches were excluded. Matches that were played on a neutral venue were also excluded, leaving 6010 team matches with 2738 injuries (Figure 2).

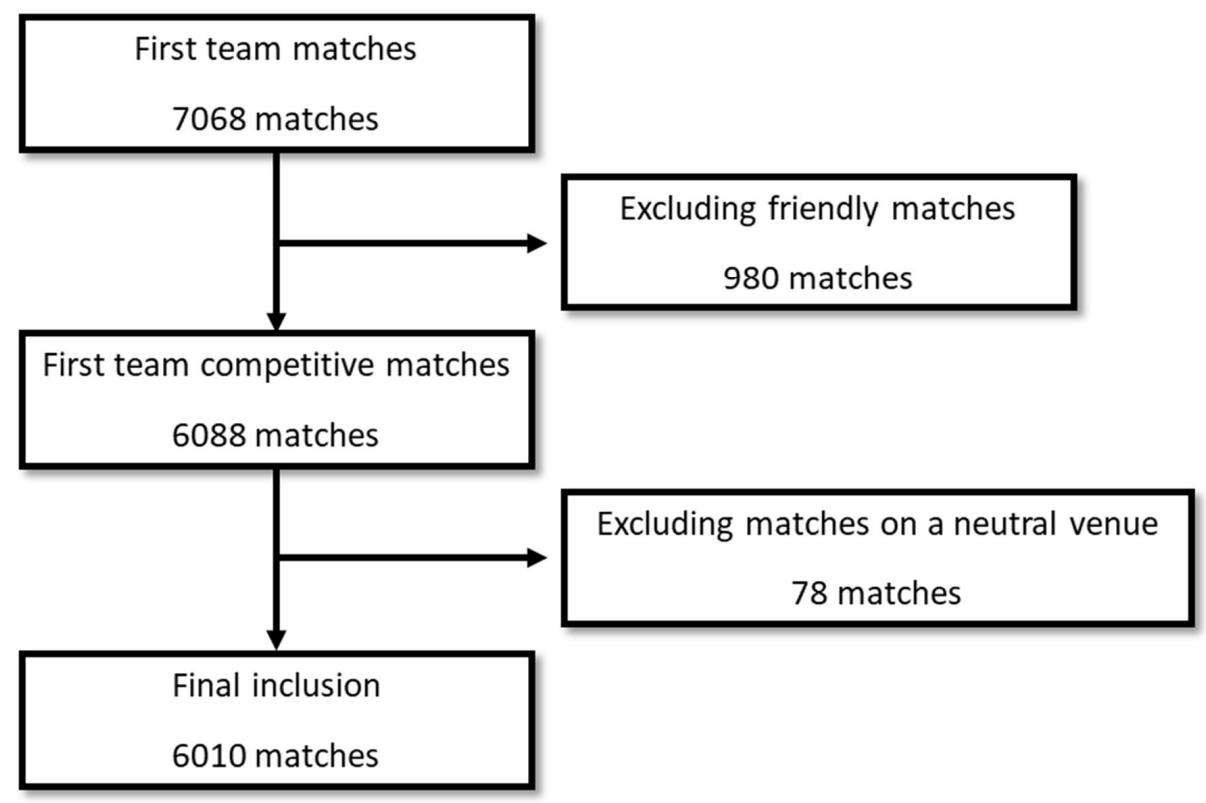

Figure 2. Flowchart of the matches included in Paper I.

Study material - Paper II

In Paper II, data from 11 consecutive seasons were analysed (2001/02 to 2011/12). As in Paper I, only competitive first team matches were included (reserve team, national team and friendly matches were excluded) leaving a total of 168,952 hours of match exposure from 8152 team matches with 4546 injuries. 
Study material - Paper III

In Paper III, data from 14 consecutive seasons were included (2001/02 to 2014/15). In this paper, individual match exposures from competitive matches were included (exposures from reserve team and friendly matches were excluded). In addition, only observations from players who had been included in the study for the previous 30 consecutive days, during which the player had not been injured or absent due to injury, were included. In addition, the players' last match before the observation had to be within the last 10 days, leaving 133,170 individual match observations for inclusion in the study (figure 3 ). A total of 166,433 match exposure hours were registered, including 4083 injuries of which 1561 were muscle injuries. 


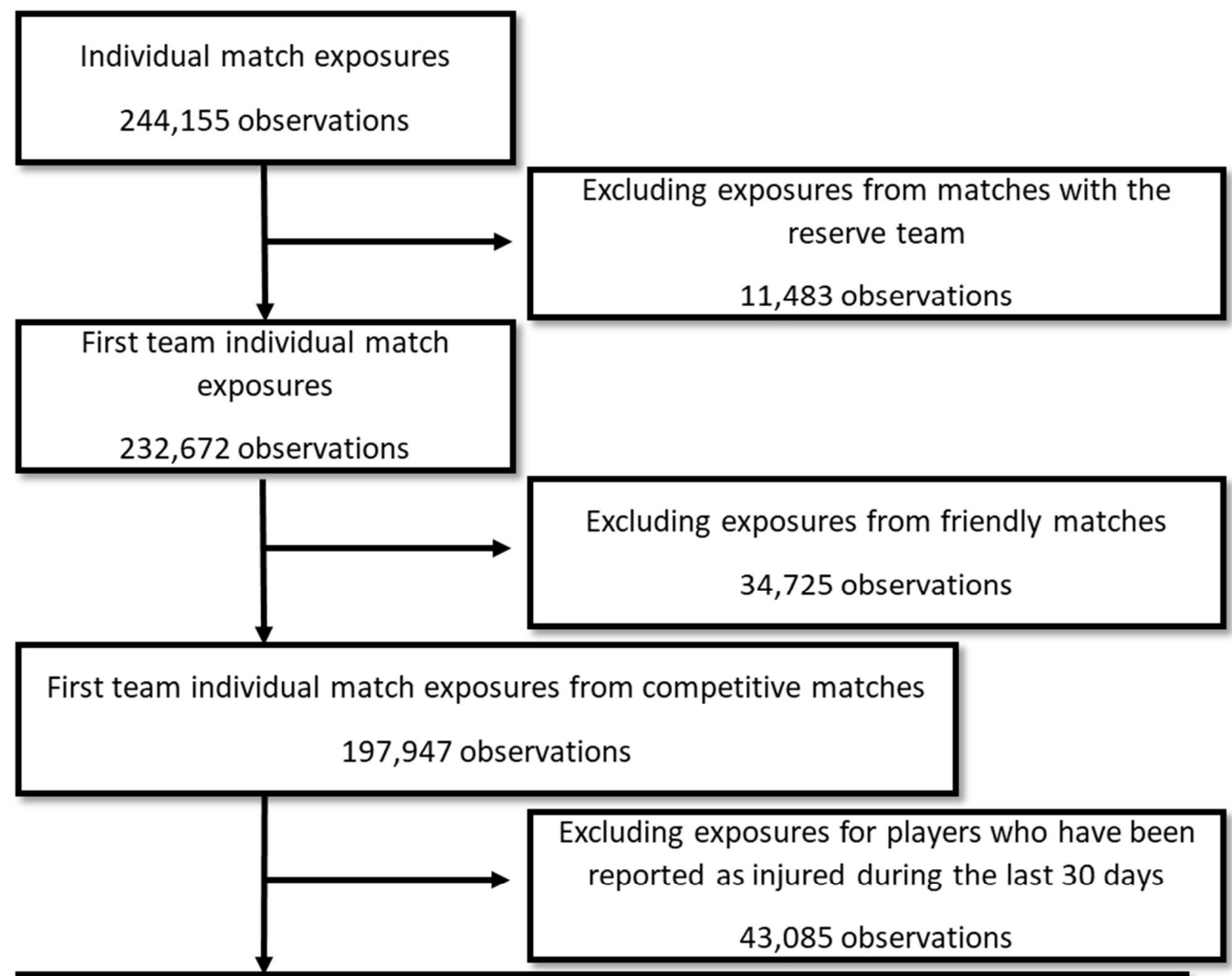

First team individual match exposures from competitive matches for players who have been uninjured for at least 30 days

154,862 observations

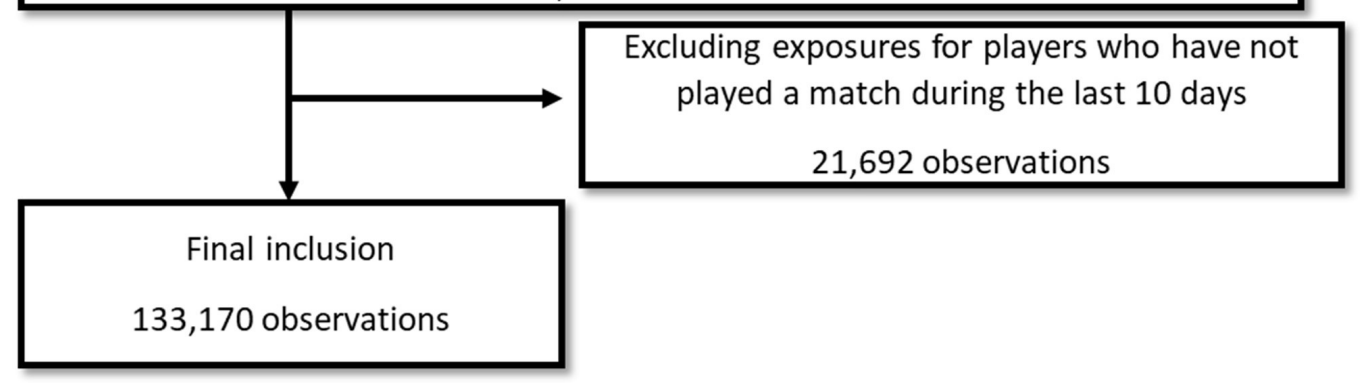

Figure 3. Flowchart of the individual match observations included in Paper III. 
Study material - Paper IV

Paper IV included data gathered over 15 consecutive seasons (2001/02 to 2015/16). In this paper, the first match exposure that was registered after RTS from all injuries that caused more than 7 days of absence was included. Injuries that caused $\leq 7$ days of absence were thus excluded. This selection was made because periods of absence that lasted no more than 7 days were believed to have a limited impact on a player's level of fitness. Match exposures when players had completed more than ten training sessions between their RTS and the match were also excluded. Thus, 5554 individual match exposures, during which 242 injuries were reported, were included in the study (figure 4).

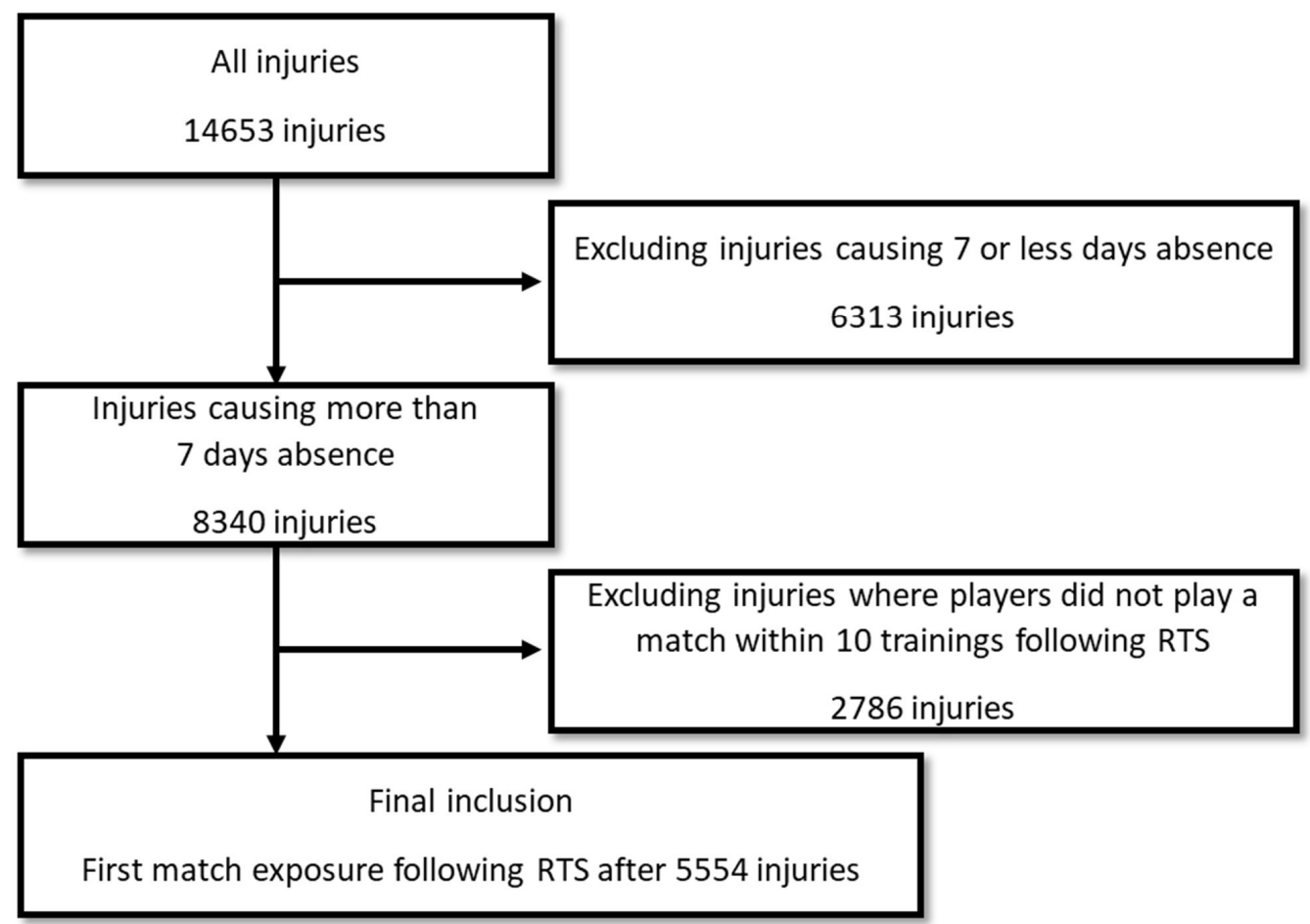

Figure 4. Flowchart of the first match exposures after RTS included in Paper IV. 


\section{Variables and statistical methods}

Injuries were used as outcome variables in all papers and are described as injury rates, injury risk or odds of injury occurrences. Injury rates were defined as the number of injury occurrences/1000 hours of exposure and are presented with the 95\% confidence interval $(\mathrm{Cl})$. Injury risk was defined as the probability that an injury would occur, whereas the odds of injury occurrences were defined as the probability that an injury would occur divided by the probability that an injury would not occur.

An overview of the primary variables that were included in the four papers, and the additional analyses, and the statistical methods that were used to analyse these variables are shown in table 10 . Statistical analyses were performed using the Statistical Package for the Social Sciences. All tests were two-sided, and the significance level was set at $p<0.05$.

Table 10. Overview of included variables and statistical methods.

\begin{tabular}{|c|c|c|c|}
\hline & Independent variables & Dependent variables & Statistical methods \\
\hline \multirow[t]{3}{*}{ Paper I } & 1. Type of competition & $\begin{array}{l}\text { 1-3. Odds of injury } \\
\text { occurrences }\end{array}$ & $\begin{array}{l}\text { 1-3. Generalised } \\
\text { estimating equations }\end{array}$ \\
\hline & 2. Match venue & & \\
\hline & 3. Match result & & \\
\hline \multirow[t]{3}{*}{ Paper II } & $\begin{array}{l}\text { 1. Short-term match } \\
\text { congestion: number of } \\
\text { days that separated a } \\
\text { match from the }\end{array}$ & 1,2 . Injury rates & $\begin{array}{l}\text { 1. Rate ratios tested } \\
\text { for significance using z } \\
\text { statistics }\end{array}$ \\
\hline & $\begin{array}{l}\text { preceding match for } \\
\text { the team }\end{array}$ & & $\begin{array}{l}\text { 2. Linear regression } \\
\text { analyses }\end{array}$ \\
\hline & $\begin{array}{l}\text { 2. Long-term match } \\
\text { congestion: number of } \\
\text { days that separated } \\
\text { five consecutive } \\
\text { matches for a team }\end{array}$ & & \\
\hline
\end{tabular}


Table 10 (continued). Overview of included variables and statistical methods.

\begin{tabular}{|c|c|c|c|}
\hline & Independent variables & Dependent variables & Statistical methods \\
\hline Paper III & $\begin{array}{l}\text { 1. Short-term match } \\
\text { congestion: number of } \\
\text { days that separated a } \\
\text { match exposure from } \\
\text { the preceding match } \\
\text { exposure for the player } \\
\text { 2. Long-term match } \\
\text { congestion: amount of } \\
\text { match exposure to } \\
\text { which the player had } \\
\text { been exposed in the } \\
\text { last } 30 \text { days }\end{array}$ & $1,2$. Injury rates & $\begin{array}{l}1,2 . \text { Poisson } \\
\text { regression analyses }\end{array}$ \\
\hline Paper IV & $\begin{array}{l}\text { 1. Training sessions } \\
\text { that a player had } \\
\text { completed between } \\
\text { RTS and his first match } \\
\text { exposure }\end{array}$ & $\begin{array}{l}\text { 1. Odds of injury } \\
\text { occurrences }\end{array}$ & $\begin{array}{l}\text { 1. Logistic regression } \\
\text { analyses }\end{array}$ \\
\hline $\begin{array}{l}\text { Additional } \\
\text { analyses }\end{array}$ & $\begin{array}{l}\text { 1. Type of competition } \\
\text { 2. Match venue } \\
\text { 3. Match result } \\
\text { 4. Short-term match } \\
\text { congestion: number of } \\
\text { days that separated a } \\
\text { match exposure from } \\
\text { the preceding match } \\
\text { exposure for the player } \\
5 \text {. Long-term match } \\
\text { congestion: amount of } \\
\text { match exposure to } \\
\text { which the player had } \\
\text { been exposed in the } \\
\text { last } 30 \text { days }\end{array}$ & 1-5. Injury rates & $\begin{array}{l}1-5 . \text { Poisson } \\
\text { regression analyses }\end{array}$ \\
\hline
\end{tabular}


Variables included in the different analyses are presented in more detail in the following sections. The statistical methods that were used to analyse these variables are also described.

\section{Match characteristics}

In Paper I, associations between three different match characteristics (type of competition, match venue, match result) and injury occurrences were analysed at team level. Information about match characteristics were collected from the teams' official homepages or other online databases. Several generalised estimating equations (GEE) were performed to analyse the associations between the different match characteristics and injury occurrences. All three match characteristics were included as independent variables in these analyses. Type of competition was categorised based on the competition: CL matches, EL matches, league matches, other cup matches. Match venue was categorised as home matches (matches that were played on the team's home venue) or away matches (matches that were played on the opposing team's home venue). Match result was categorised based on the final result of the match: won, drawn, lost.

The occurrence of (1) one and (2) two or more injuries for the teams were used as the primary response variables in two separate GEE models. As a sensitivity analysis, similar GEEs were performed, including occurrences of (1) one and (2) two or more moderate to severe injuries (injuries causing more than 7 days of absence) as response variables.

Finally, to analyse injury patterns (injury type, injury location and foul play) between the different match characteristics, Pearson's chi-squared test was used with $z$ test for pairwise comparisons of proportions. In this analysis, Bonferroni correction was used to adjust for the multiple comparisons.

To further analyse the associations between these match characteristics and injury rates during professional football matches, all 15 seasons now included in ECIS were analysed at a later stage. In these analyses, first team competitive match exposures at an individual player level were included, giving a total of 244,390 hours of match exposure. These exposures were categorised depending on the different match characteristics, identical to Paper I. Injury rates in the different categories were calculated and compared using rate ratios (RR) with corresponding $95 \% \mathrm{Cls}$. RRs were analysed with Poisson regressions using match exposure hours as an offset with league matches, home matches and matches won as the reference category for their respective match characteristic. These analyses have been added because the data have been restructured and now include hours of exposure, making it possible to calculate injury rates. All results from these analyses are previously unpublished. 
Match congestion

In Paper II and Paper III, short-term and long-term match congestion was analysed at team (Paper II) and individual (Paper III) level.

\section{Short-term match congestion}

Short-term match congestion was defined by the recovery window before a match (defined as the number of days that separated the match/match exposure from the preceding match/match exposure) in both studies. However, the recovery window in Paper II was chosen as the number of days that separated two matches for the same team (with no consideration for whether or not the same players had participated in these two matches), but the number of days separating two match exposures for the same individual player was used in Paper III (with no consideration for whether or not the match exposures were played for the same team or if the player's team had played any other matches between these match exposures).

To analyse short-term match congestion at team level, matches were categorised depending on the recovery window between two matches using two different cut-offs that have been used in previous studies:

1. $\leq 3$ days since the preceding match compared with $\geq 4$ days since the preceding match [72].

2. $\leq 4$ days since the preceding match compared with $\geq 6$ days since the preceding match [112].

Associations between match results and short-term match congestion were analysed using a chi-squared test to compare the proportion of matches won, drawn or lost between the different short-term match congestion categories. Injury rates, muscle injury rates and ligament injury rates for each of the match congestion categories were calculated and compared using RR with corresponding $95 \% \mathrm{Cls}$. The statistical significance of the RR was tested with $z$ statistics. Specific analyses of muscle injuries and ligament injuries were included because these are the two most common injury types in professional football.

To study the associations between short-term match congestion and injury rates at individual level, all match observations were categorised based on their recovery windows (categorised as $\leq 3$ days, 4 days, 5 days, 6 days, and 7-10 days between matches). Injury rates and muscle injury rates were calculated for each of these categories, and these injury rates were then compared by calculating RR with corresponding $95 \% \mathrm{Cls}$. RRs were analysed with Poisson regressions using match exposure hours as an offset. Matches after a recovery window of $\leq 3$ days were used as the reference category in these comparisons. Specific analyses of 
muscle injuries were included because they were found to be associated with match congestion in the analyses at team level. In addition, muscle injury rates to specific muscle groups (hip/groin, thigh and lower leg) were also analysed for those observations where the duration of the previous match exposure was $\geq 90$ minutes. These three muscle groups were analysed separately because they are the three most common locations of muscle injuries.

Associations between short-term match congestion at individual level and injury rates to these muscle groups, were also analysed using a cut-off between the recovery windows that were found to be associated with high muscle injury rates ( $\leq 5$ days) and the recovery windows that were associated with lower muscle injury rates ( $\geq 6$ days) in Paper III. These analyses were added to increase the statistical power. RRs between these two different recovery windows were analysed with Poisson regression using match hours as an offset. The results from these analyses are previously unpublished.

\section{Long-term match congestion}

To define long-term match congestion at team level, all matches were grouped in match sequences of five consecutive matches. The long-term match congestion in these sequences was then defined by the number of days that separated the first and the last match of the sequence. Linear regression analyses were used to analyse associations between long-term match congestion and injury rates during a match sequence. In these analyses, each match sequence was used as an observation and the long-term match congestion in that sequence was used as the independent variable. General, muscle and ligament injury rates in matches and in training during the match sequence were used as dependent variables in separate analyses.

Similar linear regression analyses were performed to analyse associations between long-term match congestion and team performance. In these analyses, two different measures of team performance during the match sequences were used as dependent variables:

1. Number of matches won

2. Points per match

Long-term match congestion at individual level was defined for all match observations by the total amount of match exposure to which the player had been exposed in the 30 days before the observation. To study associations between long-term match congestion and injury rates at an individual level, all match observations were categorised depending on the long-term match congestion variable in three groups: low ( $\leq 4.5$ hours), medium (>4.5 to $\leq 7.5$ 
hours), or high ( $>7.5$ hours). These groups were intended to separate unusually high and low long-term match congestion and the cut-offs were therefore set in conjunction with the full match (1.5 hours of exposure) that was closest to the high and low 25th percentiles (three matches, 4.5 hours; five matches, 7.5 hours, respectively). Injury rates and muscle injury rates were calculated for each of these groups. RRs between the groups were analysed with Poisson regression using match exposure hours as an offset and using the high long-term match congestion group as reference.

\section{Interaction between short- and long-term match congestion}

Possible interactions between short- and long-term match congestion at an individual level for those observations where the duration of the previous match exposure was $\geq 90$ minutes were analysed in two steps. First, muscle injury rates in the different short-term match congestion groups were compared within each of the three long-term match congestion groups. This was done to see if associations between individual short-term match congestion and injury rates were dependent on players' long-term match congestion.

Second, similar analyses were done using the new cut-off between the recovery windows that were found to be associated with high muscle injury rates ( $\leq 5$ days) and the recovery windows that were associated with lower muscle injury rates ( $\geq 6$ days) in Paper III. All comparisons of muscle injury rates in these follow-up analyses were done by analysing RRs with Poisson regression using match exposure hours as an offset. 
Training sessions between RTS and the first match exposure

In Paper IV, associations between the number of completed training sessions between RTS and the first match exposure and the odds of injury occurrences in that match were investigated. A player was considered injured until "he was given clearance by the medical staff to participate fully in team training and match play". This means that all training sessions, individual and with the rest of the team, that were completed before the medical team considered the player to be medically ready for full participation in training as well as match play were considered part of the player's rehabilitation. Consequently, the first training session after clearance from the medical team was considered the first training session after RTS. The number of training sessions between RTS and the player's first match exposure was decided based on what had been reported on the attendance records.

Associations between the number of completed training sessions between RTS and the first match exposure and the odds of injury occurrences in that first match were analysed with logistic regression analyses. In these analyses, the number of completed training sessions between RTS and the first match exposure was used as the independent variable ( 0 to 10 completed training sessions). Injury occurrences, muscle injury occurrences and non-muscle injury occurrences were used as dependent variables in three separate analyses (dichotomised to injury/no injury). Muscle injury occurrences were analysed separately because it was hypothesised that the propensity for muscle injuries would be most affected by a previous period of absence. 


\section{RESULTS}

In total, over the 15 seasons that ECIS has been conducted, more than 2,000,000 hours of exposure have been reported. There have been more than five times as much training exposure as match exposure. The median number of training sessions that teams reported was 216 (interquartile range (IQR), 196-239) per season with 5477 (IQR, 4612-6489) training hours per season. The median number of matches per season was 59 (IQR, 54-64) and a median of 1078 (IQR, 948-1173) hours of match exposure. Data at an individual player level showed that the median number of training sessions to which players were exposed per season was 162 (IQR, 109-198) and a median of 197 (IQR 134-246) training hours. The median number of matches that players participated in was 30 (IQR, 13-45) per season and a median of 33 (IQR, 13-55) match hours per season.

During this exposure, a total of 14,653 injuries were reported, 6477 (44\%) during training and $8176(56 \%)$ during matches. This represent a total injury rate of $7.2 / 1000$ hours of exposure $(95 \% \mathrm{Cl}, 7.1-7.3)$. The injury rate was more than six times higher in matches compared with training: 25.5/1000 hours of match exposure $(95 \% \mathrm{Cl}, 25.0-26.1)$ and 3.8 injuries/1000 hours of training exposure (95\% Cl, 3.7-3.9). On average, teams have reported 48 injuries per season, and $70 \%$ of all players suffered at least one injury each season with 1.6 injuries per player and season reported.

Most injuries (87\%) have affected the lower limbs, with thigh (27\%), knee (17\%), hip/groin (14\%) ankle (13\%) and lower leg/Achilles tendon (12\%) accounting for $83 \%$ of all injuries. The most common injury type was muscle injuries (37\%) followed by ligament injuries (17\%) and contusions (13\%). These three injury categories together accounted for $68 \%$ of all injuries.

\section{Injury rates in different competitions}

There were no associations between the odds of one injury occurrence during a match and the specific competition in Paper I. The odds that two injuries would occur during a match was, however, lower in other cup matches compared with league matches (OR, 0.57; 95\% Cl, 0.39-0.84). The sensitivity analysis including moderate and severe injuries confirmed that the odds of two or more injury occurrences was lower in other cup matches than in league matches (OR, 0.63; $95 \% \mathrm{Cl}, 0.42-0.95)$. In addition, the odds of moderate to severe injury occurrences were found to be higher in $\mathrm{CL}$ matches compared with league 
matches (OR, 1.26; 95\% Cl, 1.09-1.45 for one injury occurrence and OR, 1.57; 95\% $\mathrm{Cl}, 1.13-2.20$ for two injury occurrences).

Similar associations between the type of competition and injury rates were found when data from all 15 seasons were analysed. In these analyses, CL matches were found to be associated with the highest injury rate, $8 \%$ higher than league matches (RR, 1.08; 95\% Cl, 1.00-1.16), whereas other cup matches and $\mathrm{EL}$ matches were associated with a lower injury rate than found for league matches, $8 \%(\mathrm{RR}, 0.92 ; 95 \% \mathrm{Cl}, 0.85-0.99)$ and $16 \%(\mathrm{RR}, 0.84 ; 95 \% \mathrm{Cl}, 0.74-0.95)$ lower, respectively (figure 5 ). These results are previously unpublished.

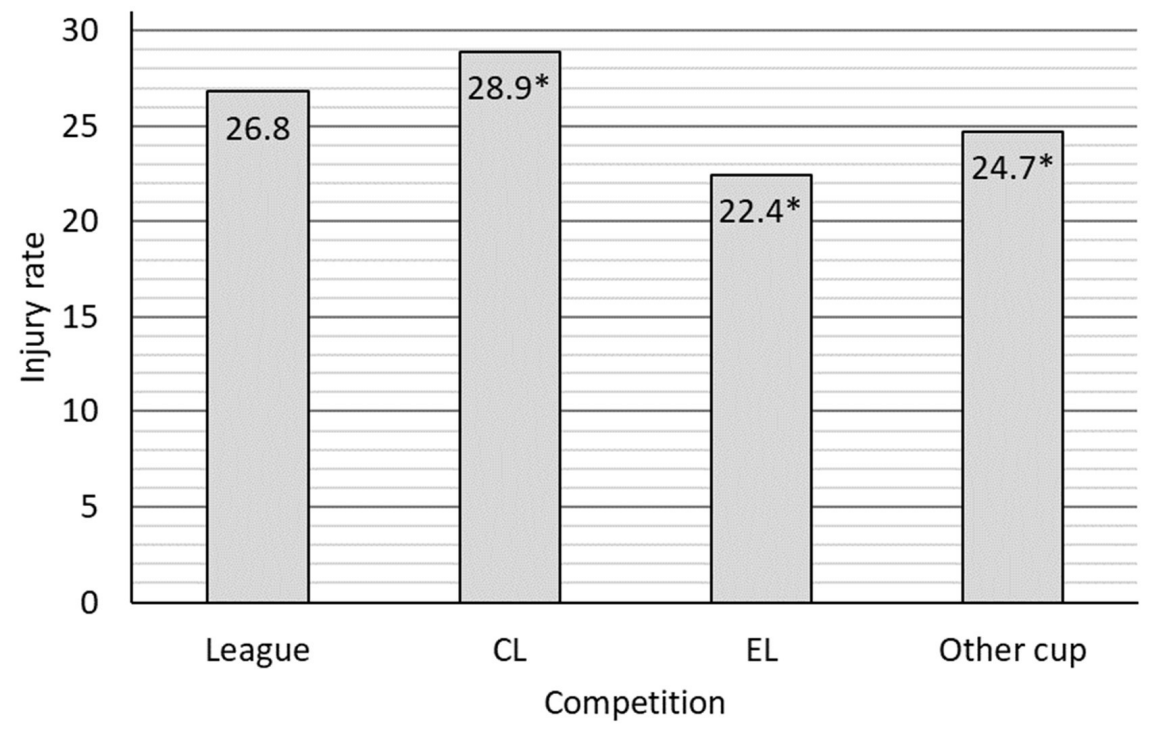

Figure 5. Injury rates (injuries/1000 hours of exposure) in matches from different competitions.

$\mathrm{CL}$, UEFA Champions League; EL, UEFA Europa League.

* indicates a significantly different injury rate compared with league matches.

In Paper I, it was also shown that there were no differences in the proportion of different injury types, injury locations or injuries caused by foul play between the different competitions. 


\section{Injury rates on different match venues}

The analyses of different match venues in Paper I showed that the odds of injury occurrences was lower in away matches compared with matches played at the home stadium (OR, $0.89 ; 95 \% \mathrm{Cl}, 0.80-0.99$ for one injury occurrence and $\mathrm{OR}$, $0.70 ; 95 \% \mathrm{Cl}, 0.60-0.82$ for two injury occurrences). The sensitivity analysis including moderate to severe injuries confirmed that the odds of two or more injury occurrences were lower in away matches $(\mathrm{OR}, 0.64 ; 95 \% \mathrm{Cl}, 0.46-0.89)$.

Similar associations were also found in the analyses of all 15 seasons showing a $9 \%$ lower injury rate in away matches compared with home matches (RR, 0.91; $95 \% \mathrm{Cl}, 0.86-0.95$ ) (figure 6). These results are previously unpublished.

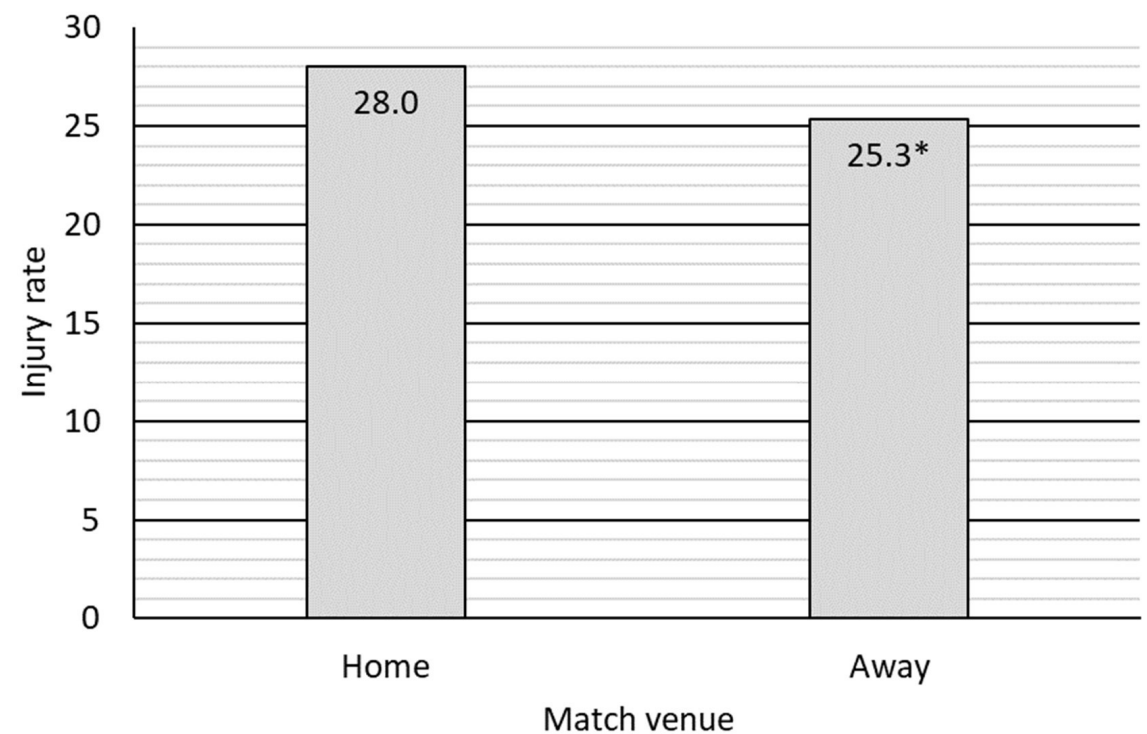

Figure 6. Injury rates (injuries/1000 hours of exposure) in matches at different match venues.

* indicates a significant different injury rate compared with home matches.

The analyses of injury patterns in Paper / showed a significantly higher proportion of muscle/tendon injuries and significantly lower proportion of joint/ligament injuries during home matches compared with matches that were played away ( $48 \%$ muscle injuries in home matches compared with $41 \%$ in away matches and $22 \%$ ligament injuries in home matches compared with $27 \%$ in away matches). In addition, a significantly higher proportion of lower limb injuries was also found during home matches whereas no difference in the proportion of injuries caused by foul play was shown between match venues. 


\section{Injury rates and match results.}

In Paper I, there were no differences in the odds of one injury occurrence between matches that were won, drawn or lost. However, the odds of two injury occurrences were higher in matches that ended with a draw $(\mathrm{OR}, 1.39 ; 95 \% \mathrm{Cl}$, $1.15-1.69)$ or loss (OR, $1.66 ; 95 \% \mathrm{Cl}, 1.38-1.98)$ compared to when teams won. These findings were confirmed by the sensitivity analysis including moderate and severe injuries (OR, 2.14; $95 \% \mathrm{Cl}, 1.60-2.88$ for matches drawn and $\mathrm{OR}, 1.98 ; 95 \%$ $\mathrm{Cl}, 1.41-2.80$ for matches lost). In addition, the odds of one moderate to severe injury occurrence was also higher in matches that were lost compared with matches that were won (OR, 1.28; 95\% $\mathrm{Cl}, 1.11-1.48)$.

In addition, the previously unpublished analyses of all 15 seasons showed that the injury rate was $14 \%$ higher in matches that were drawn compared with matches that were won (RR, 1.14; $95 \% \mathrm{Cl}, 1.07-1.21)$; the difference between matches that were lost and matches that were won was almost 30\% (RR, 1.28; $95 \% \mathrm{Cl}, 1.21-1.36$ ) (figure 7).

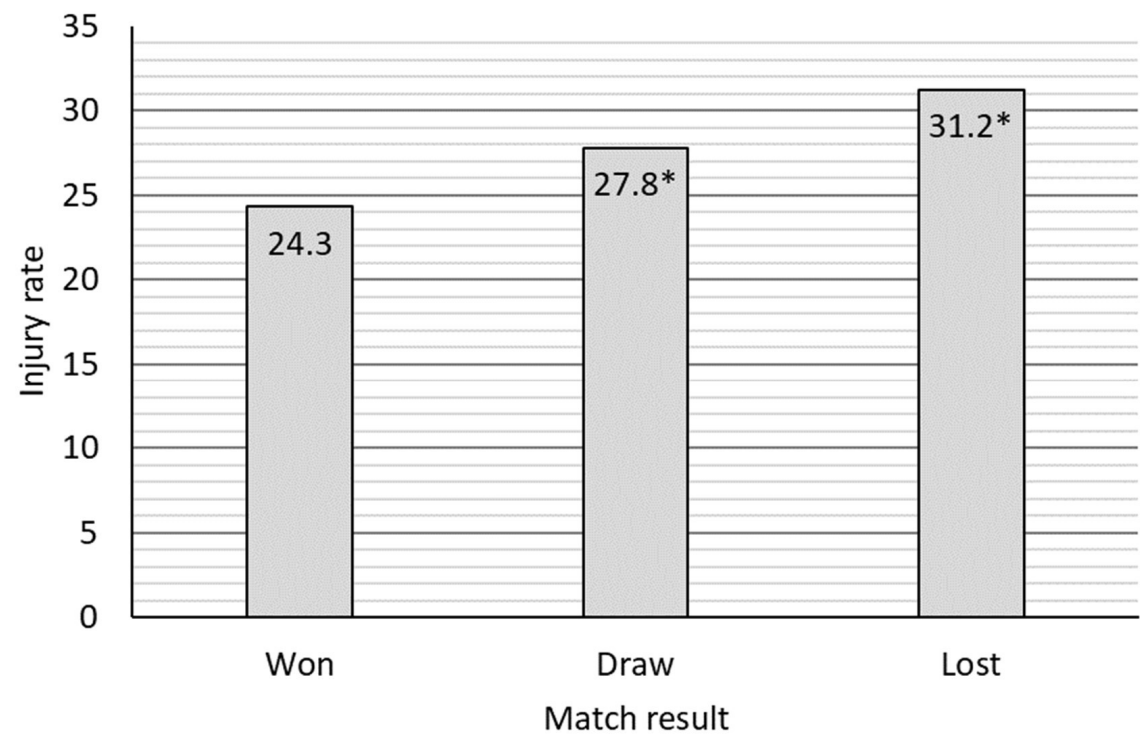

Figure 7. Injury rates (injuries/1000 hours of exposure) in matches with different match results.

* indicates a significant different injury rate compared with matches won.

No differences in the proportion of different injury types, injury locations or injuries caused by foul play were shown between the different match results (Paper I). 


\section{Short-term match congestion}

When short-term match congestion was considered at team level in Paper II, two different cut-offs were used ( $\leq 3$ days compared with $\geq 4$ days and $\leq 4$ days compared with $\geq 6$ days). These analyses showed that there were no associations between short-term match congestion and injury rate or muscle injury rate when the first cut-off ( $\leq 3$ days compared with $\geq 4$ days) was used (figure 8 ).

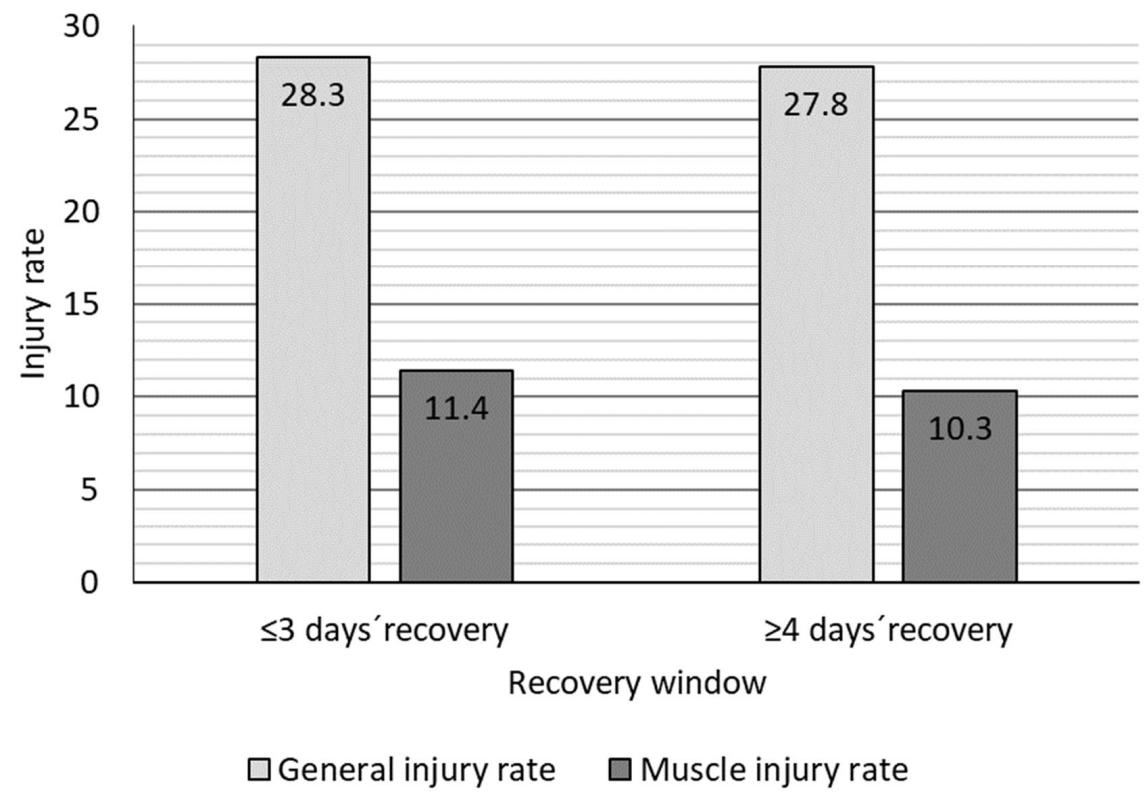

Figure 8. Injury rates (injuries/1000 hours of exposure) in league matches after different recovery windows ( $\leq 3$ days compared with $\geq 4$ days). 
When the second cut-off, $\leq 4$ days compared to $\geq 6$ days was used, significantly lower injury rate ( $R R, 1.09 ; 95 \% \mathrm{Cl}, 1.00-1.18)$ and muscle injury rate (RR, 1.32; $95 \% \mathrm{Cl}, 1.15-1.51)$ were shown in league matches following the longer recovery window (figure 9).

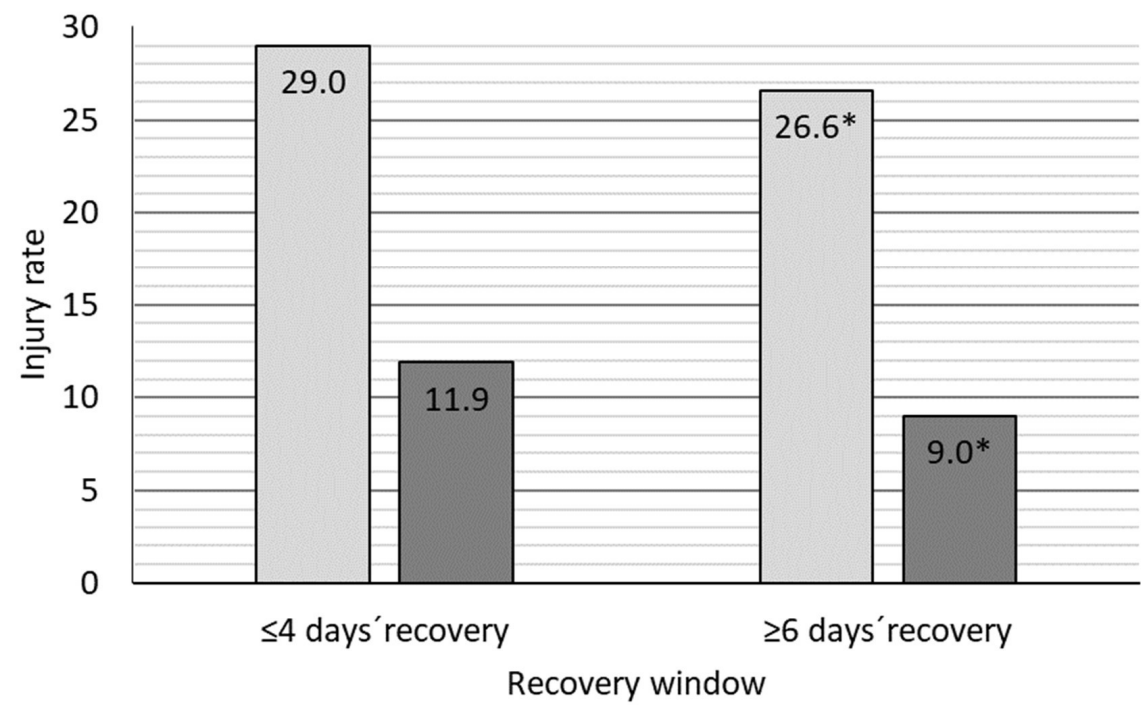

$\square$ General injury rate $\square$ Muscle injury rate

Figure 9. Injury rates (injuries/1000 hours of exposure) in league matches after different recovery windows ( $\leq 4$ days compared with $\geq 6$ days).

$*$ indicates a significant difference compared with $\leq 4$ days recovery. 
The ligament injury rate showed no association with short-term match congestion using either of the two cut-offs. In addition, no significant associations were found between short-term match congestion and team performance in any of the comparisons except for EL matches where teams performed worse after a recovery window of $\leq 3$ days compared with $\geq 4$ days (table 11).

When short-term match congestion was considered at an individual level in Paper III, no associations between the general injury rate and shortterm match congestion were found. Muscle injury rates were also equal for matches after a recovery window of 4 days or 5 days compared with $\leq 3$ days. However, similar to what was found when match congestion was considered at team level, muscle injury rates were about $20 \%$ lower when the recovery window before a match was 6 days (RR, 0.79; $95 \% \mathrm{Cl}, 0.65-0.95)$ or $7-10$ days (RR, 0.81; 95\% Cl, 0.71$0.93)$ compared with $\leq 3$ days (figure 10).

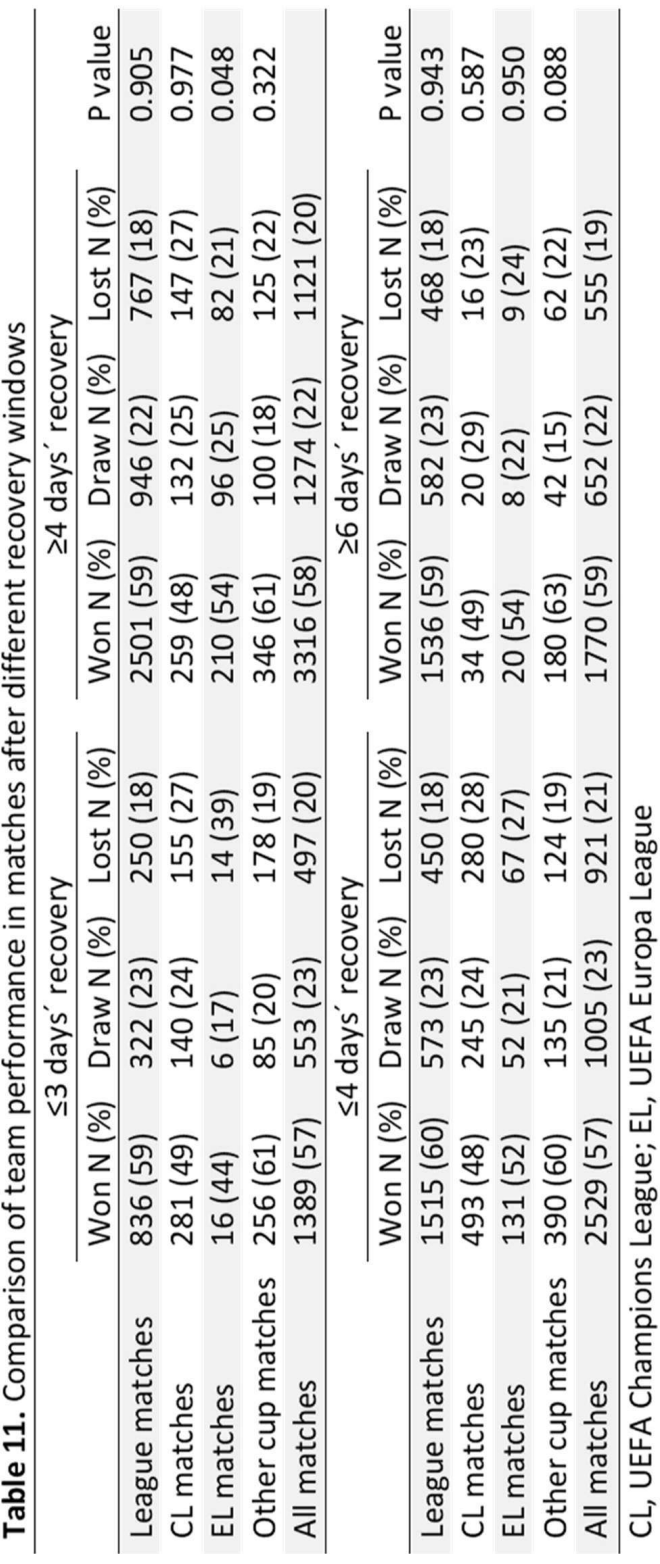




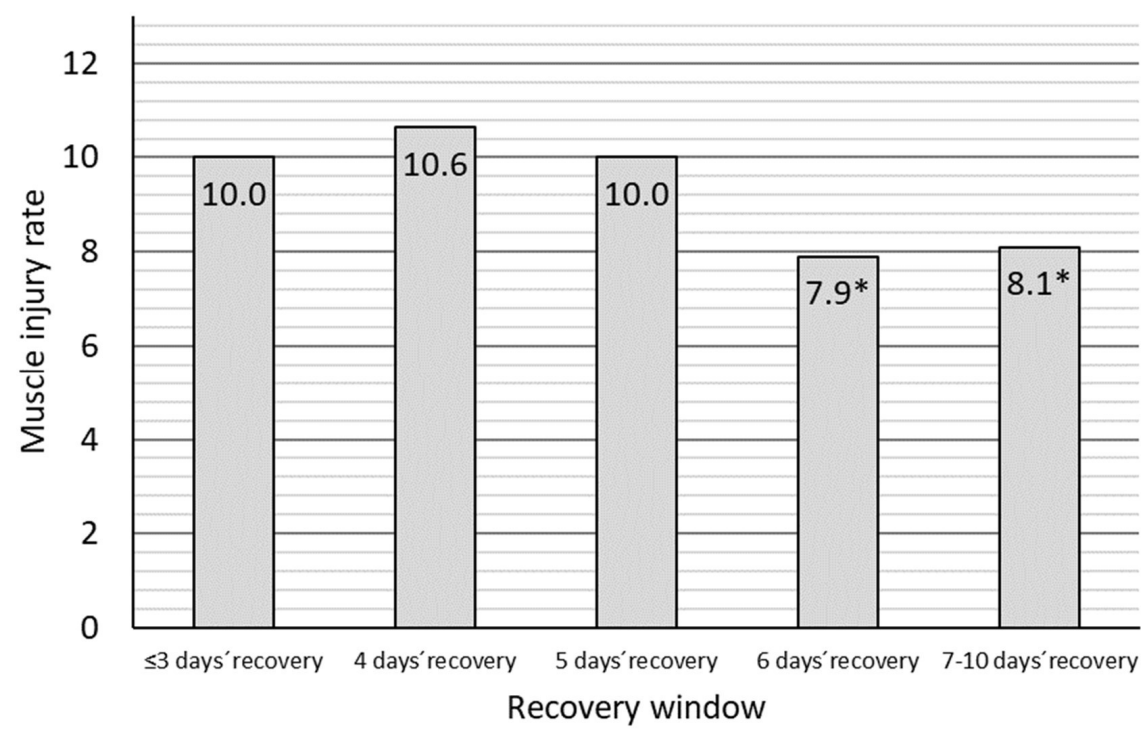

Figure 10. Injury rates (injuries/1000 hours of exposure) in matches after different recovery windows.

* indicates a significant difference compared with $\leq 3$ days recovery.

Associations between short-term match congestion and injury rates for specific muscle groups (hip/groin, thigh and lower leg) were also analysed in Paper III. These analyses showed similar, albeit non-significant, lower injury rates in matches after a recovery window of 6 or 7-10 days for all three muscle groups.

When these injury rates were analysed using the new cut-off ( $\leq 5$ days recovery window compared with $\geq 6$ days) in the follow up analyses, significant reductions after the longer recovery windows were found for thig (RR, 1.24; $95 \% \mathrm{Cl}, 1.06-$ 1.44) and hip/groin (RR, $1.36 ; 95 \% \mathrm{Cl} 1.07-1.72)$ muscle injury rates whereas the reduction in lower leg muscle injury rate was non-significant (RR, 1.34;95\% Cl, 0.95-1.88). These results are previously unpublished. 


\section{Long-term match congestion}

When considering long-term match congestion at team level in Paper II, an association between long-term match congestion and muscle injury rates during matches was found, showing that the muscle injury rate during matches was increased if long-term match congestion increased $(b=0.523 ; 95 \% \mathrm{Cl}, 0.114-$ 0.932). Also, similar to what was found when short-term match congestion was analysed, no associations were found between long-term match congestion and team performance.

In Paper III, injury rates during match exposures after a period of low ( $\leq 4.5$ hours), medium ( $>4.5$ to $\leq 7.5$ hours) or high ( $>7.5$ hours) long-term match congestion were compared to analyse long-term match congestion at an individual level. In contrast to the team-based analyses, no differences in injury rates depending on the amount of long-term match congestion before matches were shown in these analyses.

\section{Interactions between short- and long-term match congestion}

Interactions between individual short-term and long-term match congestion were analysed in two steps. In Paper III, associations between short-term match congestion and muscle injury rates were analysed within the three long-term match congestion groups. In this analysis, the same principal finding, with about $20 \%$ lower muscle injury rates when the recovery window was 6 or 7-10 days compared with $\leq 3$ days, was found in all three long-term match congestion groups. However, these differences were not statistically significant.

In the second step, similar analyses were performed using the new cut-off for long and short recovery windows ( $\leq 5$ days recovery window compared to $\geq 6$ days). In these previously unpublished analyses, lower injury rates after the longer recovery window were found in all three long-term match congestion groups. This difference was most pronounced in the low long-term match congestion group ( $R R, 0.69 ; 95 \% \mathrm{Cl}, 0.53-0.89)$, followed by the high ( $R R, 0.73$; $95 \% \mathrm{Cl}, 0.56-0.96)$ and medium ( $\mathrm{RR}, 0.79 ; 95 \% \mathrm{Cl}, 0.67-0.93)$ long-term match congestion groups (figure 11). 


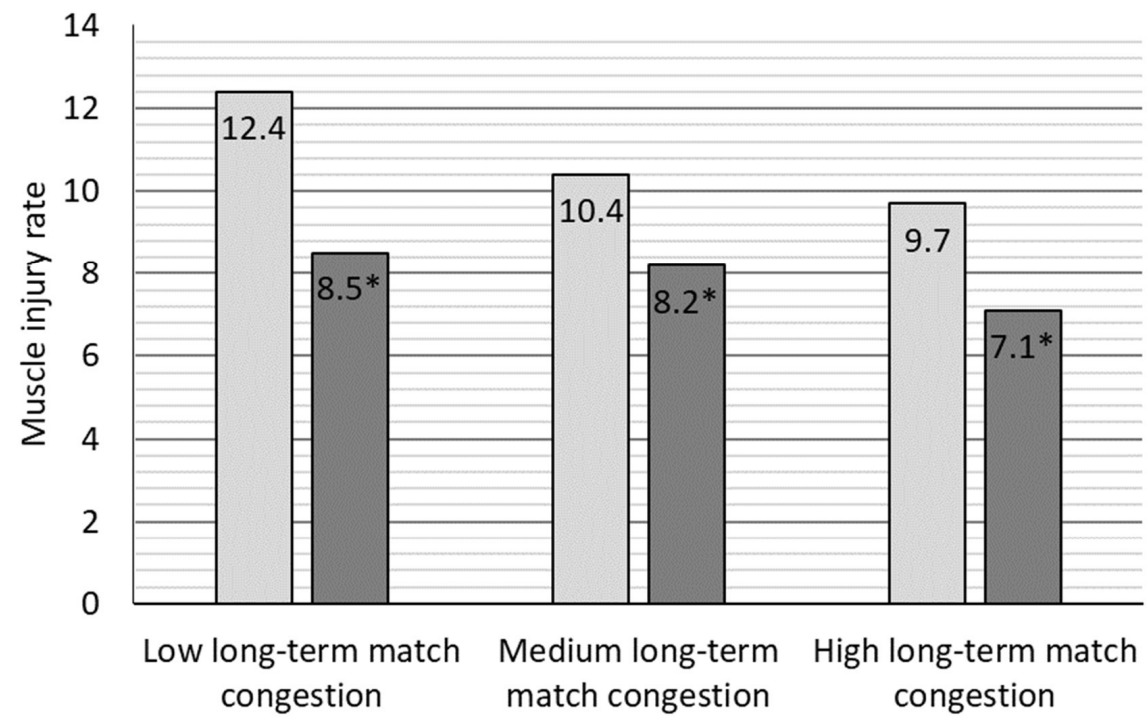

$\square$ Short recovery window ( $\leq 5$ days) $\square$ Long recovery window ( $\geq 6$ days)

Figure 11. Injury rates (injuries/1000 hours of exposure) in matches after different recovery windows within different long-term match congestion groups. Long-term match congestion is defined by the amount of match exposure to which the player has been exposed during the last 30 days.

* indicates a significant difference between short and long recovery windows within the longterm match congestion group. 


\section{The first match after RTS}

In Paper IV, the injury rate in the first match after players' RTS was 44.1 injuries $/ 1000$ match hours. This is $73 \%$ higher than the general match injury rate in the cohort (RR, 1.73; $95 \% \mathrm{Cl}, 1.52-1.96)$. Almost $50 \%$ of the injuries in these matches were muscle injuries, representing a muscle injury rate of 21.7 injuries/1000 match-hours and a non-muscle injury rate of 22.4 injuries/1000 match-hours. The risk that players would sustain an injury, a muscle injury or a non-muscle injury depending on the number of training sessions completed between RTS and their first match exposure is presented in figures 12,13 and 14 .

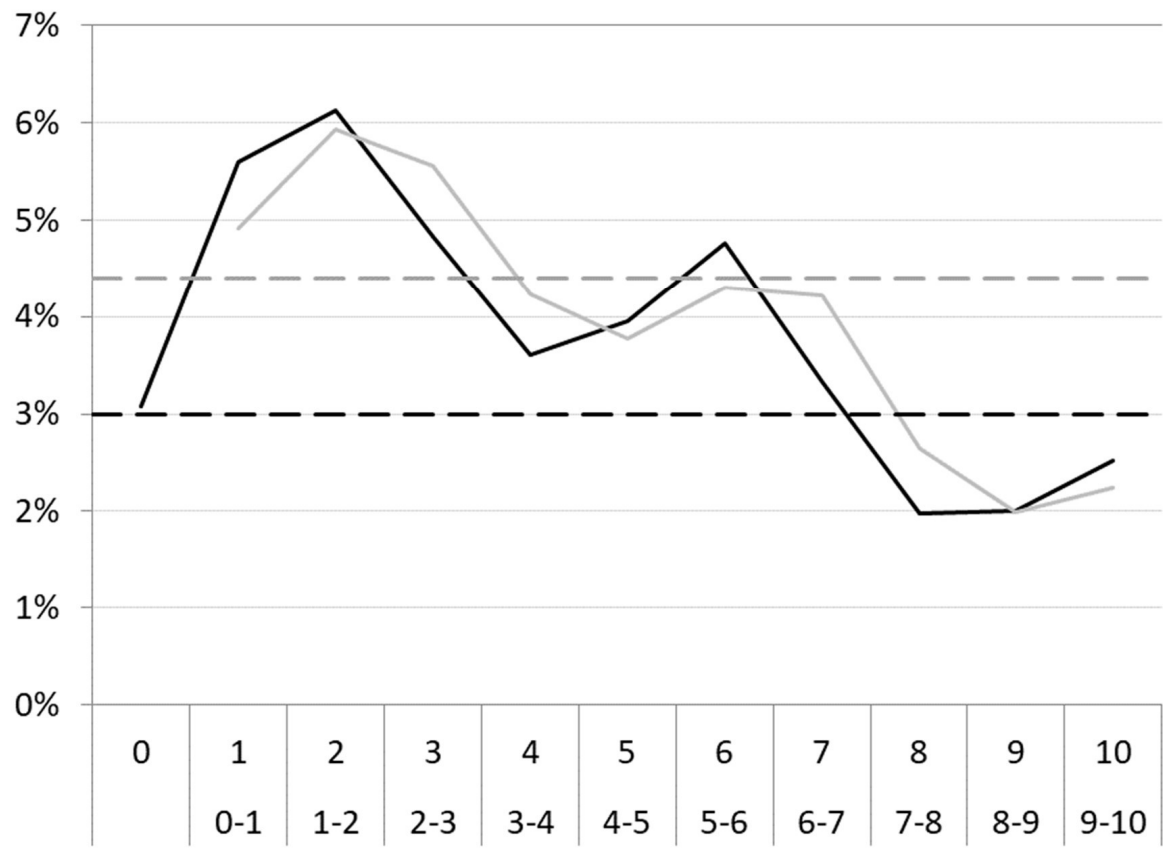

Completed training sessions between RTS and the first match

— Injury risk in the first match after RTS

__ Injury risk in the first match after RTS (moving average)

- Average injury risk in matches for the whole population

- - Average injury risk in the first match after RTS

Figure 12. Injury risk in the first match exposure after RTS. Moving average refers to the combination of data from two consecutive groups. 


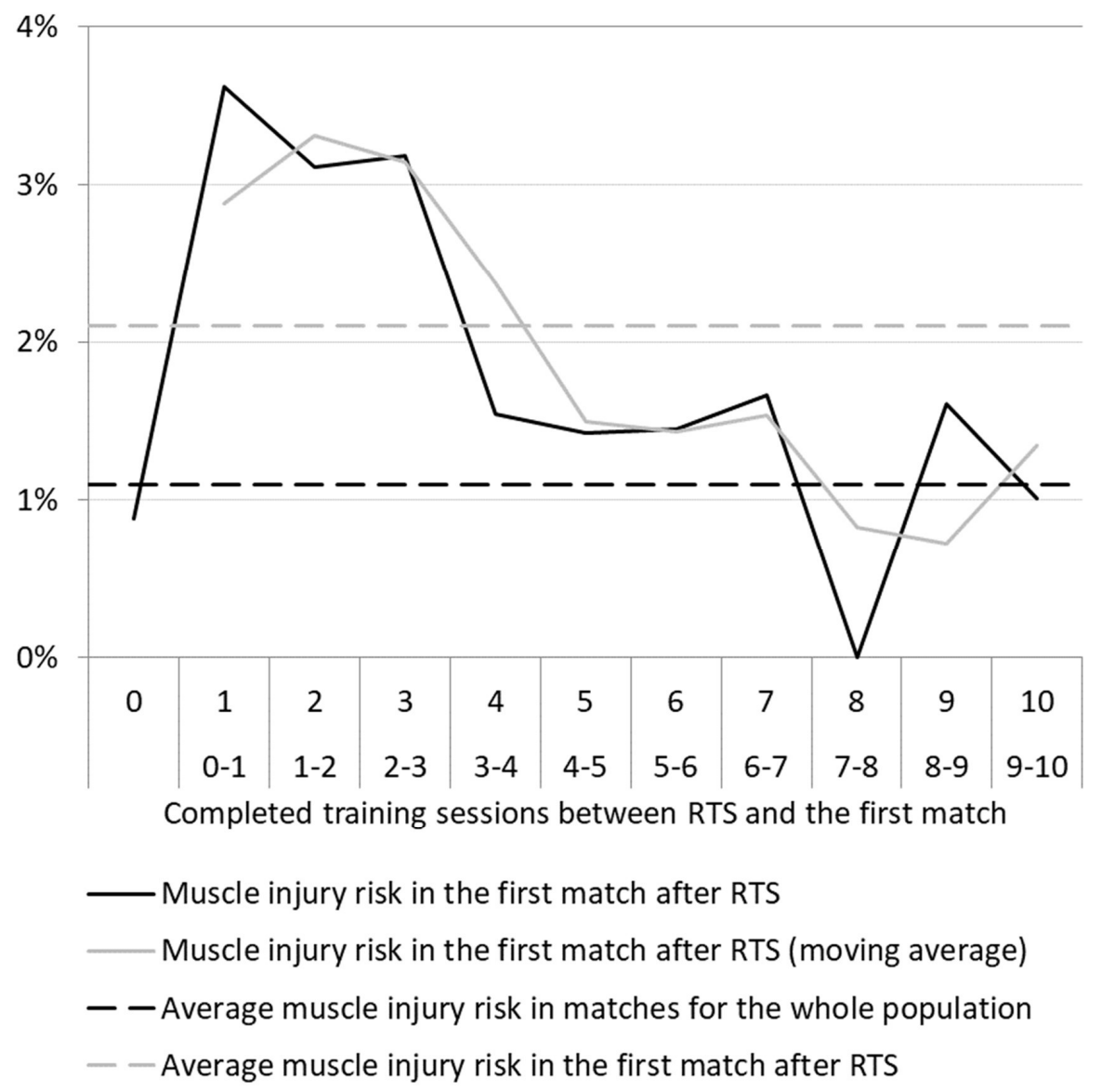

Figure 13. Muscle injury risk in the first match exposure after RTS. Moving average refers to the combination of data from two consecutive groups. 


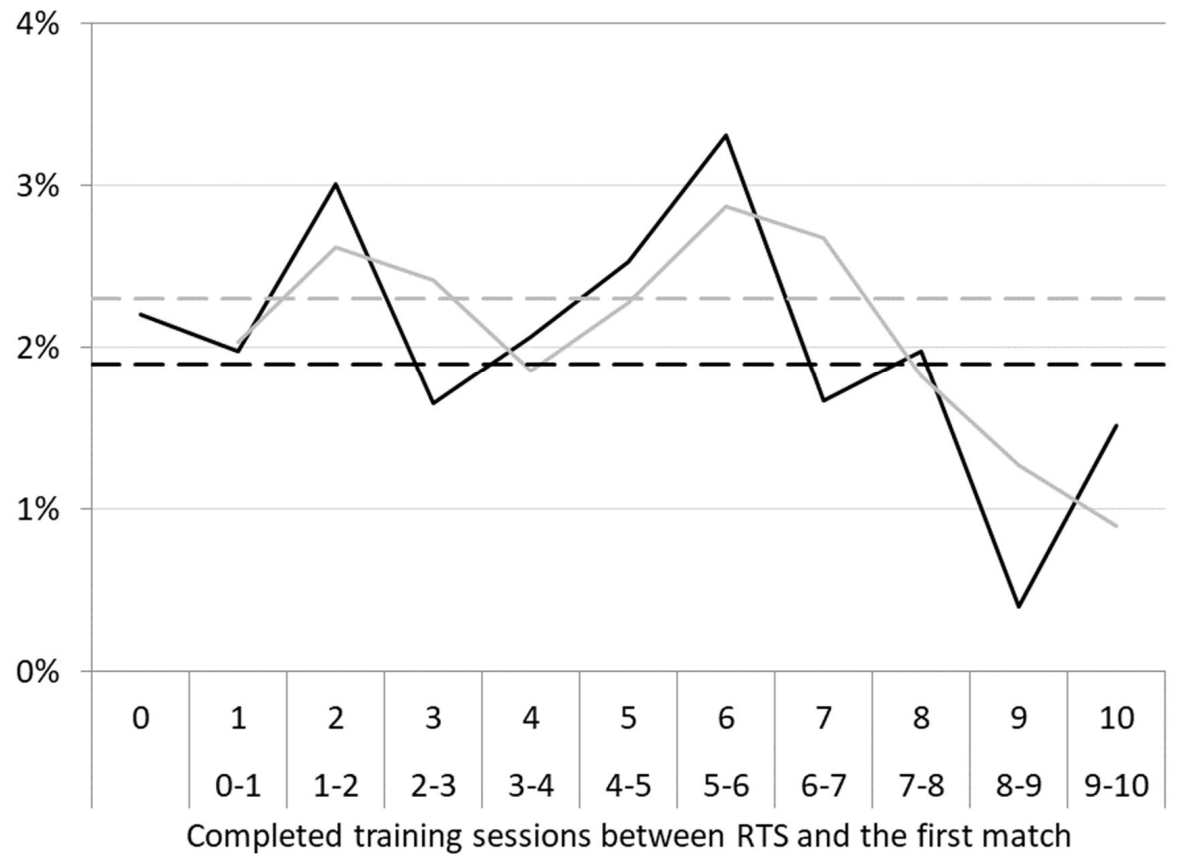

- Non-muscle injury risk in the first match after RTS

_ Non-muscle injury risk in the first match after RTS (moving average)

- - Average non-muscle injury risk in matches for the whole population

- - Average non-muscle injury risk in the first match after RTS

Figure 14. Non-muscle injury risk in the first match exposure after RTS. Moving average refers to the combination of data from two consecutive groups.

The odds that players would suffer an injury in their first match after RTS was significantly associated with the number of training sessions that they had completed before the match with a $9 \%$ reduction for every additional training session that had been completed (OR, 0.91; $95 \% \mathrm{Cl}, 0.86-0.96)$. Analyses of muscle injuries and non-muscle injuries showed that although the odds of muscle injury occurrences were significantly associated with the number of completed training session between RTS and the match (OR, 0.86; 95\% Cl, 0.79-0.93), no such association was found for the odds of non-muscle injury occurrences. 


\section{DISCUSSION}

The main finding of this thesis is that there are several match-related risk factors that are significantly associated with the injury rate in professional football matches. These results will help clinicians and other stakeholders in professional football to make accurate assessments of the level of risk to which players are exposed when playing matches. The results will also add valuable information about possibilities of reducing the injury rate during professional football matches. First, muscle injury rates could be reduced if players are given a recovery window of 6 days or more between match exposures. Second, the odds that players will sustain an injury in their first match after RTS is high but could be reduced by $9 \%$ for every additional training session that they complete before the match. A link between injuries and team performance is also indicated, suggesting that teams may perform worse in matches when they have suffered injury occurrences.

\section{Match characteristics and injury rates}

Type of competition, match venue and match result were all found to be significantly associated with the injury rate during professional football matches.

Association between injury rates and the importance of competitions

In contrast with a previous publication showing no differences in injury rates between different competition formats, [72] injury rates were found to be highest in the most important competitions, the domestic league and the CL. In addition, injuries causing more than 1 week of absence were more frequent in the $C L$ than in league matches. The $E L$ and $C L$ matches were in different categories in Paper $I$, but these two competition formats were combined in the previous publication, which makes comparisons between these studies difficult.

$\mathrm{CL}$ is often considered to be the most prestigious of all competitions in European football, and it is possible that $\mathrm{CL}$ matches are therefore more intense than matches in other competitions. It is plausible that such an increase in intensity would subject players to a higher risk of injury. These results may also indicate that players are not prepared sufficiently for the most intense games in their training. This could mean that teams should try to include demanding activities in their training, similar to those that occur during intense matches, so that they are accustomed to these activities in a controlled environment. 
More injuries at the home stadium

Teams were more likely to sustain injuries when playing at the home stadium than when playing away. These results are not in line with a previous study following the Swedish national team over six seasons, which showed no associations between match venue and injury rates [73]. The differences between these two studies could be explained by a difference between club football and national team football, because the home venue for the national team is not necessarily the same as the home venue for the individual players in their club teams; that is, the home venue of the national team could still be an unfamiliar environment for the individual players.

In addition, the proportion of muscle injuries was also higher during matches at the home stadium compared with away matches. Previous studies have shown that players' activity profile during home matches are different compared with away matches. Home teams often have more ball possession than away teams $[76,77,79,80]$ and are also more often on the offensive, [81] performing more offensive runs and other offensive actions such as shooting [76-78]. It is possible that these differences in activity profile between home and away matches could explain the differences observed in injury rates. However, this is speculative and will therefore need to be verified in future studies.

\section{Worse results in matches with injury occurrences}

Previous studies on associations between match results and injury rates have shown contradictory results $[73,84]$. The results in Paper I are in line with one of these studies showing significant associations between the injury rate during a match and the final result of the match. Based on these results, however, it is not possible to prove a causal relationship between these two variables, which means that several different explanations need to be considered. One possible explanation is that an injury occurrence during a match could force a team to make an unwanted substitution, which could potentially decrease the performance of the team. Injury occurrences could also affect team performances even though injured players may continue to participate in the match because their individual performances may be decreased due to symptoms of the injury [123].

However, it is also possible that the associations between injury occasions and match results are explained by differences in player activities during matches when teams are winning compared with when they are losing. Similar to the results for match venue, several studies have shown that teams that are behind have more ball possession than teams that are ahead [79, 80, 83]. More high intensity actions have also been observed in teams that are behind [112] and these differences in activities may explain the differences in injury rates. 


\section{Short-term match congestion}

Previous studies have analysed whether match congestion increases the injury rate during a professional match $[72,112,115,117,118]$. However, the definitions of match congestion have varied between studies and include both short-term (separation of two matches) and long-term (periods of 3-8 matches) definitions.

The analyses of team matches in Paper /I showed that the muscle injury rate was $20 \%$ higher if a team played a match with $\leq 4$ days recovery since their last match compared with $\geq 6$ days between matches. However, there were no differences in injury rates between $\leq 3$ and $\geq 4$ days of recovery. The analysis of individual match congestion showed similar results, with higher injury rates if players played a match within 3 days of a previous match compared with $\geq 6$ days of recovery between match exposures.

Similar results have also been shown in previous studies from other cohorts. In a study following a Scottish professional football team participating in the $\mathrm{CL}$ over two seasons, a six-fold higher injury rate was shown when players played football matches within 4 days of a previous match exposure compared with at least 6 days between matches [112]. In addition, there was no difference in injury rates in matches played within 3 days of recovery since a previous match exposure compared with $\geq 4$ days between matches in a study following a French professional football team over four seasons [72]. In contrast with the results from Paper II and Paper III, a study in which a French professional football team were followed over six seasons showed no difference in injury rate when matches were played within 3 days compared with more days between matches [118].

Two interesting conclusions may be drawn from these results. First, they indicate that injury rates are equal if players are given 3 or 4 days of recovery time. In professional football, a potential difference between 3 and 4 days of recovery between matches is often discussed. This discussion is often based on data showing that teams that participate in European competitions are almost twice as likely to lose a league match when it is played within 3 days after a match in an European cup compared with their overall performance in the league [124]. It has been suggested that a rule should be introduced that would allow teams to always have at least 4 days to recover between their matches to improve performance and reduce the risk of injuries [124]. However, according to the data presented in Paper II and Paper III, such a rule would have very limited impact on time loss injury rates in professional football. 
Second, injury rates are $20 \%$ lower when players are given $\geq 6$ days of recovery between their match exposures as shown in Paper III. One possible explanation for these associations between match congestion and injury rates could be that players suffer from residual fatigue after a match if they have not been given enough time to recover between two match exposures. However, most previously published studies have shown that signs of muscular fatigue often disappear within 72 hours after a football match, [61-67] whereas the results of Paper III suggest an increased injury rate up to 5 days after a previous match. Other studies have shown that the biomechanical properties of muscles change as they are fatigued after a football match or similar activity, lowering the production of maximal force and altering the angle of peak torque [125-127]. This could potentially increase the risk of injuries as muscles are subjected to different activity levels and activity patterns [128]. How these biomechanical changes develop over several days after a football match has not been studied, and it is therefore hard to say if they could contribute to the high injury rates seen up to 5 days after a match. A recent study has analysed the neuromuscular aetiology of the fatigue that has been observed after football matches. In this study, it was shown that there were both central and peripheral causes [129]. It was also indicated that the peripheral causes lasted longer than the central and it is therefore plausible that these are more important for the results presented in this thesis. More studies are however needed to better understand the aetiology of neuromuscular fatigue after football matches.

\section{Long-term match congestion}

The analyses of long-term match congestion at team level showed that muscle injury rates increased the more congested teams' match schedules were. This is in line with most previous research showing similar relationships, [115, 118] although contrasting results have also been published [117]. However, the analyses of long-term match congestion at an individual level showed no statistically significant associations with injury rates. One possible reason for the differences in the results between the team level and individual analyses could be that some variables, more connected with the team than the individual, are important for these associations. For example, teams could be forced to adjust their training schedules when they play many matches. In professional rugby, it has been shown that training intensity is lowered during periods of match congestion [130] and that a low training load could potentially be harmfull [102]. Even though rugby and football are different sports with different match demands and different definitions of match congestion, it is possible that a similar relationship between match congestion, training intensity and injuries exists also in football. This could potentially be one explanation why long-term match congestion was associated with increased muscle injury rates at team level, whereas no such association was found at player lever. 
Another explanation for this difference could be that the cut-off that was used for high long-term match congestion in the individual analyses was not high enough. In Paper III, a cut-off representing playing one match every sixth day was used. This is lower than in previous studies that have shown associations between individual long-term match congestion and injury rates $[115,118]$. One of these studies analysed a period of six matches each separated by 3 days [115]; the other study analysed three-match cycles where all matches were separated by 4 days [118]. It is possible that the definition of high long-term match congestion, representing one match every sixth day, may be too low compared with the level of match congestion that would result in an increased injury rate.

Even though similar associations between short-term match congestion and injury rates were found regardless of players' long-term match congestion in Paper III, the follow-up analyses showed that players who were not used to a lot of match exposure were more vulnerable when playing a match after a short recovery window. This could indicate that a sudden increase in match load is harmful for players, similar to what has been shown for total load previously [97].

\section{Injuries in the first match after RTS}

In Paper IV, it was shown that the odds of injuries during the first match after RTS from a previous injury was increased if players had completed few training sessions between RTS and the first match. One potential explanation for this association may be that teams are willing to take calculated risks allowing players to play in an important match soon after RTS. Another potential contributor could be that players who have been absent due to an injury and then return to football training and playing matches are exposed to a sudden increase in load [53]. Players who have been absent due to an injury may not have been exposed to the usual physical load of team training and matches. According to a recent consensus statement about load in sport, it is argued that competition/matches could be considered a sudden increase in load compared with regular training [52]. If players have recently been absent due to an injury and then make a quick return to their first match, it is plausible that they have not been able to build a sufficient level of chronic load, which could leave them less tolerant of a sudden increase in load in their first match $[53,97]$.

\section{Methodological considerations}

All papers in this thesis are based on analyses of data that were gathered for the same prospective cohort study, ECIS. The methodology of ECIS follows a consensus statement about how to conduct epidemiological studies in professional football, which means that the results can be compared with other studies following this consensus [24]. The injury rate during the 15 seasons 
included in this thesis was 3.8 injuries/1000 hours of training exposure and 25.5 injuries/1000 hours of match exposure. This is similar to the injury rates that have been reported from other similar cohorts [3, 25-32]. The most common injury type was muscle injuries, in line with previous studies of professional football. Injury rates in matches have consistently been shown to be higher than in training, and this pattern was also found in this thesis. These similarities between the ECIS cohort and other high-level football cohorts indicate that data from ECIS are representative of professional football.

There are several methodological strengths with ECIS. The study has been running for several seasons and has included several teams, which means that it is possible to make more detailed analyses than would have been possible from a smaller study sample [131]. A concern with including different teams could be that the collection of data could vary between teams and the validity of the dataset therefore could be reduced. Thus, a lot of effort was made to ensure high quality and consistency of the data that was collected. First, a study manual was provided to the contact person in all teams as they were included in the study. The manual contained definitions of the variables that were important for the study. The manual also contained detailed information about how the study forms should be completed, giving examples of different situations that might cause confusion for the contact person. Second, members of the study group have been in close communication with all teams during their participation in ECIS. Contact persons were encouraged to contact the study group to receive further guidance if they had any questions concerning any aspect of the data collection. In addition, members of the study group reviewed all data that were collected to make sure that it was complete, accurate and coherent with the study methodology. If any questions arose or any information was missing during this review, quick feedback was sent to the contact person to complete the data. Third, participating clubs received continuous overviews and reports about the medical situation in their team, based on the data that they had collected for ECIS, to keep them motivated in collecting complete and accurate data.

ECIS is also strengthened by the prospective design of the data collection. A prospective design is preferred over a retrospective design because the risk of recall bias is removed $[24,132,133]$. This has been shown in football where two thirds of all injury occurrences were missed using a retrospective design [134]. It is also difficult to make sure that all data have been gathered in a standardised way using a retrospective design [132]. A prospective design makes it possible to include the amount of football exposure in the analyses. Including exposure is important to be able to draw meaningful conclusions about the injury data [135]. 
Furthermore, according to the consensus statement there are two options for gathering exposure: team based or individual [24]. In ECIS, all exposures are gathered on an individual basis, which is essential for analyses at an individual player level as in Paper III and Paper IV. It has also been shown that studies recording exposure at an individual player level are able to capture more injuries and more precisely establish the severity of recorded injuries than studies using team-based exposure [136].

Two different definitions of injury are suggested in the consensus statement: medical attention injuries or time loss injuries. A medical attention injury is defined as any physical complaint that results in the player receiving medical attention and a time loss injury is defined as any physical complaint that results in the player being unable to take full part in future football training or match play. A time loss definition of injury is used in ECIS. This definition was chosen because it was believed that these injuries were of clinical importance for the players and the clubs, forcing players to miss out on future football exposure and leading to sick leave for the affected players. With a medical attention definition, it was believed that a lot of minimal injuries of limited clinical importance would be included [20]. However, the time loss definition has received some criticism because there is a risk that injuries, particularly overuse injuries, that do not cause absence but still have an important effect on players' performance and well-being will be ignored [40]. This concern may be even more important when considering different load variables as was done in Paper II and Paper III because it has been argued that load has as influence on overuse injuries specifically. Future studies including not only injuries that causes time loss but all physical complaints that affect players' performance as suggested by Roald Bahr et al. [40] could therefore be important to increase the understanding of how match congestion influences the performance and well-being of players in professional football.

There are also other limitations which need to be acknowledged. First, the load variable, match congestion, which was used in Paper II and Paper III, only considers the external load, whereas the reaction to this load (the internal load) is ignored. Both internal and external loads are important for the risk of injuries, and future studies should therefore consider including measures of both [52].

Second, several aspects of players' external load are not included. There are no data, for example GPS measurements, about the actual activity level during different matches, and previous studies have shown that player activity level varies substantially between matches and between different players. Moreover, previous studies have also shown that post-match fatigue is influenced by the activity level of players during a match $[63,67]$. It would therefore be interesting to be able to analyse whether the activity level during a match is important for 
the risk of sustaining an injury in a subsequent match. In addition, there are no data on the activity level of players during match-free days. More detailed information about player load, including activity level during matches and activity level during match-free days, could provide further understanding on the relationship between player load during periods of match congestion and injury rates.

Third, there is no information available on the use of different recovery modalities, such as cold-water immersion and compression garments, in the different clubs. Several modalities have been suggested to improve the recovery rate for athletes [137]. It is likely that most of the clubs use several of these modalities and that could potentially have had an influence on the relationship between injury rates and match congestion. However, it should be acknowledged that the evidence for the effectiveness of these modalities is limited at best [137].

Fourth, there is no information about the content of the training sessions that players had completed between matches and before their first match exposure after RTS, which means that important information about the physical load to which players had been exposed to is missing. In addition, there is no information about the activity level of players during their rehabilitation from the previous injury. If the acute to chronic workload ratio is important for the injury risk of these players, it would be interesting to know more details about their workload before the first match exposure after RTS. 


\section{Clinical application and future perspectives}

Working as a medical practitioner in a professional sport environment will always be a matter of balancing risk and reward [138]. Clinicians who are only interested in minimising the number of injuries in their teams will probably not last long in the job because there will always be other factors that other stakeholders, such as the players and the coaching staff, will consider more important. It should also be acknowledged that many decisions with the potential to affect players' health are not taken by medical professionals in isolation but will in most cases be shared decisions between players, coaching staff and clinicians $[139,140]$.

These decisions will often come down to weighing up between the risk that a player will suffer an injury and the possible consequences of such an injury on the one hand and the potential reward that could come from subjecting the player to that risk on the other hand. The process of making these decisions has been described in the Strategic Assessment of Risk and Risk Tolerance (StARRT) framework, using the RTS decision as an example [141-143]. According to this framework the RTS decision process can be described in three steps:

1. Evaluating the health status of the player with special consideration for the players' previous injuries.

2. Assessing the level of risk of injury during participation based on the health status of the player and the level of stress that participation would constitute.

3. Considering factors that could modify the level of risk that is considered acceptable.

Injury risk after RTS

In this thesis, it has been shown that the injury rate in the first match after RTS is almost twice as high as the general injury rate in match play. Going back to the StARRT framework, that could mean two things. Either teams have made correct assessments of the level of risk for their players as they RTS, which means that they consider the almost twice as high injury rate in the first match to be acceptable, or their risk assessments have been inaccurate. The results of this thesis can contribute to these decisions in several ways. First, they could help teams to make accurate estimations of risk when players RTS showing that the injury rate is almost twice as high in their first match exposure compared with the general injury rate in football matches. Second, they could inform teams that the injury rate is significantly reduced with every training session that their players complete before that first match.

From this thesis and other previous publications, it seems clear that players are at increased risk of injuries as they RTS $[10,46,48,49]$. This could be an indication 
that the RTS criteria that are currently used in professional football do not provide sufficient information about whether players can return to football without sustaining a subsequent injury [51]. Future studies should therefore continue to evaluate these criteria. It will also be important to design specific criteria for return to football to evaluate whether players are ready for the physical demands of playing football matches.

Future studies should also focus on the relationship, indicated in this thesis, between the amount of training that players have completed before their first match exposure after RTS and their risk of injury. In amateur football, a coachcontrolled rehabilitation program has been shown to reduce the injury rate for players as they RTS. According to this rehabilitation program players should complete a number of training sessions together with the team before they are allowed to return to competition [144]. The data presented in figure 12 and 13 indicates that the injury risk during players' first match exposure following RTS are similar to the general injury risk of the population if they have completed 7-8 training sessions before they return to sport. Future studies should continue to investigate this relationship in more detail to try to find out the amount of training load and level of fitness that players need to attain to be able to return to playing matches without increased risk of injury.

\section{Risk for injury in relation to match congestion}

Even though the StARRT framework was developed to describe the decisionmaking process concerning RTS, [141-143] it could just as easily be used when considering match congestion and deciding whether a player should play in a match or should rest. This thesis will inform teams about the increased injury rate that their players face when playing matches with a short time of recovery between them. When making these decisions, teams should also be aware that players who are not used to playing a lot of matches are even more likely to get injured if they play two matches in a short time span.

Based on the results of this thesis and previous publications, $[112,115,118]$ it seems likely that match congestion increases the risk of injury in professional football. However, the underlying mechanisms of this increased risk have yet to be explained. Most of the markers of player fatigue that have traditionally been examined in previous studies in this environment return to baseline values within 3-4 days after a football match and therefore probably do not explain the increased injury rate observed 5 days after a match [61-67]. One exception to this, however, is the biomechanical changes that have been observed after a football match or similar activity [125-127]. It has not been established how long these changes persist after a match, and future studies measuring biomechanical properties over several days after a match will have the potential to establish 
whether or not they could play a role in the observed relationship between match congestion and injury rates.

Once the underlying mechanisms explaining why match congestion is associated with an increased injury rate have been established, there will be more potential to investigate different methods that could be used to reduce injury rates during periods of match congestion, such as different recovery modalities and player rotation.

\section{Risk tolerance in professional football}

Deciding if a level of risk should be considered acceptable will depend on the possible consequences of the injuries. Many injuries can have long-lasting consequences for the injured player, such as pain and symptoms of common mental disorders $[12,14]$. This thesis, however, also suggests that there are other consequences of injury occurrences that are related to the performance of the team. Teams are more likely to have less favourable results in matches if they have injury occurrences during the match. Because team performance is often considered the most important factor in professional sports, showing a link between team performance and injuries could be a very effective way to improve the priority of medical issues within professional football teams. For example, coaches may be less willing to risk players getting injured if they believe that it might also affect the performance of the team. A previous study of European club football, also based on data from ECIS, indicated a link between team performance during full seasons and injury variables. In that study, lower injury rates and higher player availability for matches were both shown to be associated with better team performance [145]. If a similar link between team performance and injuries also explains the results in Paper $I$, that could be a powerful argument to convince clubs to give more priority to keeping their players healthy. Many of the results in this thesis, e.g. the increased injury rate in important matches and the increased injury rate after few training sessions between RTS and the first match exposure, could be consequences of teams accepting a higher level of injury risk in some circumstances. That would suggest the possibility of reducing injury rates simply by accepting a lower level of risk for players, again highlighting why it could be important to prove a link between injuries and performance. Future studies with information about the current score in a match when an injury occurs as well as the final result of the match could potentially provide more information about how the results of specific matches are influenced by injury occurrences. 


\section{CONCLUSIONS}

- Injuries are more frequent in matches played in the home stadium compared with matches played in other stadiums.

- UEFA Champions League is the competition with the highest injury rate, followed by the domestic league, domestic cups and UEFA Europa League.

- Injuries are more common in matches lost or drawn than in matches won.

- Muscle injury rates are increased when teams are exposed to a prolonged period of match congestion.

- A small recovery window between two matches (less than 6 days) is associated with a higher muscle injury rate.

- The injury rate following a short recovery window (less than 6 days) was highest for players that had been exposed to few match hours ( $\leq 4.5$ hours) during the last 30 days before the match.

- Players are more likely to sustain a subsequent injury if they play a match shortly after their return to training after an injury. 


\section{SAMMANFATTNING}

Bakgrund: Skador är vanliga inom professionell fotboll, särskilt i samband med matcher, och de orsakar lidande för spelare både kortsiktigt och långsiktigt. Det är därför viktigt att försöka förhindra dessa skador. Ett av de viktigaste stegen för att kunna förhindra skador är att känna till och förstå olika riskfaktorer som kan bidra till att skador uppstår.

Syfte: Syftet med denna avhandling är därför att undersöka flera matchrelaterade faktorer som skulle kunna ha betydelse för risken att drabbas av en skada i samband med en professionell fotbollsmatch.

Metod: Avhandlingen består av fyra delarbeten och samtliga analyser är baserade på data som har samlats in i en stor prospektiv kohortstudie som har fortlöpt sedan 2001: UEFA Elite Club Injury Study. Medicinska team från 61 lag har inkluderats i studien och de har prospektivt samlat data om fotbollsexponering och skador för spelarna i deras lag.

Associationer mellan följande matchfaktorer och skador har analyserats:

- Matchsammanhang; matcharena, slutresultat och tävlingssammanhang

- Matchtäthet, på både kort och lång sikt och på både individ- och lagnivå

- Antalet genomförda träningar mellan återgång till idrott efter en skada och första matchtillfället.

Resultat: Alla matchfaktorer som har analyserats visade sig vara associerat med skadefrekvensen. Skadefrekvensen var högre i matcher på hemmaplan jämfört med bortamatcher, i matcher som förlorades eller slutade oavgjort jämfört med matcher som slutade med vinst, och i ligamatcher och Champions League matcher jämfört med Europa League matcher och andra cupmatcher (Delarbete I).

Högre skadefrekvens, framförallt gällande muskelskador, sågs också när tiden för återhämtning mellan två matcher var kort. Dessa samband mellan matchtäthet och skadefrekvens sågs både när matchtäthet beaktades på lagnivå (Delarbete II) och individnivå (Delarbete III). 
Avslutningsvis sågs också högre skadefrekvens i en spelares första match efter en skadefrånvaro om spelaren hade genomfört få träningar mellan sin återgång och sin första match (Delarbete IV).

Slutsatser: Flera matchrelaterade riskfaktorer bidrar till risken att drabbas av en skada i samband med professionella fotbollsmatcher. En bättre kunskap om riskfaktorer kan vara till hjälp för att på ett bättre sätt kunna uppskatta skaderisken som fotbollsspelare utsätts för i olika situationer (till exempel i samband med täta matcher och när spelare återgår till sin idrott efter en skadefrånvaro). Kunskap om riskfaktorer kan också erbjuda möjligheter att minska antalet skador inom fotbollen genom att motverka dessa riskfaktorer med lämpliga åtgärder. 


\section{ACKNOWLEDGEMENTS}

Martin Hägglund, my main supervisor. Thank you for introducing me to the world of sports medicine and for giving me the opportunity to be a part of it. Your thoroughness and dedication to this thesis has made all the difference. Thank you for being a role model showing that integrity, professionalism and wit will take you far.

Markus Waldén, my co-supervisor. Thank you for always believing in me. Knowing that I have your support whenever needed has made this process that much easier. Thank you also for taking the responsibility to tutor me through the postconference/meeting parts of being a PhD-student.

Jan Ekstrand, my co-supervisor. Thank you for allowing me to profit from the impressive work that you have been responsible for over the last sixteen years. Thank you also for making it possible for me to combine my professional life with family life, without your flexibility and willingness to find solutions it would not have been possible.

Henrik Magnusson, thank you for your impressive attention to details and for always being willing to help. I can't see how this thesis would have been possible without your help.

Colleagues from the Football Research Group and the Division of Physiotherapy, Linköping University. Even though most of my PhD studies have been in exile far away from colleagues and fellow PhD-students I have always felt your support. Thank you for your feedback and friendship.

Family and friends, thank you for your generosity and support. But most of all, thank you for everything that has nothing to do with muscle strains, PowerPoints and P-values.

Mum, Dad, Agge and Stefan, thank you for life, love and laughter. Thank you for believing in me and allowing me to do things my own way in my own pace, I know it could not have always been easy. Thank you for ALWAYS being there. 
Elias and Leia, thank you for putting things in perspective. With all your differences, you will always have at least two things in common, the joy that you bring to your father's life and the endless love I feel for you both.

Josefine, thank you for challenging me, for motivating me and for making me want to be the best that I can be. Thank you for loving me, leading me and our family. Thank you for being you, your strength, patience and understanding. Thank you for everything. 


\section{REFERENCES}

1. International Federation of Association Football. FIFA Big Count 2006. [pamphlet on the Internet]. Zürich: International Federation of Association Football; 2007. [cited 2017 Oct 22]. Available from:

http://www.fifa.com/mm/document/fifafacts/bcoffsurv/bigcount.statspackage -7024.pdf.

2. Ekstrand J, Waldén $M$, Hägglund $M$. Hamstring injuries have increased by $4 \%$ annually in men's professional football, since 2001: a 13-year longitudinal analysis of the UEFA Elite Club injury study. Br J Sports Med. 2016;50(12):731-7.

3. Waldén M, Hägglund M, Ekstrand J. Injuries in Swedish elite football--a prospective study on injury definitions, risk for injury and injury pattern during 2001. Scand J Med Sci Sports. 2005;15(2):118-25.

4. Union of European Football Associations. Regulations of the UEFA Champions League 2015-18 Cycle. [pamphlet on the Internet]. Nyon: Union of European Football Associations. [cited 2017 Oct 22]. Available from: http://www.uefa.com/MultimediaFiles/Download/Regulations/uefaorg/Regulat ions/02/35/87/89/2358789_DOWNLOAD.pdf.

5. Union of European Football Associations UEFA. Regulations of the UEFA Europa League 2015-18 Cycle 2015. [pamphlet on the Internet]. Nyon: Union of European Football Associations. [cited 2017 Oct 22]. Available from: http://www.uefa.com/MultimediaFiles/Download/Regulations/uefaorg/Regulat ions/02/23/69/59/2236959_DOWNLOAD.pdf.

6. Warburton DE, Charlesworth S, Ivey A, Nettlefold L, Bredin SS. A systematic review of the evidence for Canada's Physical Activity Guidelines for Adults. Int J Behav Nutr Phys Act. 2010;11;7:39. 
7. Kyu HH, Bachman VF, Alexander LT, Mumford JE, Afshin A, Estep K, et al. Physical activity and risk of breast cancer, colon cancer, diabetes, ischemic heart disease, and ischemic stroke events: systematic review and dose-response meta-analysis for the Global Burden of Disease Study 2013. BMJ. 2016;9;354:i3857.

8. Samitz G, Egger M, Zwahlen M. Domains of physical activity and all-cause mortality: systematic review and dose-response meta-analysis of cohort studies. Int J Epidemiol. 2011;40(5):1382-400.

9. Krustrup P, Aagaard P, Nybo L, Petersen J, Mohr M, Bangsbo J. Recreational football as a health promoting activity: a topical review. Scand J Med Sci Sports. 2010;20 Suppl 1:1-13.

10. Hägglund M, Waldén M, Ekstrand J. Injury recurrence is lower at the highest professional football level than at national and amateur levels: does sports medicine and sports physiotherapy deliver? Br J Sports Med. 2016;50(12):751-8.

11. Drawer S, Fuller CW. Evaluating the level of injury in English professional football using a risk based assessment process. Br J Sports Med. 2002;36(6):44651.

12. Krajnc Z, Vogrin M, Recnik G, Crnjac A, Drobnic M, Antolic V. Increased risk of knee injuries and osteoarthritis in the non-dominant leg of former professional football players. Wien Klin Wochenschr. 2010;122 Suppl 2:40-3.

13. Gouttebarge V, Backx FJ, Aoki H, Kerkhoffs GM. Symptoms of common mental disorders in professional football (soccer) across five European countries. J Sports Sci Med. 2015;14(4):811-8.

14. Kilic O, Aoki H, Goedhart E, Hägglund M, Kerkhoffs G, Kuijer P, et al. Severe musculoskeletal time-loss injuries and symptoms of common mental disorders in professional soccer: a longitudinal analysis of 12-month follow-up data. Knee Surg Sports Traumatol Arthrosc. 2017; doi: 10.1007/s00167-017-4644-1. 
15. Gouttebarge V, Aoki H, Kerkhoffs G. Symptoms of common mental disorders and adverse health behaviours in male professional soccer players. J Hum Kinet. 2015;49:277-86.

16. Arliani GG, Astur DC, Yamada RK, Yamada AF, Miyashita GK, Mandelbaum B, et al. Early osteoarthritis and reduced quality of life after retirement in former professional soccer players. Clinics (Sao Paulo). 2014;69(9):589-94.

17. Lohkamp M, Kromer TO, Schmitt H. Osteoarthritis and joint replacements of the lower limb and spine in ex-professional soccer players: A systematic review. Scand J Med Sci Sports. 2017;27(10):1038-49.

18. Larsen E, Jensen PK, Jensen PR. Long-term outcome of knee and ankle injuries in elite football. Scand J Med Sci Sports. 1999;9(5):285-9.

19. van Mechelen W, Hlobil H, Kemper HC. Incidence, severity, aetiology and prevention of sports injuries. A review of concepts. Sports Med. 1992;14(2):8299.

20. Hägglund $M$, Waldén $M$, Bahr R, Ekstrand J. Methods for epidemiological study of injuries to professional football players: developing the UEFA model. $\mathrm{Br}$ J Sports Med. 2005;39(6):340-6.

21. Engebretsen L, Soligard T, Steffen K, Alonso JM, Aubry M, Budgett R, et al. Sports injuries and illnesses during the London Summer Olympic Games 2012. Br J Sports Med. 2013;47(7):407-14.

22. Junge A, Engebretsen L, Mountjoy ML, Alonso JM, Renström PA, Aubry MJ, et al. Sports injuries during the Summer Olympic Games 2008. Am J Sports Med. 2009;37(11):2165-72.

23. Soligard T, Steffen K, Palmer D, Alonso JM, Bahr R, Lopes AD, et al. Sports injury and illness incidence in the Rio de Janeiro 2016 Olympic Summer Games: A prospective study of 11274 athletes from 207 countries. Br J Sports Med. 2017;51(17):1265-71. 
24. Fuller CW, Ekstrand J, Junge A, Andersen TE, Bahr R, Dvorak J, et al. Consensus statement on injury definitions and data collection procedures in studies of football (soccer) injuries. Br J Sports Med. 2006;40(3):193-201..

25. aus der Fünten K, Faude O, Lensch J, Meyer T. Injury characteristics in the German professional male soccer leagues after a shortened winter break. J Athl Train. 2014;49(6):786-93.

26. Ekstrand J, Hägglund M, Kristenson K, Magnusson H, Waldén M. Fewer ligament injuries but no preventive effect on muscle injuries and severe injuries: an 11-year follow-up of the UEFA Champions League injury study. Br J Sports Med. 2013;47(12):732-7.

27. Haxhiu B, Murtezani A, Zahiti B, Shalaj I, Sllamniku S. Risk factors for injuries in professional football players. Folia Med. 2015;57(2):138-43.

28. Kristenson K, Bjørneboe J, Waldén M, Andersen TE, Ekstrand J, Hägglund M. The Nordic Football Injury Audit: higher injury rates for professional football clubs with third-generation artificial turf at their home venue. Br J Sports Med. 2013;47(12):775-81.

29. Noya Salces J, Gómez-Carmona PM, Gracia-Marco L, Moliner-Urdiales D, Sillero-Quintana M. Epidemiology of injuries in first division Spanish football. J Sports Sci. 2014;32(13):1263-70.

30. Shalaj I, Tishukaj F, BachI N, Tschan H, Wessner B, Csapo R. Injuries in professional male football players in Kosovo: a descriptive epidemiological study. BMC Musculoskelet Disord. 2016;17(338):1-9.

31. van Beijsterveldt AM, Stubbe JH, Schmikli SL, van de Port IG, Backx FJ. Differences in injury risk and characteristics between Dutch amateur and professional soccer players. J Sci Med Sport. 2015;18(2):145-9.

32. Bjørneboe J, Bahr R, Andersen TE. Gradual increase in the risk of match injury in Norwegian male professional football: a 6-year prospective study. Scand J Med Sci Sports. 2014;24(1):189-96. 
33. Waldén $M$, Hägglund $M$, Ekstrand J. Time-trends and circumstances surrounding ankle injuries in men's professional football: an 11-year follow-up of the UEFA Champions League injury study. Br J Sports Med. 2013;47(12):74853.

34. Lundblad $M$, Waldén $M$, Magnusson $H$, Karlsson J, Ekstrand J. The UEFA injury study: 11-year data concerning $346 \mathrm{MCL}$ injuries and time to return to play. Br J Sports Med. 2013;47(12):759-62.

35. Waldén $M$, Hägglund $M$, Magnusson $H$, Ekstrand J. ACL injuries in men's professional football: a 15-year prospective study on time trends and return-toplay rates reveals only $65 \%$ of players still play at the top level 3 years after $A C L$ rupture. Br J Sports Med. 2016;50(12):744-50.

36. Meeuwisse WH. Assessing causation in sport injury: A multifactorial model. Clin J Sport Med. 1994;4(3):166-70.

37. Bahr R, Krosshaug T. Understanding injury mechanisms: a key component of preventing injuries in sport. Br J Sports Med. 2005;39(6):324-9.

38. Meeuwisse WH, Tyreman H, Hagel B, Emery C. A dynamic model of etiology in sport injury: the recursive nature of risk and causation. Clin J Sport Med. 2007;17(3):215-9.

39. Windt J, Gabbett TJ. How do training and competition workloads relate to injury? The workload-injury aetiology model. Br J Sports Med. 2017;51(5):42835.

40. Bahr R. No injuries, but plenty of pain? On the methodology for recording overuse symptoms in sports. Br J Sports Med. 2009;43(13):966-72.

41. Hawkins RD, Hulse MA, Wilkinson C, Hodson A, Gibson M. The association football medical research programme: an audit of injuries in professional football. Br J Sports Med. 2001;35(1):43-7. 
42. Mendiguchia J, Alentorn-Geli E, Idoate F, Myer GD. Rectus femoris muscle injuries in football: a clinically relevant review of mechanisms of injury, risk factors and preventive strategies. Br J Sports Med. 2013;47(6):359-66.

43. Waldén M, Krosshaug T, Bjørneboe J, Andersen TE, Faul O, Hägglund M. Three distinct mechanisms predominate in non-contact anterior cruciate ligament injuries in male professional football players: a systematic video analysis of 39 cases. Br J Sports Med. 2015;49(22):1452-60.

44. McCall A, Carling C, Nedelec M, Davison M, Le Gall F, Berthoin S, et al. Risk factors, testing and preventative strategies for non-contact injuries in professional football: current perceptions and practices of 44 teams from various premier leagues. Br J Sports Med. 2014;48(18):1352-7.

45. McCall A, Carling C, Davison M, Nedelec M, Le Gall F, Berthoin S, et al. Injury risk factors, screening tests and preventative strategies: a systematic review of the evidence that underpins the perceptions and practices of 44 football (soccer) teams from various premier leagues. Br J Sports Med. 2015;49(9):583-9.

46. Hägglund $M$, Waldén $M$, Ekstrand J. Previous injury as a risk factor for injury in elite football: a prospective study over two consecutive seasons. Br J Sports Med. 2006; 40(9):767-72.

47. Toohey LA, Drew MK, Cook JL, Finch CF, Gaida JE. Is subsequent lower limb injury associated with previous injury? A systematic review and meta-analysis. Br J Sports Med. 2017; doi: 10.1136/bjsports-2017-097500.

48. Nordström A, Nordström P, Ekstrand J. Sports-related concussion increases the risk of subsequent injury by about $50 \%$ in elite male football players. Br J Sports Med. 2014;48(19):1447-50.

49. Waldén $M$, Hägglund $M$, Ekstrand J. High risk of new knee injury in elite footballers with previous anterior cruciate ligament injury. Br J Sports Med. 2006;40(2):158-62. 
50. Finch CF, Cook J, Kunstler BE, Akram M, Orchard J. Subsequent injuries are more common than injury recurrences: An analysis of 1 season of prospectively collected injuries in professional Australian football. Am J Sports Med. 2017;45(8):1921-7.

51. Ardern CL, Glasgow P, Schneiders A, Witvrouw E, Clarsen B, Cools A, et al. 2016 Consensus statement on return to sport from the First World Congress in Sports Physical Therapy, Bern. Br J Sports Med. 2016;50(14):853-64.

52. Soligard T, Schwellnus M, Alonso JM, Bahr R, Clarsen B, Dijkstra HP, et al. How much is too much? (Part 1) International Olympic Committee consensus statement on load in sport and risk of injury. Br J Sports Med. 2016;50(17):103041.

53. Blanch $P$, Gabbett TJ. Has the athlete trained enough to return to play safely? The acute:chronic workload ratio permits clinicians to quantify a player's risk of subsequent injury. Br J Sports Med. 2016;50(8):471-5.

54. Croisier JL, Ganteaume S, Binet J, Genty M, Ferret JM. Strength imbalances and prevention of hamstring injury in professional soccer players: a prospective study. Am J Sports Med. 2008;36(8):1469-75.

55. Fousekis K, Tsepis E, Poulmedis P, Athanasopoulos S, Vagenas G. Intrinsic risk factors of non-contact quadriceps and hamstring strains in soccer: a prospective study of 100 professional players. Br J Sports Med. 2011;45(9):70914.

56. Fousekis K, Tsepis E, Vagenas G. Intrinsic risk factors of noncontact ankle sprains in soccer: a prospective study on 100 professional players. Am J Sports Med. 2012;40(8):1842-50.

57. van Dyk N, Bahr R, Burnett AF, Whiteley R, Bakken A, Mosler A, et al. A comprehensive strength testing protocol offers no clinical value in predicting risk of hamstring injury: a prospective cohort study of 413 professional football players. Br J Sports Med. 2017; doi: 10.1136/bjsports-2017-097754. 
58. van Dyk N, Bahr R, Whiteley R, Tol JL, Kumar BD, Hamilton B, et al. Hamstring and quadriceps isokinetic strength deficits are weak risk factors for hamstring strain injuries: A 4-year cohort study. Am J Sports Med. 2016;44(7):1789-95.

59. Mohr M, Krustrup P, Bangsbo J. Fatigue in soccer: a brief review. J Sports Sci. 2005;23(6):593-9.

60. Nédélec M, McCall A, Carling C, Legall F, Berthoin S, Dupont G. Recovery in soccer: part I - post-match fatigue and time course of recovery. Sports Med. 2012;42(12):997-1015.

61. Clarke N, Farthing JP, Lanovaz JL, Krentz JR. Direct and indirect measurement of neuromuscular fatigue in Canadian football players. Appl Physiol Nutr Metab. 2015;40(5):464-73.

62. Fatouros IG, Chatzinikolaou A, Douroudos II, Nikolaidis MG, Kyparos A, Margonis $\mathrm{K}$, et al. Time-course of changes in oxidative stress and antioxidant status responses following a soccer game. J Strength Cond Res.

2010;24(12):3278-86.

63. Nédélec M, McCall A, Carling C, Legall F, Berthoin S, Dupont G. The influence of soccer playing actions on the recovery kinetics after a soccer match. J Strength Cond Res. 2014;28(6):1517-23.

64. Ascensão A, Rebelo A, Oliveira E, Marques F, Pereira L, Magalhães J. Biochemical impact of a soccer match - analysis of oxidative stress and muscle damage markers throughout recovery. Clin Biochem. 2008;41(10-11):841-51.

65. Djaoui L, Diaz-Cidoncha Garcia J, Hautier C, Dellal A. Kinetic post-match fatigue in professional and youth soccer players during the competitive period. Asian J Sports Med. 2016;7(1):e28267.

66. Rampinini E, Bosio A, Ferraresi I, Petruolo A, Morelli A, Sassi A. Matchrelated fatigue in soccer players. Med Sci Sports Exerc. 2011;43(11):2161-70. 
67. Draganidis D, Chatzinikolaou A, Avloniti A, Barbero-Álvarez JC, Mohr M, Malliou $P$, et al. Recovery kinetics of knee flexor and extensor strength after a football match. PloS one. 2015;10(6):e0128072.

68. Souglis AG, Papapanagiotou A, Bogdanis GC, Travlos AK, Apostolidis NG, Geladas ND. Comparison of inflammatory responses to a soccer match between elite male and female players. J Strength Cond Res. 2015;29(5):1227-33.

69. Souglis A, Bogdanis GC, Giannopoulou I, Papadopoulos C, Apostolidis N. Comparison of inflammatory responses and muscle damage indices following a soccer, basketball, volleyball and handball game at an elite competitive level. Res Sports Med. 2015;23(1):59-72.

70. Waldén M, Hägglund M, Orchard J, Kristenson K, Ekstrand J. Regional differences in injury incidence in European professional football. Scand J Med Sci Sports. 2013;23(4):424-30.

71. Orchard JW, Waldén M, Hägglund M, Orchard JJ, Chivers I, Seward H, et al. Comparison of injury incidences between football teams playing in different climatic regions. Open Access J Sports Med. 2013;4:251-60.

72. Carling C, Orhant E, LeGall F. Match injuries in professional soccer: interseasonal variation and effects of competition type, match congestion and positional role. Int J Sports Med.2010;31(4):271-6.

73. Ekstrand J, Waldén $M$, Hägglund $M$. Risk for injury when playing in a national football team. Scand J Med Sci Sports. 2004;14(1):34-8.

74. Goumas C. Home advantage and referee bias in European football. Eur J Sport Sci. 2014;14 Suppl 1:S243-9.

75. Armatas V, Pollard R. Home advantage in Greek football. Eur J Sport Sci. 2014;14(2):116-22. 
76. Lago-Peñas C, Lago-Ballesteros J. Game location and team quality effects on performance profiles in professional soccer. J Sports Sci Med. 2011;10(3):46571.

77. Poulter DR. Home advantage and player nationality in international club football. J Sports Sci. 2009;27(8):797-805.

78. Seçkin A, Pollard R. Home advantage in Turkish professional soccer. Percept Mot Skills. 2008;107(1):51-4.

79. Bradley PS, Lago-Peñas C, Rey E, Sampaio J. The influence of situational variables on ball possession in the English Premier League. J Sports Sci. 2014;32(20):1867-73.

80. Lago C, Martin R. Determinants of possession of the ball in soccer. J Sports Sci. 2007;25(9):969-74.

81. Lago C. The influence of match location, quality of opposition, and match status on possession strategies in professional association football. J Sports Sci. 2009;27(13):1463-9.

82. Thomas S, Reeves C, Smith A. English soccer teams' aggressive behavior when playing away from home. Percept Mot Skills. 2006;102(2):317-20.

83. Lago-Peñas C, Gómez-López M. How important is it to score a goal? The influence of the scoreline on match performance in elite soccer. Percept Mot Skills. 2014;119(3):774-84.

84. Hägglund $M$, Waldén $M$, Ekstrand J. UEFA injury study--an injury audit of European Championships 2006 to 2008. Br J Sports Med. 2009;43(7):483-9..

85. Akenhead R, Nassis GP. Training load and player monitoring in high-level football: Current practice and perceptions. Int J Sports Physiol Perform. 2016;11(5):587-93. 
86. Cummins C, Orr R, O'Connor H, West C. Global positioning systems (GPS) and microtechnology sensors in team sports: A systematic review. Sports Med. 2013;43(10):1025-42.

87. Coutts AJ, Duffield R. Validity and reliability of GPS devices for measuring movement demands of team sports. J Sci Med Sport. 2010;13(1):133-5.

88. Gray AJ, Jenkins D, Andrews MH, Taaffe DR, Glover ML. Validity and reliability of GPS for measuring distance travelled in field-based team sports. J Sports Sci. 2010;28(12):1319-25.

89. Johnston RJ, Watsford ML, Kelly SJ, Pine MJ, Spurrs RW. Validity and interunit reliability of $10 \mathrm{~Hz}$ and $15 \mathrm{~Hz}$ GPS units for assessing athlete movement demands. J Strength Cond Res. 2014;28(6):1649-55.

90. Scott MT, Scott TJ, Kelly VG. The validity and reliability of global positioning systems in team sport: A brief review. J Strength Cond Res. 2016;30(5):1470-90.

91. Gomez-Piriz PT, Jiménez-Reyes $P$, Ruiz-Ruiz C. Relation Between total body load and session rating of perceived exertion in professional soccer players. J Strength Cond Res. 2011;25(8):2100-3.

92. Foster C, Florhaug JA, Franklin J, Gottschall L, Hrovatin LA, Parker S, et al. A new approach to monitoring exercise training. J Strength Cond Res.

2001;15(1):109-15.

93. Kelly DM, Strudwick AJ, Atkinson G, Drust B, Gregson W. The withinparticipant correlation between perception of effort and heart rate-based estimations of training load in elite soccer players. J Sports Sci.

2016;34(14):1328-32.

94. Owen AL, Forsyth JJ, Wong del P, Dellal A, Connelly SP, Chamari K. Heart rate-based training intensity and its impact on injury incidence among elite-level professional soccer players. J Strength Cond Res. 2015;29(6):1705-12. 
95. Gabbett TJ. The training-injury prevention paradox: should athletes be training smarter and harder? Br J Sports Med. 2016;50(5):273-80..

96. Ehrmann FE, Duncan CS, Sindhusake D, Franzsen WN, Greene DA. GPS and injury prevention in professional soccer. J Strength Cond Res. 2016;30(2):360-7.

97. Malone S, Owen A, Newton M, Mendes B, Collins KD, Gabbett TJ. The acute:chonic workload ratio in relation to injury risk in professional soccer. J Sci Med Sport. 2017;20(6):561-5.

98. Killen NM, Gabbett TJ, Jenkins DG. Training loads and incidence of injury during the preseason in professional rugby league players. J Strength Cond Res. 2010;24(8):2079-84.

99. Gabbett TJ, Jenkins DG. Relationship between training load and injury in professional rugby league players. J Sci Med Sport.2011;14(3):204-9.

100. Rogalski B, Dawson B, Heasman J, Gabbett TJ. Training and game loads and injury risk in elite Australian footballers. J Sci Med Sport. 2013;16(6):499-503.

101. Colby MJ, Dawson B, Heasman J, Rogalski B, Gabbett TJ. Accelerometer and GPS-derived running loads and injury risk in elite Australian footballers. J Strength Cond Res. 2014;28(8):2244-52.

102. Cross MJ, Williams S, Trewartha G, Kemp SPT, Stokes KA. The influence of in-season training loads on injury risk in professional rugby union. Int J Sports Physiol Perform. 2016;11(3):350-5.

103. Veugelers KR, Young WB, Fahrner B, Harvey JT. Different methods of training load quantification and their relationship to injury and illness in elite Australian football. J Sci Med Sport. 2016;19(1):24-8. 
104. Malone S, Roe M, Doran DA, Gabbett TJ, Collins KD. Protection against spikes in workload with aerobic fitness and playing experience: the role of the acute:chronic workload ratio on injury risk in elite gaelic football. Int J Sports Physiol Perform. 2017;12(3):393-401.

105. Bradley PS, Sheldon W, Wooster B, Olsen P, Boanas P, Krustrup P. Highintensity running in English FA Premier League soccer matches. J Sports Sci. 2009;27(2):159-68.

106. Mohr M, Krustrup P, Bangsbo J. Match performance of high-standard soccer players with special reference to development of fatigue. J Sports Sci. 2003;21(7):519-28.

107. Barnes C, Archer DT, Hogg B, Bush M, Bradley PS. The evolution of physical and technical performance parameters in the English Premier League. Int J Sports Med. 2014;35(13):1095-100.

108. Bradley PS, Carling C, Archer D, Roberts J, Dodds A, Di Mascio M, et al. The effect of playing formation on high-intensity running and technical profiles in English FA Premier League soccer matches. J Sports Sci. 2011;29(8):821-30.

109. Bradley PS, Lago-Peñas C, Rey E, Gomez Diaz A. The effect of high and low percentage ball possession on physical and technical profiles in English FA Premier League soccer matches. J Sports Sci. 2013;31(12):1261-70.

110. da Mota GR, Thiengo CR, Gimenes SV, Bradley PS. The effects of ball possession status on physical and technical indicators during the 2014 FIFA World Cup Finals. J Sports Sci. 2016;34(6):493-500.

111. Carling C, McCall A, Le Gall F, Dupont G. What is the extent of exposure to periods of match congestion in professional soccer players? J Sports Sci. 2015;33(20):2116-24.

112. Dupont G, Nédélec M, McCall A, McCormack D, Berthoin S, Wisløff U. Effect of 2 soccer matches in a week on physical performance and injury rate. Am J Sports Med. 2010;38(9):1752-8. 
113. Folgado H, Duarte R, Marques $P$, Sampaio J. The effects of congested fixtures period on tactical and physical performance in elite football. J Sports Sci. 2015;33(12):1238-47.

114. Lago-Peñas C, Rey E, Lago-Ballesteros J, Casáis L, Domínguez E. The influence of a congested calendar on physical performance in elite soccer. $J$ Strength Cond Res. 2011;25(8):2111-7.

115. Dellal A, Lago-Peñas C, Rey E, Chamari K, Orhant E. The effects of a congested fixture period on physical performance, technical activity and injury rate during matches in a professional soccer team. Br J Sports Med. 2015;49(6):390-4.

116. Djaoui L, Wong del P, Pialoux V, Hautier C, Da Silva CD, Chamari K, et al. Physical activity during a prolonged congested period in a top-class European football team. Asian J Sports Med. 2014;5(1):47-53.

117. Carling C, Le Gall F, Dupont G. Are physical performance and injury risk in a professional soccer team in match-play affected over a prolonged period of fixture congestion? Int J Sports Med.2012;33(1):36-42.

118. Carling C, McCall A, Le Gall F, Dupont G. The impact of short periods of match congestion on injury risk and patterns in an elite football club. Br J Sports Med. 2016;50(12):764-8.

119. Ekstrand J, Hägglund $M$, Waldén M. Injury incidence and injury patterns in professional football: the UEFA injury study. Br J Sports Med. 2011;45(7):553-8.

120. Waldén $M$, Hägglund $M$, Ekstrand J. UEFA Champions League study: a prospective study of injuries in professional football during the 2001-2002 season. Br J Sports Med. 2005;39(8):542-6.

121. D'Hooghe M. Why is UEFA carrying out injury studies? Br J Sports Med. 2016;50(12):707. 
122. Union of European Football Associations. UEFA rankings for club competitions [Internet]. Nyon: Union of European Football Associations; 2016. [cited 2017.Oct 22]. Available from:

https://www.uefa.com/memberassociations/uefarankings/country/season=201 6/index.html

123. Clarsen B, Myklebust G, Bahr R. Development and validation of a new method for the registration of overuse injuries in sports injury epidemiology: the Oslo Sports Trauma Research Centre (OSTRC) overuse injury questionnaire. Br J Sports Med. 2013;47(8):495-502.

124. Verheijen R. Study on recovery days [pamphlet on the Internet]. Amsterdam: World Football Academy; 2012. [cited 2017 Oct 22]. Available from: http://worldfootballacademy.com/wp-content/uploads/2012/05/WFA_Studyon-recovery-days.pdf

125. Jones RI, Ryan B, Todd Al. Muscle fatigue induced by a soccer match-play simulation in amateur Black South African players. J Sports Sci.

2015;33(12):1305-11.

126. Marshall PW, Lovell R, Jeppesen GK, Andersen K, Siegler JC. Hamstring muscle fatigue and central motor output during a simulated soccer match. PloS one. 2014;9(7):e102753.

127. Small K, McNaughton L, Greig M, Lovell R. The effects of multidirectional soccer-specific fatigue on markers of hamstring injury risk. J Sci Med Sport. 2010;13(1):120-5.

128. Stutzig N, Siebert T. Muscle force compensation among synergistic muscles after fatigue of a single muscle. Hum Mov Sci. 2015;42:273-87.

129. Thomas K, Dent J, Howatson G, Goodall S. Etiology and recovery of neuromuscular fatigue after simulated soccer match play. Med Sci Sports Exerc. 2017;49(5):955-64. 
130. Moreira A, Kempton T, Aoki MS, Sirotic AC, Coutts AJ. The impact of 3 different-length between-matches microcycles on training loads in professional rugby league players. Int J Sports Physiol Perform. 2015;10(6):767-73.

131. Brooks JH, Fuller CW. The influence of methodological issues on the results and conclusions from epidemiological studies of sports injuries. Sports Med. 2006;36(6):459-72.

132. Fletcher RH, Fletcher SW, Fletcher SG. Clinical Epidemiology: the essentials. 5 ed. Philadelphia: Lippincott Williams \& Wilkins; 2012.

133. Petrie A, Sabin C. Medical Statistics at a Glance, 3 ed. Hoboken: WileyBlackwell; 2009.

134. Junge A, Dvorak J. Influence of definition and data collection on the incidence of injuries in football. Am J Sports Med. 2000;28(5 Suppl):S40-6.

135. Brooks JH, Fuller CW. The influence of methodological issues on the results and conclusions from epidemiological studies of sports injuries: illustrative examples. Sports Med. 2006;36(6):459-72.

136. Kristenson K, Bjørneboe J, Waldén M, Andersen TE, Ekstrand J, Hägglund M. Injuries in male professional football: A prospective comparison between individual and team-based exposure registration. Scand J Med Sci Sports.

2016;26(10):1225-32.

137. Nédélec M, McCall A, Carling C, Legall F, Berthoin S, Dupont G. Recovery in soccer : part II-recovery strategies. Sports Med. 2013;43(1):9-22.

138. McCall A, Lewin C, O'Driscoll G, Witvrouw E, Ardern C. Return to play: the challenge of balancing research and practice. Br J Sports Med. 2017;51(9):702-3.

139. Dijkstra HP, Pollock N, Chakraverty R, Ardern C. Return to play in elite sport: a shared decision-making process. Br J Sports Med. 2017;51(5):419-20. 
140. Matheson GO, Shultz R, Bido J, Mitten MJ, Meeuwisse WH, Shrier I. Returnto-play decisions: are they the team physician's responsibility? Clin J Sport Med. 2011;21(1):25-30.

141. Creighton DW, Shrier I, Shultz R, Meeuwisse WH, Matheson GO. Return-toplay in sport: a decision-based model. Clin J Sport Med. 2010;20(5):379-85.

142. Shrier I, Matheson GO, Boudier-Revéret M, Steele RJ. Validating the threestep return-to-play decision model. Scand J Med Sci Sports. 2015;25(2):e231-9.

143. Shrier I. Strategic Assessment of Risk and Risk Tolerance (StARRT) framework for return-to-play decision-making. Br J Sports Med.

2015;49(20):1311-5.

144. Hägglund M, Waldén M, Ekstrand J. Lower reinjury rate with a coachcontrolled rehabilitation program in amateur male soccer: a randomized controlled trial. Am J Sports Med. 2007;35(9):1433-42.

145. Hägglund $M$, Waldén $M$, Magnusson $H$, Kristenson $K$, Bengtsson $H$, Ekstrand J. Injuries affect team performance negatively in professional football: an 11-year follow-up of the UEFA Champions League injury study. Br J Sports Med. 2013;47(12):738-42. 


\section{Papers}

The papers associated with this thesis have been removed for copyright reasons. For more details about these see:

http:// urn.kb.se/ resolve?urn=urn:nbn:se:liu:diva-142788 